\title{
What can flux tracking teach us about water age distribution patterns and their temporal dynamics?
}

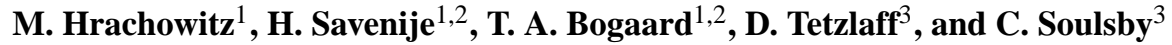 \\ ${ }^{1}$ Water Resources Section, Faculty of Civil Engineering and Applied Geosciences, Delft University of Technology, \\ Stevinweg 1, 2600 GA Delft, The Netherlands \\ ${ }^{2}$ UNESCO-IHE Institute for Water Education, Westvest 7, 2601 DA Delft, The Netherlands \\ ${ }^{3}$ Northern Rivers Institute, School of Geosciences, University of Aberdeen, Aberdeen, AB24 3UF, UK
}

Correspondence to: M. Hrachowitz (m.hrachowitz@tudelft.nl)

Received: 24 August 2012 - Published in Hydrol. Earth Syst. Sci. Discuss.: 4 October 2012

Revised: 1 December 2012 - Accepted: 10 January 2013 - Published: 7 February 2013

\begin{abstract}
The complex interactions of runoff generation processes underlying the hydrological response of streams remain not entirely understood at the catchment scale. Extensive research has demonstrated the utility of tracers for both inferring flow path distributions and constraining model parameterizations. While useful, the common use of linearity assumptions, i.e. time invariance and complete mixing, in these studies provides only partial understanding of actual process dynamics. Here we use long-term $(<20 \mathrm{yr})$ precipitation, flow and tracer (chloride) data of three contrasting upland catchments in the Scottish Highlands to inform integrated conceptual models investigating different mixing assumptions. Using the models as diagnostic tools in a functional comparison, water and tracer fluxes were then tracked with the objective of exploring the differences between different water age distributions, such as flux and resident water age distributions, and characterizing the contrasting water age pattern of the dominant hydrological processes in the three study catchments to establish an improved understanding of the wetness-dependent temporal dynamics of these distributions.

The results highlight the potential importance of partial mixing processes which can be dependent on the hydrological functioning of a catchment. Further, tracking tracer fluxes showed that the various components of a model can be characterized by fundamentally different water age distributions which may be highly sensitive to catchment wetness history, available storage, mixing mechanisms, flow path connectivity and the relative importance of the different hydrological processes involved. Flux tracking also revealed that, although
\end{abstract}

negligible for simulating the runoff response, the omission of processes such as interception evaporation can result in considerably biased water age distributions. Finally, the modeling indicated that water age distributions in the three study catchments do have long, power-law tails, which are generated by the interplay of flow path connectivity, the relative importance of different flow paths as well as by the mixing mechanisms involved. In general this study highlights the potential of customized integrated conceptual models, based on multiple mixing assumptions, to infer system internal transport dynamics and their sensitivity to catchment wetness states.

\section{Introduction}

The runoff generation process dynamics underlying observed stream flow responses are not yet well understood in most catchments (e.g. McDonnell et al., 2010; Beven, 2010). While hydrologists often have good conceptual understanding of which processes are likely to be relevant (e.g. McMillan et al., 2011; Fenicia et al., 2011), the spatio-temporal process heterogeneity in catchments generates considerable challenges to quantitative assessment (cf. Savenije, 2009). Given the frequent absence of suitable data, the emphasis of many hydrological modeling studies on the stream flow response (e.g. Fenicia et al., 2006; Clark et al., 2008; Seibert and Beven, 2009) rather than more integrated response measures, such as tracer data, is thus hampering efforts towards more fundamental understanding of catchment process 
dynamics. As Kirchner (2006) pointed out, this limited understanding of flow processes dictates that we can get the right answers, but frequently for the wrong reasons. The limited understanding is in part rooted in the partial decoupling of the hydraulic response, as observed at a stream gauge, from the actual flow paths water is routed to the stream (cf. Kirchner, 2003). In the vast majority of catchments, the hydraulic response is only partially driven by advective flow processes, such as preferential subsurface flow, characterized by translatory movement of the individual water particles due to the elevation head (cf. Berne et al., 2005; Anderson et al., 2009a,b). Rather, varying - but frequently major - contributions to stream flow are typically generated by diffuse flow processes (cf. Berne et al., 2005). These processes, such as the groundwater response, are driven by the pressure head and the resulting translation of a pressure wave. The observed stream flow response generated by these processes thus rather reflects the translation of a pressure wave than the actual advective movement of individual water particles. It thereby conceals the actual flow paths of water particles routed through what is traditionally referred to as passive or immobile zone, as it is hydraulically only dependent on water stored above the stream level, i.e. active or dynamic storage (Zuber, 1986). Characterizing the dynamics of flow paths in both, the active and the passive zone, is essential for understanding solute and thus pollutant transport (e.g. Dunn et al., 2008a; Wenninger et al., 2008; Birkel et al., 2011c). It can also potentially provide better insights into the spatiotemporal heterogeneity of catchment response patterns, ultimately leading to more realistic catchment conceptualizations and thus model formulations (e.g. Fenicia et al., 2008a; Birkel et al., 2011b; Soulsby et al., 2010).

Information on flow paths can be gained by introducing qualitative metrics using the variability of natural tracers as "time stamps" to tag water and solute inputs along actual flow paths. Flow path distributions are then reflected by distributions of water age, traditionally referred to as transit time distributions (TTD). Many previous tracer studies focused either on detailed physical description of the transport processes themselves (e.g. Destouni et al., 2001; Cvetkovic and Haggerty, 2002; Lindgren et al., 2004; Fiori and Russo, 2008; Botter et al., 2009) or used relatively simple black-box models to estimate integrated catchment descriptors of flow path distributions such as TTD and mean transit times (MTT) (e.g. Kirchner et al., 2000; McGlynn et al., 2003; McGuire et al., 2005; Soulsby et al., 2006; Hrachowitz et al., 2010a; Godsey et al., 2010; Tetzlaff et al., 2011). While transport process studies provided crucial insights in small-scale dynamics, black-box model inter-comparison studies have shed light on the physical controls of the long-term average TTDs on the catchment scale (e.g. Laudon et al., 2007; Broxton et al., 2009; Hrachowitz et al., 2009a; Tetzlaff et al., 2009a; Katsuyama et al., 2009, 2010; Lyon et al., 2010a; Speed et al., 2010; Ali et al., 2012; Asano and Uchida, 2012; Capell et al., 2012a; McGrane et al., 2012).
Although known since the early days of tracer hydrology (e.g. Niemi, 1977; Turner et al., 1987), the importance of temporal dynamics in flow paths distributions and thus in TTDs was often overlooked. Whilst it is often valid for groundwater systems (Maloszewski and Zuber, 1982) to assume steady-state conditions and hence time-invariant TTDs, for surface water systems this simplification conceals many of the dynamics crucial for understanding the processes controlling the system. Another important aspect for process understanding is the well-established fact that the age distributions of water discharged from (flux water age distributions) and stored in (resident water age distributions) a catchment as well as the transit time distributions (i.e. transfer functions), according to which individual input signals, routed through a catchment, are fundamentally different from each other (e.g. Kreft and Zuber, 1978). The frequent use of the linearity assumption, i.e. time-invariant TTDs together with complete mixing which resulted in these different distributions to be identical, almost eliminated this crucial point from general perception as recently stressed by Botter et al. (2011) and Rinaldo et al. (2011).

Although not explicitly introducing time-variance, some black-box modeling studies previously highlighted dependence of TTDs on catchment wetness in a dual way (Ruiz et al., 2002b; Weiler et al., 2003; Roa-Garcia and Weiler, 2010; Stewart et al., 2010, 2012; Munoz-Villers and McDonnell, 2012). In other words, different time-invariant representations of TTDs were assigned to different flow components, i.e. flows from fast and slow model components, resulting in changing TTDs for individual storm events, depending on the contributions from the respective flow components. Recently some studies explicitly addressed the time-invariance topic in detail and allowed for a dynamic representation of flow path distributions (Botter et al., 2010, 2011; Hrachowitz et al., 2010b; Morgenstern et al., 2010; McGuire and McDonnell, 2010; Van der Velde et al., 2010; Birkel et al., 2012a; Heidbüchel et al., 2012; Cvetkovic et al., 2012).

Increasingly, integrated models are being used to obtain representations of runoff and solute/tracer responses in the stream (e.g. Uhlenbrook and Sieber, 2005; Vaché and McDonnell, 2006; Iorgulescu et al., 2007; McGuire et al., 2007; Page et al., 2007; Fenicia et al., 2010; Lindström et al., 2010; Lyon et al., 2010b; Birkel et al., 2011a,c; Arheimer et al., 2012; Capell et al., 2012b; Bertuzzo et al., 2013). For example, Dunn et al. $(2007,2010)$ used a conceptual model in the context of virtual experiments (cf. Weiler and McDonnell, 2004) to infer first order controls on TTDs under state-steady assumptions. Similarly, Shaw et al. (2008) elegantly linked steady-state TTDs to model structure. However, the full potential of such integrated conceptual models to serve as diagnostic tools (cf. McDonnell et al., 2007; Dunn et al., 2008b; Zehe and Sivapalan, 2009) was not fully realized until recently when a few studies started investigating the spatio-temporal dynamics of flow path distributions and what is controlling them (e.g. Botter et al., 2010; Van 
Table 1. Characteristics of the three study catchments.

\begin{tabular}{|c|c|c|c|}
\hline Catchment & $\begin{array}{l}\text { Strontian } \\
\text { Allt Coire } \\
\text { nan Con }\end{array}$ & $\begin{array}{l}\text { Loch Ard } \\
\text { Burn } 11\end{array}$ & $\begin{array}{l}\text { Feshie Allt } \\
\text { a'Mharcaidh }\end{array}$ \\
\hline Grid reference & NM 793688 & NS 470988 & NH 882043 \\
\hline Observation period & 1986-2003 & 1988-2003 & 1985-2006 \\
\hline Area $\left(\mathrm{km}^{2}\right)$ & 8.0 & 1.4 & 9.6 \\
\hline Average annual precipitation $\left(\mathrm{mm} \mathrm{yr}^{-1}\right)$ & 2690 & 2200 & 1100 \\
\hline Average annual potential evaporation $\left(\mathrm{mm} \mathrm{yr}^{-1}\right)^{\mathrm{a}}$ & 523 & 625 & 550 \\
\hline Mean annual temperature $\left({ }^{\circ} \mathrm{C}\right)$ & 7.2 & 8.7 & 5.3 \\
\hline Elevation range $(\mathrm{m})$ & $18-755$ & $99-282$ & $330-1022$ \\
\hline Mean slope $\left({ }^{\circ}\right)$ & 17.0 & 9.0 & 16.0 \\
\hline Proportion responsive soil cover $(-)^{b}$ & 0.79 & 1.00 & 0.35 \\
\hline Drainage density $\left(\mathrm{km} \mathrm{km}^{-2}\right)$ & 3.8 & 2.2 & 1.3 \\
\hline Land Use ${ }^{c}$ & $\mathrm{~F} / \mathrm{M}$ & $\mathrm{F}$ & M \\
\hline$Q_{5}\left(\mathrm{~mm} \mathrm{~d}^{-1}\right)$ & 24.12 & 20.62 & 5.32 \\
\hline$Q_{95}\left(\mathrm{~mm} \mathrm{~d}^{-1}\right)$ & 0.27 & 0.12 & 0.81 \\
\hline
\end{tabular}

${ }^{a}$ Estimated with Penman-Monteith method; ${ }^{\mathrm{b}}$ histosols and regosols; ${ }^{\mathrm{c}}$ F ... Forest, M .... Moorland vegetation

der Velde et al., 2012). In one of these rare attempts, Sayama and McDonnell (2009) analyzed the spatio-temporal patterns in two contrasting catchments. They found significant differences in the variability of MTT in response to rainfall events, and concluded that both storage depth and rainfall pattern control the spatio-temporal pattern of flow path distributions. This is consistent with the findings of McGuire and McDonnell (2010), Hrachowitz et al. (2010b) and Birkel et al. (2012a) using black-box models. In another example, McMillan et al. (2012) illustrated the general effect of fluctuations in catchment wetness on TTDs, highlighting the importance of non-steady state conditions. A different approach for better understanding flow path dynamics is suggested by Davies et al. (2011) who make use of the Multiple Interacting Pathways (MIP) concept introduced by Beven et al. (1989). Yet, still little is known about the actual dynamics linking spatio-temporal patterns of distributions of water age to flow processes and wetness conditions in catchments.

In this study we used conceptual models of three contrasting upland catchments in the Scottish Highlands as tools to explore the potential routing of incoming water and tracer (Chloride) signals (derived from long-term data) through the systems following a virtual experiment philosophy (cf. Weiler and McDonnell, 2004). By making use of model internal fluxes and states, we tracked and analyzed the modeled temporal dynamics of water age distributions, interpreting them as potential representations of reality in a functional intercomparison (cf. Uchida et al., 2006). The objectives of the study were thus to (1) analyze, assess and interpret the differences of modeled flux water age, resident water age and transit time distributions in different flow components, (2) investigate the effect of different mixing assumptions on the modeled water age distributions and (3) test how the temporal dynamics of modeled water age distributions relate to changes in the hydrological regime, i.e. the feedback processes between dominant flow paths, antecedent wetness and storage dynamics.

\section{Study area}

The distinct nature of the three study catchments is illustrated by a summary of their characteristics (Fig. 1 and Table 1) as well as by the respective hydrographs and chloride $\left(\mathrm{Cl}^{-}\right)$ chemographs (Fig. 2). The Allt Coire nan Con catchment (COIR; $8 \mathrm{~km}^{2}$ ) at Strontian is characterized by the wet and temperate maritime climate of the Scottish West coast with a long-term average precipitation of ca. $2700 \mathrm{~mm} \mathrm{yr}^{-1}$ and a mean annual temperature of $7.2^{\circ} \mathrm{C}$. The steep catchment ranges from sea level to an elevation of $\sim 750 \mathrm{~m}$. Its slopes are covered by poorly drained peats and gleys formed over slowly permeable glacial drift and relatively impermeable schists and gneisses of the Moine series (Ferrier and Harriman, 1990). These soils are characterized by mainly fast, lateral drainage, allowing only limited recharge (cf. Soulsby and Reynolds, 1993) which produce extremely flashy catchment responses (Fig. 2a, Table 1). Base flow, on the other hand, is sustained at very low levels from slowly draining deeper soil horizons, drift and bedrock groundwater. Further, the low level of attenuation in the $\mathrm{Cl}^{-}$signal (Fig. 2a) indicates very short transit times of water in the catchment (cf. Tetzlaff et al., 2009b). Land cover in the lower catchment was dominated by mature coniferous forest (Picea sitchensis) whilst the upper slopes are heather-dominated moorland (Calluna vulgaris).

The Burn 11 catchment (BU11; $1.4 \mathrm{~km}^{2}$ ) at Loch Ard in central Scotland receives an average precipitation of $2200 \mathrm{~mm} \mathrm{yr}^{-1}$ with a mean annual temperature of $8.7^{\circ} \mathrm{C}$. 


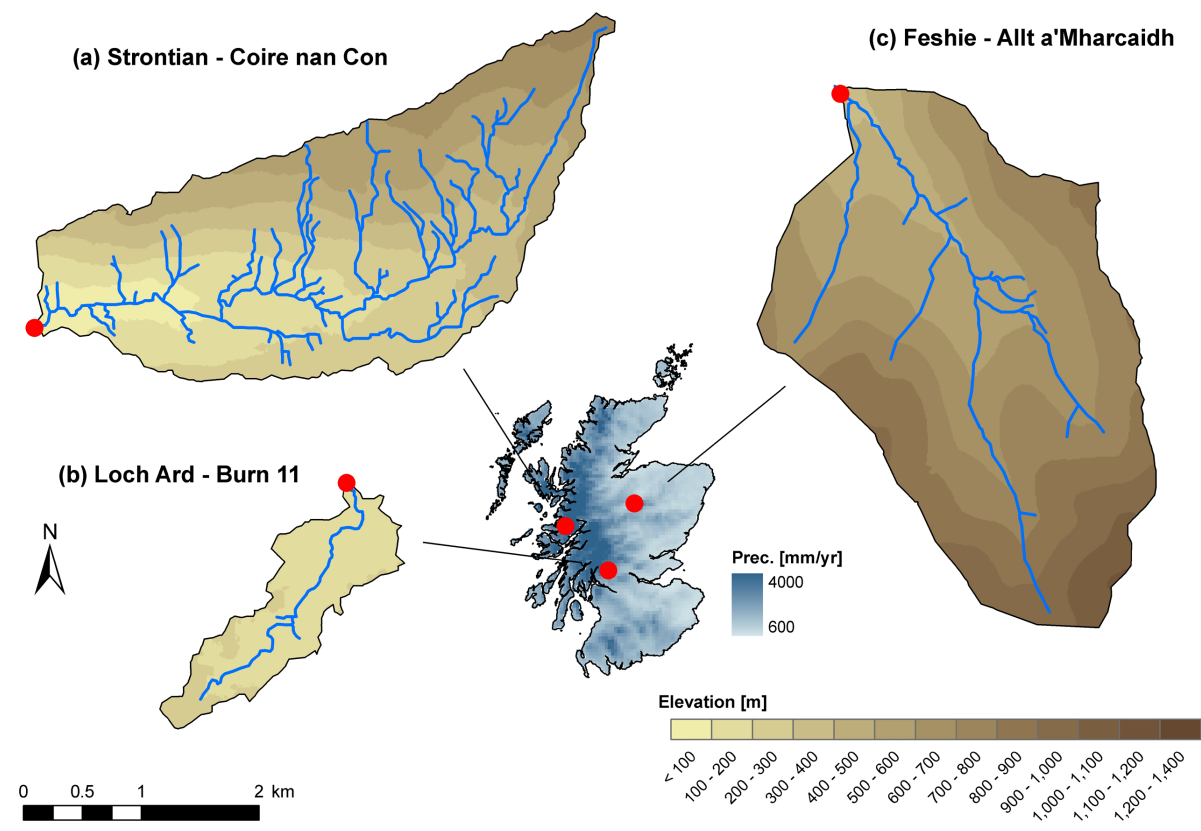

Fig. 1. Long-term mean annual precipitation and elevation maps of the 3 study catchments in the Scottish Highlands.

This catchment exhibits a much more subdued topography with an elevation range between 100 to $280 \mathrm{~m}$. The metamorphic Dalradian geology is covered by low permeability glacial drifts (Miller et al., 1990), which together with the high precipitation amounts results in poorly drained peaty gleys and peat soils (Tetzlaff et al., 2007), which maintain low soil moisture deficits and thus high degrees of connectivity for much of the year. Similar to the COIR catchment, storm runoff is likely to be dominated by fast lateral flow processes (cf. Soulsby et al., 2007), although base flow contributions are more significant in BU11 than at COIR (Fig. 2b). Land cover is dominated by coniferous forest (Picea sitchensis; $75 \%)$ and to a minor extent grassland ( $25 \%$; National River Flow Archive).

The Allt a'Mharcaidh (MHAR) is located in the Cairngorm Mountains at elevations between 330 and $1020 \mathrm{~m}$. The sub-arctic climate results in relatively low precipitation of about $1100 \mathrm{~mm} \mathrm{yr}^{-1}$ and mean annual temperatures of $5.3^{\circ} \mathrm{C}$. In this study it is the only catchment that receives significant amounts of precipitation as snow ( $\sim 30 \%$; Helliwell et al., 1998). It is underlain by fractured granite of lower Old Red Sandstone age, covered by thick deposits of locallyderived drift of up to $10 \mathrm{~m}$ in depth (Soulsby et al., 1998). While the gently sloping valley bottoms are covered by deep peats, the steep slopes are characterized by more freely draining alpine soils and podzols (Soulsby et al., 2000), recharging groundwater and sustaining relatively elevated base flow levels (Fig. 2c, Table 1). Among the study catchments this site exhibits the highest degree of damping in the $\mathrm{Cl}^{-}$stream signal, suggesting relatively long catchment transit times. Land cover is dominated by alpine heath above $500 \mathrm{~m}$, while some mixed, natural forest can be found at lower elevations (Pinus sylvestris, Betula spp.; $10 \%$ ).

\section{Data and methods}

\subsection{Hydrological and geochemical data}

Daily stream flow, precipitation and mean temperature were available for the period 1 May 1986-11 July 2003 in the COIR at Strontian (Fig. 2a), for the 1 January 1988-31 December 2003 period at BU11 at Loch Ard (Fig. 2b), and for 1 October 1985-1 October 2006 in the MHAR (Fig. 2c). Flow data were obtained from the Scottish Environmental Protection Agency (SEPA), while daily precipitation was interpolated from daily data of adjacent British Atmospheric Data Centre sites (BADC, stations Dunstaffnage, Aberfoyle and Aviemore) and volumes recorded on a weekly (BU11, MHAR) or fortnightly (COIR) basis in open funnel bulk deposition samplers in the catchments. Daily temperature data were available from the BADC stations Dunstaffnage (COIR), Aberfoyle (BU11), Lagganalia, Cairngorm lift and Cairngorm summit (MHAR). The potential evaporation was estimated with the Penman-Monteith method and was roughly consistent with long-term estimates for the individual regions (1961-1990, MORECS).

Weekly or fortnightly precipitation samples (see above) as well as simultaneous stream water dip samples at the individual catchment outlets (Fig. 1) were analyzed for chloride $\left(\mathrm{Cl}^{-}\right)$concentration. All water samples were filtered through a $0.45 \mu \mathrm{m}$ polycarbonate membrane filter. $\mathrm{Cl}^{-}$concentrations were determined by ion chromatography (Dionex 
(a) Strontian - Allt Coire Nan Con
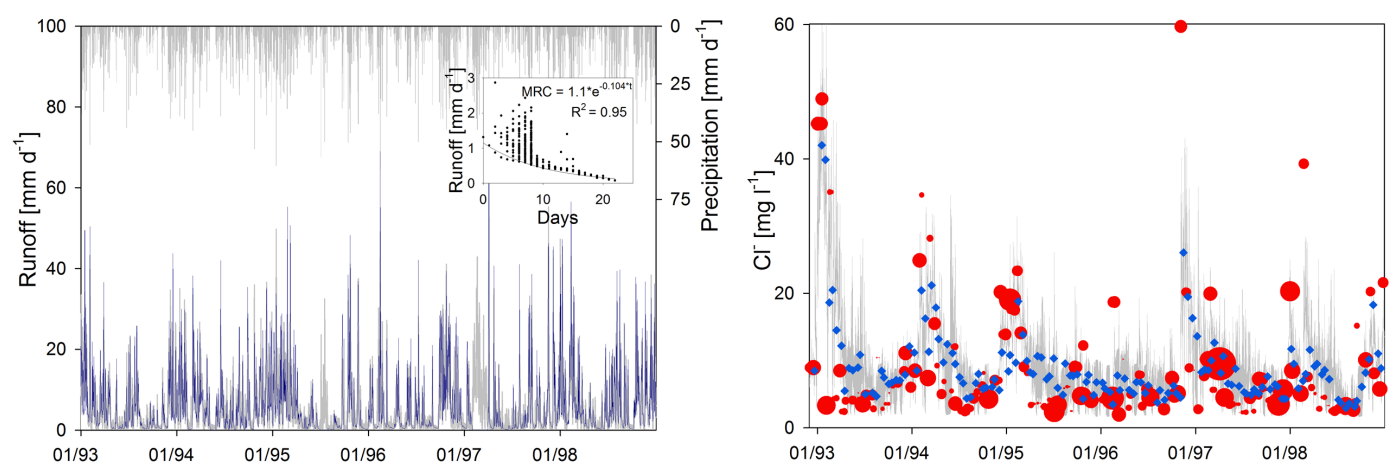

(b) Loch Ard - Burn 11
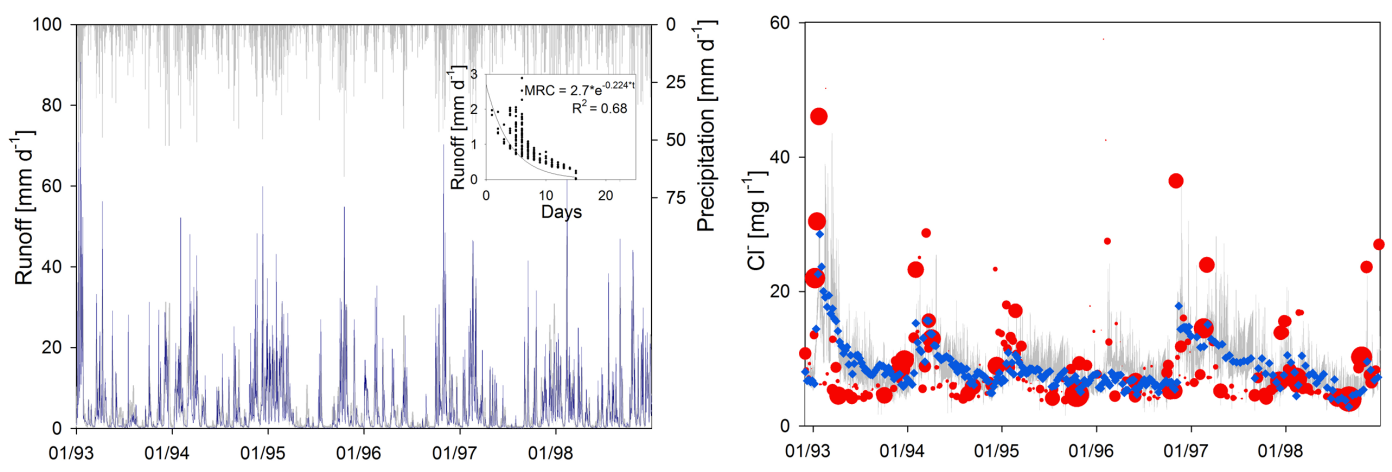

(c) Feshie - Allt a'Mharcaidh
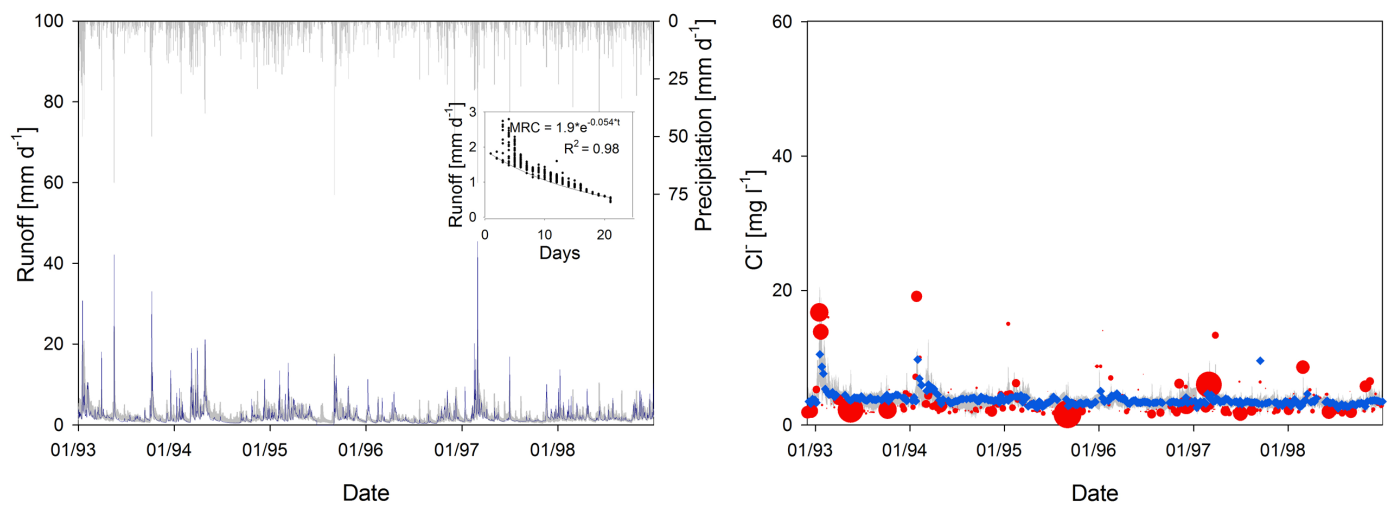

Fig. 2. Left column: time series of observed daily precipitation (-) and runoff $(-)$ and modeled runoff (-) for a selected characteristic 5-yr period. The insets show the Master recession curves. Right column: time series of observed $\mathrm{Cl}^{-}$input (red dots) and output (blue dots) concentrations. The symbol size indicates the mass flux. The grey shaded area is the $95 \%$ uncertainty interval of the modeled stream concentration using all pareto optimal parameterizations.

DX100/DX120). Daily $\mathrm{Cl}^{-}$input fluxes for modeling were estimated using the bulk $\mathrm{Cl}^{-}$concentrations of the preceding sampling period and weighing them with the available daily precipitation data.

As discussed by others (e.g. Neal et al., 1988), stream water $\mathrm{Cl}^{-}$flux typically exceeds the precipitation $\mathrm{Cl}^{-}$flux. This apparent disequilibrium was previously shown to be caused by occult and dry deposition (Neal et al., 2004; Page et al., 2007), previous land use change, such as deforestation (Oda et al., 2009; Guan et al., 2010) or biochemical cycling (Bastviken et al., 2007). Further, plants require $\mathrm{Cl}^{-}$ and thus take up $\mathrm{Cl}^{-}$stored in the root zone at varying rates (e.g. Kauffman et al., 2003; Lovett et al., 2005; Van der Velde et al., 2010). Here these combined imbalances in catchment $\mathrm{Cl}^{-}$budgets were accounted for by rescaling the input concentrations using lumped adjustment factors as successfully 
applied in earlier studies (e.g. Tetzlaff et al., 2007; Dunn and Bacon, 2008; Shaw et al., 2008; McMillan et al., 2012). Although, this strategy ignores potential temporal variability in unobserved $\mathrm{Cl}^{-}$cycling processes, the effects of these processes are limited in the wet and cool Scottish climate and in the absence of more detailed information considered negligible. This assumption is supported by evidence from a recent comparative tracer study with water isotopes (Kirchner et al., 2010). Note that $\mathrm{Cl}^{-}$turnover by plants was omitted in the present study, as this process was considered of minor importance in the cool Scottish climate, with low transpiration rates (and thus limited sap flow) and relatively low amounts of organic matter turnover (i.e. litter fall) from the Heather moorland vegetation and coniferous forests in the study catchments (e.g. Liu et al., 2004).

\subsection{Hydrological models}

Lumped conceptual models were used to track water and tracer fluxes through the system. As recently re-iterated by Ye et al. (2012), the dominant processes controlling runoff patterns are influenced by complex interactions of climate, vegetation and landscape factors. In the absence of detailed a priori knowledge on the dominant runoff processes and due to the contrasting characteristics of the three study catchments, a flexible modeling strategy was thus adopted (e.g. Clark et al., 2008; Fenicia et al., 2008a, 2011; Kavetski and Fenicia, 2011). This ensured the use of the model architectures best representing the dominant processes in the individual catchments given the information available on the respective catchments.

The DYNAMIT (DYNAmic MIxing Tank) modeling framework used in this study is loosely based on the FLEX model (e.g. Fenicia et al., 2006). Following the flexible modeling approach, a suite of different model structures of varying process representations and complexity derived from process conceptualization based on the information available were tested for each catchment. For reasons of computational capacity, the most suitable model structure for each catchment was identified by a preliminary scan using 5 -yr calibration and validation periods. The model structures most suitable for further analysis were selected on basis of their NashSutcliffe efficiencies (Nash and Sutcliffe, 1970) for stream flow and their respective values for the Akaike information criterion (AIC; Akaike, 1970), which penalizes additional parameters and thus balances statistical fit and model complexity (e.g. Schoups et al., 2008). Note that a detailed exposition of the model selection issue is not a primary aim of this paper. Rather we take the selected models as feasible representations of the best available model structures to explore water age distributions as a primary objective. Thus, for brevity and clarity only the components of the three model structures identified as optimal and subsequently used in the study are reported here.
The selected model structures for the study catchments as well as the water balance and flux equations of the individual model components are given in Fig. $3 \mathrm{a}-\mathrm{c}$ as well as in Table 2 and a complete list of symbols is given in Appendix A. Note that in the following all model parameters are shown in bold. The backbone of the three models consists of three reservoirs: an unsaturated ( $S_{\mathrm{U}}$, Eq. 3), a fast responding $\left(S_{\mathrm{F}}\right.$, Eq. 4$)$ and a slow responding reservoir $\left(S_{\mathrm{S}}\right.$, Eq. 5$)$. The model of the high-elevation MHAR catchment included an additional semi-distributed snow component $\left(S_{\mathrm{SN}}, \mathrm{Eq} .1\right)$. Daily temperature lapse rates (see Hydrological data section) were used to determine the snow water equivalent in $100 \mathrm{~m}$ elevation intervals. Snow melt $(M)$ for each elevation zone $i$ was then computed with the degree-day method (Eq. 6) and based on the free calibration parameters threshold temperature $\left(\mathbf{T}_{\mathrm{T}}\right)$ and melt factor $\left(\mathbf{F}_{\mathrm{M}}\right)$. The model structure for the heavily forested BU11 catchment on the other hand included an interception storage ( $S_{\mathrm{I}}$, Eq. 2), allowing an effective separation of two fundamentally different processes (e.g. Calder, 1990; Sutanto et al., 2012) which has only recently received significant attention in modeling studies (e.g. Savenije, 2004; Fenicia et al., 2008b; Gerrits et al., 2010): evaporation of water stored on surfaces (e.g. canopy, forest floor) and transpiration of root zone water by plants. Water leaves $S_{\mathrm{I}}$ by overflow, generating effective precipitation $\left(P_{\mathrm{E}}\right)$ once the maximum interception capacity $\left(\mathbf{I}_{\max }\right)$ is exceeded and by evaporation at the potential evaporation rate $\left(E_{\mathrm{SI}}, \mathrm{Eq} .8\right)$. Note, that in the absence of snow and/or interception components $P_{\mathrm{E}}$ equals the total precipitation $P$ (Eq. 9). Upon reaching the soil $P_{\mathrm{E}}$ is split into water infiltrating into the unsaturated zone $\left(R_{\mathrm{U}}\right.$, Eq. 12) and excess water according to a runoff generation coefficient $\left(C_{\mathrm{R}}\right.$, Eq. 16$)$. Here, $C_{\mathrm{R}}$ is given by a logistic function representing the catchment wide soil moisture storage capacity in the root zone $\left(\mathbf{S}_{\mathrm{U}_{\max }}\right)$, roughly reflecting the soil moisture content at field capacity (FC), and a shape factor $(\beta)$. Excess water not stored in $S_{\mathrm{U}}$ is routed either to $S_{\mathrm{F}}\left(R_{\mathrm{F}}\right.$, Eq. 13) or via preferential recharge to $S_{\mathrm{S}}\left(R_{\mathrm{P}}\right.$, Eq. 14) according to coefficient $\mathbf{C}_{\mathrm{P}}$. Percolation of water from $S_{\mathrm{U}}$ to $S_{\mathrm{S}}$ and thus recharge of the slow responding reservoir $\left(R_{\mathrm{S}}\right.$, Eq. 15) is represented by a linear relationship of the relative soil moisture with a maximum percolation capacity $\left(\mathbf{P}_{\max }\right)$. Recharge fluxes $R_{\mathrm{F}}$ and $R_{\mathrm{S}}$ are lagged (Eqs. 17 and 22) by triangular transfer functions $h_{\mathrm{F}}$ (Eq. 18) and $h_{\mathrm{S}}$ (Eq. 23), based on the lag parameters $\mathbf{T}_{\mathrm{F}}$ and $\mathbf{T}_{\mathrm{S}}$ which represent the number of time steps in the lag routine (e.g. Kavetski and Fenicia, 2011). The lag routine itself conceptualizes the system internal time delay introduced by fluxes between different model states. Note, that if $\mathbf{T}_{\mathrm{F}}=\mathbf{T}_{\mathrm{S}}=1$, no time lag is present. Plants were assumed to tap water not only from $S_{\mathrm{U}}\left(E_{\mathrm{SU}}\right)$ but also from $S_{\mathrm{F}}\left(E_{\mathrm{SF}}\right)$ which was assumed to be within the root zone. The proportion of transpiration coming from $S_{\mathrm{U}}\left(C_{\mathrm{E}}\right.$, Eq. 11) was thus expressed as a linear function of the moisture content in $S_{\mathrm{U}}$ over the total moisture content in $S_{\mathrm{U}}$ and $S_{\mathrm{F}}$. Transpiration from the unsaturated zone $\left(E_{\mathrm{SU}}\right)$ was then represented by a linear function of the relative soil moisture 
Table 2. State and flux equations of the models used in the analysis.

\begin{tabular}{|c|c|c|c|c|}
\hline Process & Water balance & Eq. & Constitutive relationships & Eq. \\
\hline Snow & $\mathrm{d} S_{\mathrm{SN}} / \mathrm{d} t=\sum_{i} P_{\mathrm{SN}, i}-M_{i}$ & (1) & $M=\sum_{i} \min \left(S_{\mathrm{SN}, i}, \mathbf{F}_{\mathrm{M}}\left(T_{i}-\mathbf{T}_{\mathrm{T}}\right)\right)$ & (6) \\
\hline Interception & $\mathrm{d} S_{\mathrm{I}} / \mathrm{d} t=P_{\mathrm{R}}-P_{\mathrm{TF}}-E_{\mathrm{SI}}$ & (2) & $\begin{array}{l}P_{\mathrm{TF}}=P_{\mathrm{R}}-\min \left(\mathbf{I}_{\max }-S_{\mathrm{I}}, P_{\mathrm{R}}\right) \\
E_{\mathrm{SI}}=\min \left(E_{\mathrm{P}}, S_{\mathrm{I}}\right)\end{array}$ & $\begin{array}{l}(7) \\
(8)\end{array}$ \\
\hline Unsaturated zone & $\mathrm{d} S_{\mathrm{U}} / \mathrm{d} t=P_{\mathrm{E}}-E_{\mathrm{SU}}-R_{\mathrm{F}}-R_{\mathrm{P}}-R_{\mathrm{S}}$ & (3) & $\begin{array}{l}P_{\mathrm{E}}=P_{\mathrm{TF}}+M \\
E_{\mathrm{SU}}=E_{\mathrm{P}} \min \left(1, \frac{S_{\mathrm{U}}}{\mathrm{S}_{\mathrm{U}_{\max }}} \frac{1}{\mathrm{~L}_{\mathrm{p}}}\right) C_{\mathrm{E}} \\
C_{\mathrm{E}}=\frac{S_{\mathrm{U}}}{S_{\mathrm{U}}+S_{\mathrm{F}}} \\
R_{\mathrm{U}}=\left(1-C_{\mathrm{R}}\right) P_{\mathrm{E}} \\
R_{\mathrm{F}}=C_{\mathrm{R}}\left(1-\mathbf{C}_{\mathrm{P}}\right) P_{\mathrm{E}} \\
R_{\mathrm{P}}=C_{\mathrm{R}} \mathbf{C}_{\mathrm{P}} P_{\mathrm{E}} \\
R_{\mathrm{S}}=\mathbf{P}_{\max }\left(\frac{S_{\mathrm{U}}}{\mathrm{S}_{\mathrm{U}_{\max }}}\right) \\
C_{\mathrm{R}}=\frac{1}{\left(1+\exp \left(\frac{-S_{\mathrm{U}} / \mathrm{s}_{\mathrm{U}_{\max }}+0.5}{\beta}\right)\right)}\end{array}$ & $\begin{array}{c}(9) \\
(10) \\
(11) \\
(12) \\
(13) \\
(14) \\
(15) \\
(16)\end{array}$ \\
\hline Fast reservoir & $\mathrm{d} S_{\mathrm{F}} / \mathrm{d} t=R_{\mathrm{F}}^{*}-E_{\mathrm{SF}}-Q_{\mathrm{F}}-Q_{\mathrm{OF}}$ & (4) & $\begin{array}{l}R_{\mathrm{F}}^{*}=R_{\mathrm{F}} * h_{\mathrm{F}} \\
h_{\mathrm{F}}=\left\{\begin{array}{l}t / \mathbf{T}_{\mathrm{F}}^{2}, t \leq \mathbf{T}_{\mathrm{F}} \\
0, t>\mathbf{T}_{\mathrm{F}}\end{array}\right. \\
E_{\mathrm{SF}}=\min \left(E_{\mathrm{P}}\left(1-C_{\mathrm{E}}\right), S_{\mathrm{F}}\right) \\
Q_{\mathrm{F}}=\mathbf{K}_{\mathrm{F}} S_{\mathrm{F}} \\
Q_{\mathrm{OF}}=\max \left(S_{\mathrm{F}}-\mathbf{S}_{\mathrm{F}_{\max }}, 0\right)\end{array}$ & $\begin{array}{l}(17) \\
(18) \\
(19) \\
(20) \\
(21)\end{array}$ \\
\hline Slow reservoir & $\mathrm{d} S_{\mathrm{S}} / \mathrm{d} t=R_{\mathrm{S}}^{*}+R_{\mathrm{P}}-Q_{\mathrm{S}}$ & (5) & $\begin{aligned} R_{\mathrm{S}}^{*} & =R_{\mathrm{S}} * h_{\mathrm{S}} \\
h_{\mathrm{S}} & =\left\{\begin{array}{l}t / \mathbf{T}_{\mathrm{S}}^{2}, t \leq \mathbf{T}_{\mathrm{S}} \\
0, t>\mathbf{T}_{\mathrm{S}}\end{array}\right. \\
Q_{\mathrm{S}} & =\mathbf{K}_{\mathrm{S}} S_{\mathrm{S}}\end{aligned}$ & $\begin{array}{l}(22) \\
(23) \\
(24)\end{array}$ \\
\hline
\end{tabular}

and threshold value $\mathbf{L}_{\mathrm{P}}$, which is the fraction of $\mathbf{S}_{\mathrm{U}_{\max }}$ below which the potential evaporation/transpiration $E_{\mathrm{P}}$ is constrained by the water available in $S_{\mathrm{U}}$ (Eq. 10). $E_{\mathrm{SF}}$, on the other hand, was assumed to occur at potential rate as $S_{\mathrm{F}}$ represents an ensemble of fast flow paths, such as macro pores, which are likely to be active only under temporally and locally saturated conditions (Eq. 19). As $S_{\mathrm{F}}$ and $S_{\mathrm{S}}$ were conceptualized as linear reservoirs, water drainage $\left(Q_{\mathrm{SF}}, Q_{\mathrm{SS}}\right)$ is determined by the storage coefficients $K_{\mathrm{F}}$ and $K_{\mathrm{S}}$ (Eqs. 20 and 24). In two of the models, the architecture of $S_{\mathrm{F}}$ allows for a third flow component, conceptualizing overland flow $\left(Q_{\mathrm{OF}}\right)$. As the model is run on a daily basis, the amount discharged as $Q_{\mathrm{OF}}$ at a given time step is simply expressed as the volume of water exceeding the maximum storage capacity of $S_{\mathrm{F}}$ at the respective time step, i.e. $\mathbf{S}_{\mathrm{F}_{\max }}$ (Eq. 21).

\subsection{Mixing models}

The low-pass filter characteristics of catchments, attenuating the amplitudes and high-frequency variability of tracer input signals, were identified early (e.g. Martinec et al., 1974; Maloszewski and Zuber, 1982). Due to the elemental difference between hydrologic response and particle response (e.g. Beven, 1981; Neal et al., 1988; Roa-Garcia and Weiler,
2010; Heidbüchel et al., 2012), standard conceptual models can rarely accommodate stream tracer dynamics. This is partly the result of stream tracer concentrations reflecting the actual particle movement by advective and diffusive processes at specific flow velocities along actual flow lines, potentially routing particles through the passive storage at depths below stream level, depending on the geology (e.g. Asano and Uchida, 2012) and relief (e.g. Gleeson and Manning, 2008). In contrast, substantial proportions of stream flow are generated by the propagation of pressure waves whose celerity is different to the particle flow velocities (Beven, 1981) and which are controlled by the pressure head or, in other words, the storage height above the stream level alone, i.e. dynamic or active storage $(\mathrm{Zu}-$ ber, 1986). The combined differences between identifiable flow path lengths and flow velocities of tagged (i.e. tracer) and untagged (i.e. water only) fluxes consequently entail a shift between the flow path distributions of water and tracer, traditionally referred to as hydrologic response function (HRF; e.g. Nippgen et al., 2011) and transit time distribution (TTD), respectively (e.g. Heidbüchel et al., 2012). Barnes and Bonell (1996) suggested that both responses, stream flow and tracer concentration, can be accommodated in a conceptual model by introducing a storage component 
(a) Strontian - Coire nan Con

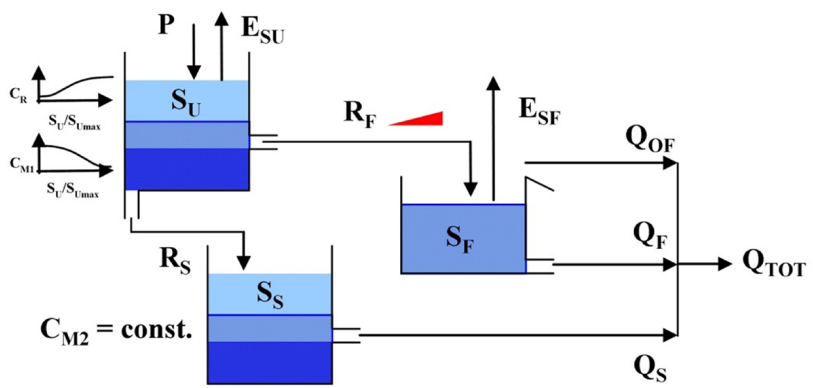

(c) Feshie - Allt a'Mharcaidh

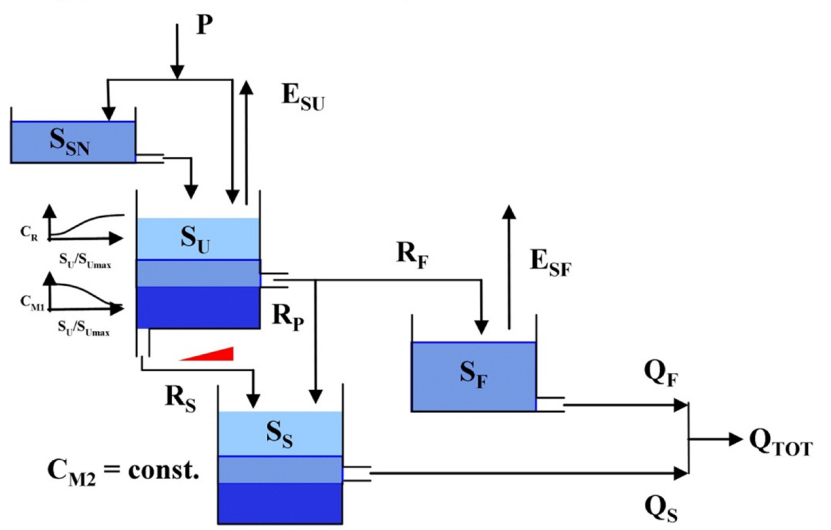

(b) Loch Ard - Burn 11

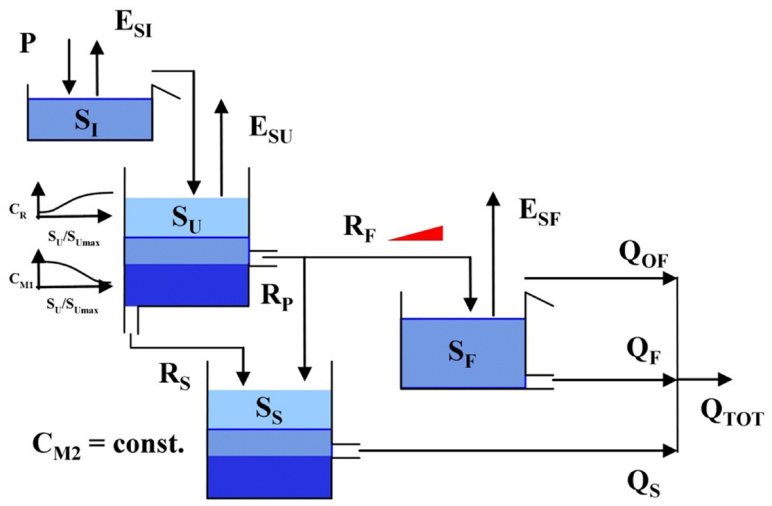

(d) $\mathrm{C}_{\mathrm{M}, \mathrm{dyn}}$
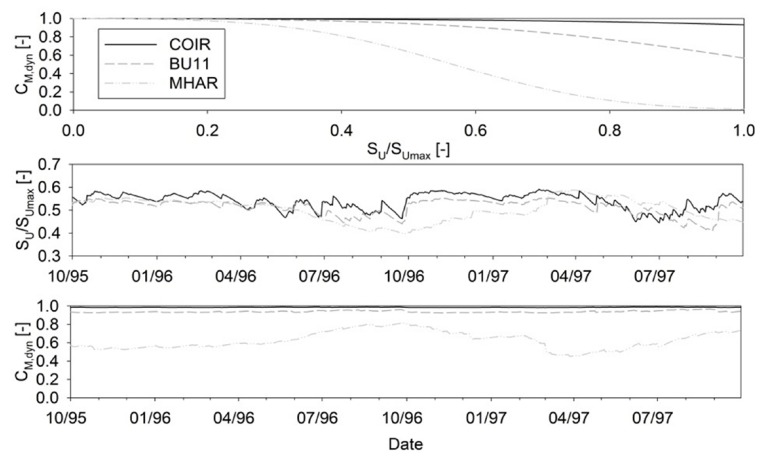

Fig. 3. Selected model structures for the three study catchments (a-c). Light blue shades indicate volumes not affected by mixing, medium blue shades indicate the fraction of the active volume subject to mixing and the dark blue shades indicate the passive mixing storage. The red triangles indicate the presence of a lag function in the specified parts of the models. The panels in (d) show the dynamic mixing coefficient $C_{\mathrm{M}, \mathrm{SU}}=f\left(S_{\mathrm{U}} / S_{\mathrm{U}_{\max }} \mid \mu_{\mathrm{CM}, \mathrm{SU}}, \sigma_{\mathrm{CM}, \mathrm{SU}}\right)$, the temporal dynamics of $S_{\mathrm{U}} / S_{\mathrm{U}_{\max }}$ as well as of $C_{\mathrm{M}, \mathrm{SU}}$ for a selected 2-yr period for the three study catchments.

that does not affect the hydrologic response but only the tracer dynamics. Conceptually such a passive storage is interpreted as water that is temporally (e.g. soil moisture below field capacity FC) or constantly (e.g. groundwater below the dynamic storage) present in the system but does not actively contribute to stream flow generation although being gradually replaced by mixing with new water entering the system. In a model the passive storage is thus represented by a threshold in some or all storage components of a model below which tagged water fluxes can undergo "mixing" processes to reproduce the tracer concentration observed in the stream according to the TTD, at the same time maintaining a water outflow rate as determined by the HRF (Fig. 3; e.g. Dunn et al., 2007; Shaw et al., 2008; Fenicia et al., 2010).

Note, that in the absence of detailed knowledge of the actual mixing processes, the term "mixing" here refers to the combined processes of potential dispersive and diffusive mixing in the soil itself as well as in-stream mixing of water particles entering the catchment at different times and locations and being routed to the stream through different flow routes. In this study two potential mixing scenarios, employing a total of three different mixing processes, i.e. complete, static and dynamic partial mixing, were investigated.

\subsubsection{Complete mixing}

The complete mixing (CM) model, used in most studies based on conceptual models (e.g. Dunn et al., 2007; McMillan et al., 2012) assumes instantaneous and complete mixing of the incoming signal between the active $\left(S_{\mathrm{a}}\right)$ and passive compartments $\left(S_{\mathrm{p}}\right)$ in each of the modeled storage components, following the tracer balance equation for each modeled storage component (e.g. Birkel et al., 2011a):

$\frac{\mathrm{d}\left(c_{i} S_{i}\right)}{\mathrm{d} t}=\sum_{j} c_{\mathrm{I}, j} I_{j}-\sum_{k} c_{i} O_{k}$,

where $S_{i}=S_{\mathrm{a}, i}+S_{\mathrm{p}, i}$ is the total water stored in each of the $i$ model storages [L], $c_{i}=c_{\mathrm{a}, i}=c_{\mathrm{p}, i}$ is the respective tracer concentration $\left[\mathrm{ML}^{-1}\right], I$ are the $j$ different water inflow rates $\left[\mathrm{L} \mathrm{T}^{-1}\right]$ to a given component (e.g. effective precipitation $P_{\mathrm{E}}$ to the unsaturated zone $S_{\mathrm{U}}$ or slow and preferential 
Table 3. Parameters used in the three model setups with the initial sampling range as well as the optimal parameters and the parameter ranges of Pareto members (in brackets) for the three study catchments.

\begin{tabular}{|c|c|c|c|c|c|}
\hline \multirow[t]{2}{*}{ Parameter } & \multirow[t]{2}{*}{ Unit } & \multirow{2}{*}{$\begin{array}{l}\text { Initial } \\
\text { range }\end{array}$} & \multicolumn{3}{|c|}{ Calibrated parameters } \\
\hline & & & $\begin{array}{c}\text { Strontian - } \\
\text { Allt Coire } \\
\text { nan Con }\end{array}$ & $\begin{array}{l}\text { Loch Ard - } \\
\text { Burn } 11\end{array}$ & $\begin{array}{l}\text { Feshie - Allt } \\
\text { a'Mharcaidh }\end{array}$ \\
\hline $\mathbf{T}_{\mathrm{T}}$ & $\left({ }^{\circ} \mathrm{C}\right)$ & $-1.5-1.5$ & - & - & $\begin{array}{c}0.59 \\
(0.18-0.62)\end{array}$ \\
\hline $\mathbf{F}_{\mathrm{M}}$ & $\left(\mathrm{mm}^{\circ} \mathrm{C}^{-1} \mathrm{~d}^{-1}\right)$ & $0-5$ & - & - & $\begin{array}{c}5.1 \\
(3.3-5.2)\end{array}$ \\
\hline $\mathbf{I}_{\max }$ & $(\mathrm{mm})$ & $0-3$ & - & $\begin{array}{c}2.1 \\
(0.72-2.58)\end{array}$ & - \\
\hline $\mathbf{S}_{\mathrm{U}_{\max }}$ & $(\mathrm{mm})$ & $0-1500$ & $\begin{array}{c}366 \\
(152-450)\end{array}$ & $\begin{array}{c}528 \\
(335-568)\end{array}$ & $\begin{array}{c}1181 \\
(871-1193)\end{array}$ \\
\hline$\beta$ & $(-)$ & $0-1$ & $\begin{array}{c}0.03 \\
(0.02-0.47)\end{array}$ & $\begin{array}{c}0.02 \\
(0.01-0.04)\end{array}$ & $\begin{array}{c}0.56 \\
(0.13-0.70)\end{array}$ \\
\hline $\mathbf{L}_{\mathrm{P}}$ & $(-)$ & $0-1$ & $\begin{array}{c}0.73 \\
(0.62-0.94)\end{array}$ & $\begin{array}{c}0.95 \\
(0.80-0.96)\end{array}$ & $\begin{array}{c}0.75 \\
(0.62-0.83)\end{array}$ \\
\hline $\mathbf{T}_{\mathrm{F}}$ & (d) & $1-3$ & $\begin{array}{c}1.06 \\
(1.04-1.22)\end{array}$ & $\begin{array}{c}1.55 \\
(1.42-1.94)\end{array}$ & - \\
\hline $\mathbf{S}_{\mathrm{F}_{\max }}$ & $(\mathrm{mm})$ & $0-100$ & $\begin{array}{c}20.8 \\
(13.5-24.5)\end{array}$ & $\begin{array}{c}21.3 \\
(15.6-24.5)\end{array}$ & - \\
\hline $\mathbf{K}_{\mathrm{F}}$ & $\left(d^{-1}\right)$ & $0-5$ & $\begin{array}{c}0.98 \\
(0.95-2.71)\end{array}$ & $\begin{array}{c}1.61 \\
(1.36-3.45)\end{array}$ & $\begin{array}{c}1.17 \\
(0.91-1.99)\end{array}$ \\
\hline $\mathbf{P}_{\max }$ & $\left(\mathrm{mm} \mathrm{d}^{-1}\right)$ & $0-4$ & $\begin{array}{c}0.35 \\
(0.32-1.99)\end{array}$ & $\begin{array}{c}0.48 \\
(0.32-0.75)\end{array}$ & $\begin{array}{c}0.83 \\
(0.64-1.42)\end{array}$ \\
\hline $\mathbf{C}_{\mathrm{P}}$ & $(-)$ & $0-1$ & - & $\begin{array}{c}0.12 \\
(0.07-0.29)\end{array}$ & $\begin{array}{c}0.62 \\
(0.49-0.71)\end{array}$ \\
\hline $\mathbf{T}_{\mathrm{S}}$ & (d) & $1-10$ & - & - & $\begin{array}{c}2.7 \\
(2.56-8.45)\end{array}$ \\
\hline $\mathbf{K}_{\mathrm{S}}^{*}$ & $\left(d^{-1}\right)$ & MRC $^{*}$ & $0.10^{*}$ & $0.22^{*}$ & $0.05^{*}$ \\
\hline$\mu_{\mathrm{CM}, \mathrm{SU}}$ & $(-)$ & $0-10$ & $\begin{array}{c}1.94 \\
(1.79-2.87)\end{array}$ & $\begin{array}{c}1.07 \\
(0.98-2.05)\end{array}$ & $\begin{array}{c}0.55 \\
(0.46-0.59)\end{array}$ \\
\hline$\sigma_{\mathrm{CM}, \mathrm{SU}}$ & $(-)$ & $0-1$ & $\begin{array}{c}0.65 \\
(0.60-0.97)\end{array}$ & $\begin{array}{c}0.35 \\
(0.33-0.65)\end{array}$ & $\begin{array}{c}0.18 \\
(0.17-0.22)\end{array}$ \\
\hline $\mathbf{C}_{\mathrm{M}, \mathrm{SS}}$ & $(-)$ & $0-1$ & $\begin{array}{c}0.19 \\
(0.16-0.72)\end{array}$ & $\begin{array}{c}0.12 \\
(0.10-0.35)\end{array}$ & $\begin{array}{c}0.10 \\
(0.08-0.23)\end{array}$ \\
\hline $\mathbf{S}_{\mathrm{P}, \mathrm{SS}}$ & $(\mathrm{mm})$ & $0-75000$ & $\begin{array}{c}1120 \\
(865-6332)\end{array}$ & $\begin{array}{c}10568 \\
(2762-12825)\end{array}$ & $\begin{array}{c}10218 \\
(7521-14103)\end{array}$ \\
\hline
\end{tabular}

* Storage coefficient of $S_{\mathrm{S}}$ (slow reservoir) fixed according to MRC.

recharge, $R_{\mathrm{S}}$ and $R_{\mathrm{P}}$, respectively, to the slow responding storage $S_{\mathrm{S}}$; see Table 2) with the corresponding inflow tracer concentrations $c_{\mathrm{I}, j}\left[\mathrm{ML}^{-1}\right], O$ are the $k$ various water outflow rates $\left[\mathrm{L} \mathrm{T}^{-1}\right]$ from a given model component (e.g. $E_{\mathrm{SU}}$, $R_{\mathrm{F}}, R_{\mathrm{P}}$ and $R_{\mathrm{S}}$ from $S_{\mathrm{U}}$; Table 2). Note that in the complete mixing case, $S_{\mathrm{a}, i}$ are the states of the $i$ model storage elements (here: $S_{\mathrm{SN}}, S_{\mathrm{I}}, S_{\mathrm{U}}, S_{\mathrm{F}}$ and $S_{\mathrm{S}}$ ) while $S_{\mathrm{p}, i}=\mathbf{S}_{\mathrm{P}, i}$ are calibration parameters. For the complete mixing case in this study a passive storage $S_{\mathrm{p}, i}$ was only considered for the slow responding reservoir, i.e. $\mathbf{S}_{\mathrm{P}, \mathrm{SS}}$ (Fig. 3a-c, Table 3).

\subsubsection{Static partial mixing}

Experimental evidence suggests that the complete mixing assumption is too simplistic for surface water systems (e.g. Godsey et al., 2009; Rouxel et al., 2011). This is true in particular for systems with pronounced switches between rapid shallow subsurface (e.g. macropores) or overland flow 
on the one hand and matrix flow on the other hand (e.g. Van Schaik et al., 2008; Legout et al., 2009; Königer et al., 2010). Although the dynamic interaction of these different flow processes was in the past successfully modeled using dual mixing models, allowing for different mixing mechanisms in the soil matrix and the bypass flow, respectively (e.g. Vogel et al., 2008; Stumpp and Maloszewski, 2010), partial mixing is rarely considered in conceptual modeling studies (e.g. Page et al., 2007; Van der Velde et al., 2012). Here, partial mixing is conceptualized as instantaneous, partial mixing between $S_{\mathrm{a}}$ and $S_{\mathrm{p}}$ (cf. Fenicia et al., 2010). Thus, only a part of the mobile water $\left(S_{\mathrm{a}}\right)$ contributing to stream flow, as determined by the dimensionless mixing coefficient $\mathbf{C}_{\mathrm{M}, i}$, is mixed with water in $S_{\mathrm{p}}$ according to

$$
\begin{aligned}
& \frac{\mathrm{d}\left(c_{\mathrm{a}, i} S_{\mathrm{a}, i}\right)}{\mathrm{d} t}=\sum_{j}\left(c_{\mathrm{I}, j} I_{\mathrm{a}, j}+c_{\mathrm{p}, i} I_{\mathrm{p}, j}\right)-\sum_{k} c_{\mathrm{a}, i} O_{k} \\
& \frac{\mathrm{d}\left(c_{\mathrm{p}, i} S_{\mathrm{p}, i}\right)}{\mathrm{d} t}=\sum_{j}\left(c_{\mathrm{I}, j} I_{\mathrm{p}, j}-c_{\mathrm{p}, i} I_{\mathrm{p}, j}\right),
\end{aligned}
$$

where $I_{\mathrm{p}, j}=I_{j} \mathbf{C}_{\mathrm{M}, i} \mathrm{~d} t$ and $I_{\mathrm{a}, j}=I_{j}\left(1-\mathbf{C}_{\mathrm{M}, i} \mathrm{~d} t\right)$ are the $j$ individual water influxes to the $i$ active $\left(S_{\mathrm{a}, i}\right)$ and passive storage compartments $\left(S_{\mathrm{p}, i}\right) . I_{\mathrm{p}, j}$ can thus be conceptualized as the proportion of input $I$ to a storage component that is mixed with water in $S_{\mathrm{p}, i}$. As the water balance of $S_{\mathrm{p}, i}$ is 0 , all the water $I_{\mathrm{p}, j}$ entering the passive storage compartment $S_{\mathrm{p}, i}$ with tracer concentration $c_{\mathrm{I}, j}$ is subsequently released to $S_{\mathrm{a}, i}$ with concentration $c_{\mathrm{p}, i}$. Note, that mixing coefficient $\mathbf{C}_{\mathrm{M}, i}$ is a lumped parameter combining dispersive processes, caused by different flow velocities through soil matrix pore spaces of different size and diffusive exchange processes between $S_{\mathrm{a}, i}$ and $S_{\mathrm{p}, i}$. If warranted by data, a separation of dispersive and diffusive mixing could be readily incorporated.

\subsubsection{Dynamic partial mixing}

The importance of dynamic aspects of partial mixing was recently highlighted by several studies. Closely linked to the well-known soil moisture hysteresis (e.g. Brutsaert, 2005) in general and thus to capillarity and macropore effects in particular (e.g. Beven and Germann, 1982), for example Brooks et al. (2009) observed in a catchment with Mediterranean climate that water entering the soil after a dry period first moves into small pores. As the soil is wetting up, new water is increasingly bypassing the small pores and is routed through the system along preferential flow paths, thus showing decreased interaction with water stored in the small pores ("First-in-last-out" mechanism). Somewhat contrasting conclusions were drawn by Legout et al. (2007) and Klaus et al. (2013). They reported high initial proportions of "new" water followed by higher contributions of "old" water with increased soil moisture content, as relatively well-mixed water from the matrix is increasingly complementing water released over preferential flow pathways. To at least partially reconcile these different interpretations, we suggest a dynamic partial mixing mechanism with a dimensionless mixing coefficient $C_{\mathrm{M}, i}$ that is controlled by the soil moisture content according to

$C_{\mathrm{M}, i}=\frac{1}{2}-\frac{1}{2} \operatorname{erf}\left(\frac{\frac{S_{\mathrm{U}}}{\mathrm{S}_{\max }}-\mu_{\mathrm{C}_{\mathrm{M}, i}}}{\sigma_{\mathrm{C}_{\mathrm{M}, \mathrm{i}}} \sqrt{2}}\right)$,

where $\mu_{\mathrm{C}_{\mathrm{M}, i}}[-]$ and $\sigma_{\mathrm{C}_{\mathrm{M}, i}}[-]$ are shape parameters. The dynamic mixing coefficient $C_{\mathrm{M}, i}$, subsequently applied in the tracer balance equations (Eqs. 26-27), thus decreases with increased soil moisture content (Fig. 3d). Under conditions with low soil moisture content, most of the incoming "new" water enters the soil matrix, where it is assumed to be completely mixed with the resident water, while only a minor proportion is released over preferential flow pathways (Eqs. 12-14). However, in spite of high exchange rates under dry conditions, i.e. $\sim$ complete mixing, the proportion of "new" water released is high due to low absolute "old" water volumes available for mixing in the matrix and little water being released from the matrix by percolation. When the soil is wetting up, a smaller proportion of water is infiltrating into the matrix due to the increased matrix potential (or reduced matrix suction) and it is increasingly routed through preferential flow pathways with comparably high flow velocites (Eqs. 12-14). As a consequence, the higher degree of soil-tube filling and/or the gradual activation of larger soiltubes translate into proportionally reduced contact surfaces for dispersive exchange as well as into shorter contact times for diffusive exchange between preferential flow paths and matrix, subsequently permitting only lower total exchange rates between these two compartments. However, the overall proportion of older water released can potentially increase due to higher percolation rates from water stored in the matrix (Eq. 15), which is broadly consistent with observations reported by Weiler and Naef (2003).

Dynamic partial mixing was only considered where significant changes in soil moisture content below FC occur, i.e. for the unsaturated or root zone $\left(S_{\mathrm{U}}\right)$ as the soil moisture content in the unsaturated transition zone below the root zone as well as in the groundwater storage $\left(S_{\mathrm{S}}\right)$ can be assumed to be $\Theta_{\mathrm{SU}} \geq \mathrm{FC}$ and $\Theta_{\mathrm{SS}}=1$, respectively. Thus, here the dynamic $S_{\mathrm{a}, \mathrm{SU}}$ is water that is eventually released as $R_{\mathrm{F}}$ and $R_{\mathrm{P}}$ to $S_{\mathrm{F}}$ and $S_{\mathrm{S}}$ (i.e. preferential flow; Eqs. 13-14), while the dynamic $S_{\mathrm{p}, \mathrm{SU}}$ is water stored in $S_{\mathrm{U}}$ (i.e. matrix water; Eq. 3).

In the following analysis two scenarios, each employing different combinations of mixing assumptions, were tested: (1) complete mixing in all model components, i.e. $C_{\mathrm{M}, 1 \ldots i}=1$ as a benchmark, thereafter referred to as complete mixing model scenario $(\mathrm{CM})$ and (2) dynamic partial mixing in $S_{\mathrm{U}}$ according to $C_{\mathrm{M}, \mathrm{SU}}=f\left(S_{\mathrm{U}}, \mathbf{S}_{\mathrm{U}_{\max }} \mid \mu_{\mathrm{CM}, \mathrm{SU}}, \sigma_{\mathrm{CM}, \mathrm{SU}}\right)$, static partial mixing in $S_{\mathrm{S}}$ according to $\mathbf{C}_{\mathrm{M}, \mathrm{SS}}$ (representing the combined mixing processes in the unsaturated transition zone and $S_{\mathrm{S}}$ ) and complete mixing in the remaining components, thereafter referred to as partial mixing model scenario 
(PM; Fig. 3, Table 3). Supported by experimental evidence from the Scottish Highlands (Birkel et al., 2011b), overland flow was conceptualized as overflow of the fast responding reservoir $S_{\mathrm{F}}$ in the hydrological model thus also reflecting its tracer composition. Initial states of tracer concentration in the individual components were assumed to be reflected by the long-term base flow mean tracer concentrations (cf. Hrachowitz et al., 2011a). Note that, although $\mathrm{Cl}^{-}$turnover by plants can under certain circumstances play a significant role (cf. Lovett et al., 2005), it was in the cool Scottish climate, also in the absence of suitable data warranting the inclusion of this process, considered negligible as individual process in the models (cf. Kirchner et al., 2000; Page et al., 2007; Shaw et al., 2008) due to low transpiration rates (and thus limited sap flow) and limited organic matter turnover in the Heather moorland vegetation and the coniferous forests of the study catchments (cf. Liu et al., 2004).

The combined water balance and mixing models were run on daily time steps. The observed weekly tracer input concentrations were distributed uniformly over the preceding 7 days. For efficiency and adequate numerical stability the models are solved numerically using an explicit 4th order Runge-Kutta scheme.

\subsection{Model calibration}

The selected models (Fig. 3) for the three study catchments were calibrated using Monte-Carlo sampling. The $10^{7}$ realizations for each model were based on uniform prior parameter distributions within the initial ranges given in Table 3 . The individual model performances were subsequently assessed with a combined multi-objective (e.g. Gupta et al., 1998) and multi-criteria (e.g. Schoups et al., 2005) strategy in order to limit parameter uncertainty and ensure the model's capability of reproducing distinct aspects of the system response. The chosen performance criteria were stream flow and stream tracer concentration. The performance objectives included the Nash-Sutcliffe efficiency $\left(E_{\mathrm{NS}, Q}\right.$; Nash and Sutcliffe, 1970), the Nash-Sutcliffe efficiency for the logarithm of the flows $\left(E_{\mathrm{NS}, \log _{Q}}\right)$ and the volumetric efficiency $\left(E_{\mathrm{V}, Q}\right.$; Criss and Winston, 2008) for the hydrograph as well as $E_{\mathrm{NS}, \mathrm{C}}$ and $E_{\mathrm{V}, \mathrm{C}}$ for the stream tracer concentrations. Hence, the models were evaluated according to a total of 5 performance measures. Additionally, the modelled average annual combined actual evaporation (Eq. 8) and transpiration amounts (Eqs. 10 and 19) were constrained to $\pm 25 \%$ of the long-term annual averages as estimated by MORECS (cf. Hough and Jones, 1997). To limit the effects of epistemic error, significant "rogue" observations, such as peaks in the observed runoff when no precipitation or snow melt was occurring, were removed from the calibration time series based on expert judgment (cf. Beven and Westerberg, 2011).

Calibration eventually resulted in 5-D pareto fronts for each model, representing the sets of pareto-optimal solutions with respect to the 5 selected performance measures.
As pareto-optimal sets of solutions are not dominated by any other solution as a result of trade-off effects, no objectively "best" solution can be distinguished (e.g. Fenicia et al., 2007). Thus, to document the sensitivity of the models to pareto-optimal solutions the 5th and 95th percentiles of the pareto-optimal parameter values as well as the corresponding sensitivity intervals around the modeled hydroand chemographs were computed. However, for clarity and conciseness of the paper, only one pareto-optimal solution for each model was chosen for the subsequent analysis. As frequently done, the most balanced solution for each model was used for this purpose, i.e. the solution with the minimum Euclidean distance $D_{\mathrm{E}}$ to the perfect model, $E_{\mathrm{NS}, i}=V_{\mathrm{E}, i}=1$ (e.g. Schoups et al., 2005):

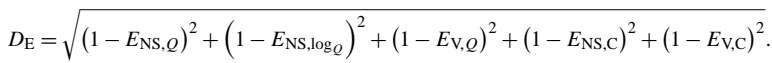

It should be noted that storage coefficient $\mathbf{K}_{\mathrm{S}}$ was not treated as a free calibration parameter. It was rather directly determined from master recession curves (MRC) for each catchment using the automated match-stripping method suggested by Lamb and Beven (1997) and previously successfully applied (e.g. Fenicia et al., 2006; Hrachowitz et al., 2011b). Briefly, the MRC is based on recession periods longer than specified thresholds ( $48 \mathrm{~h}$ in this study). The individual recession segments are then assembled into one synthetic recession curve, in which the segments are sorted based on tail-end discharge values. Starting from the segment with the lowest tail-end value, the following segments are shifted in time until overlap occurs and collated to the synthetic curve (insets Fig. 2, Table 3).

\subsection{Flux tracking}

As experimental evidence supports the assumption that conservative tracers essentially "follow the water" (e.g. Kirchner et al., 2010), water fluxes can be tracked through the system as soon as the controlling mixing volumes and processes are adequately parameterized. Briefly, for each time step, the fluxes and states in all model storage components are known. Both, fluxes and states are represented in multidimensional matrices. Each matrix element represents the water volume of a certain age contributing to the total flux or state at time $t$ (Fig. 4). Consequently, the relative contributions constitute the various age distributions of water at each time step. For a detailed description the reader is referred to McMillan et al. (2012).

It is emphasized that the tracking analysis presented hereafter is based on modeling results, adopting a virtual experiment approach. Thus, the employed models are interpreted as best available representations of the system and model internal dynamics are assumed to approximate real world dynamics. On the one hand this can be justified by the extensive model selection strategy which allows to reject unsuitable model structures. On the other hand the multiple objective calibration approach increases model realism and predictive 


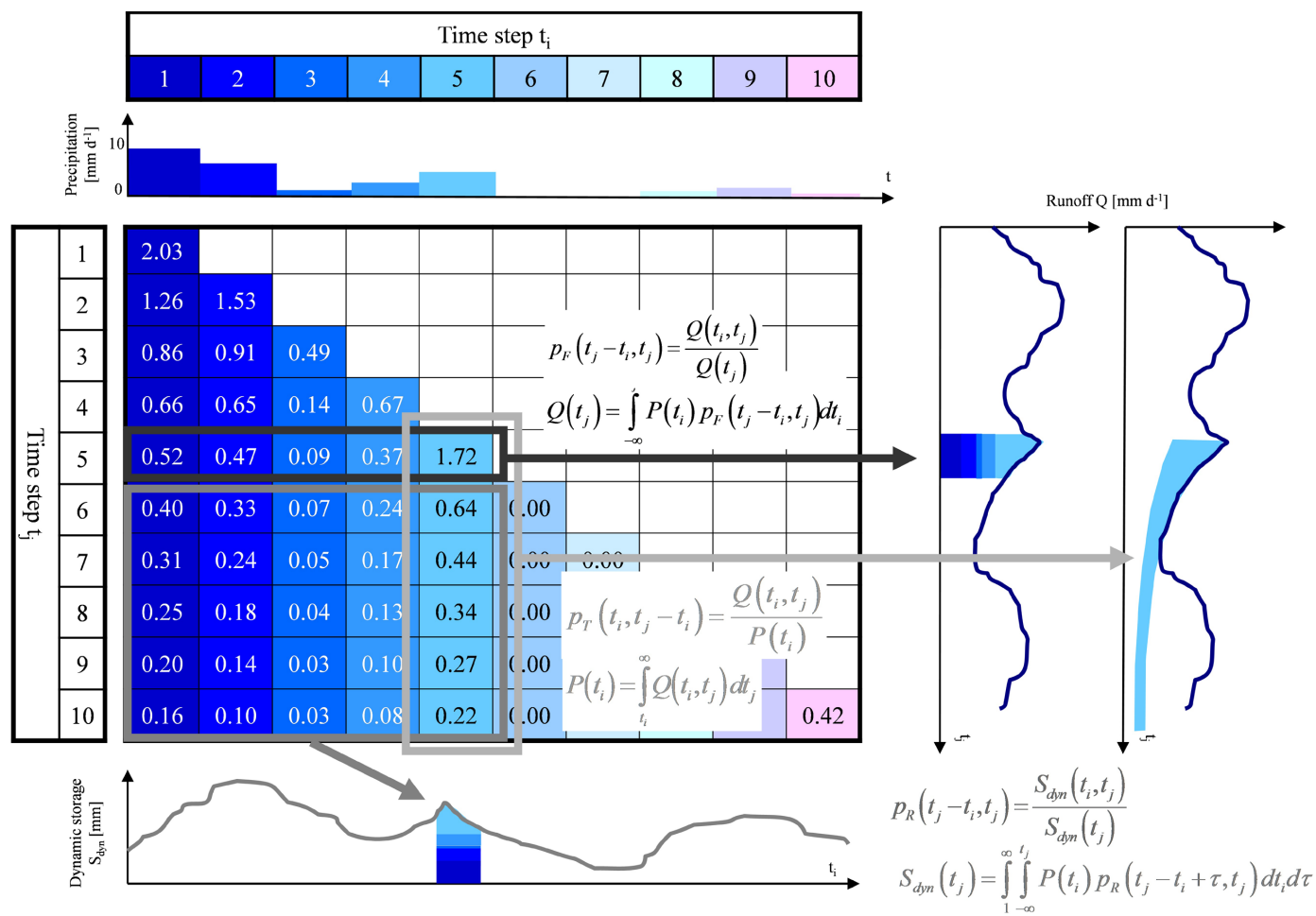

Fig. 4. Synthetic, illustrative example of the three different age distributions $p_{\mathrm{F}}$ (flux age distribution), $p_{\mathrm{R}}$ (resident age distribution) and $p_{\mathrm{T}}$ (transit time distribution). Value in each cell of the grid indicates the runoff generated from precipitation entering the system at $t_{i}$ and exiting at $t_{j}$. Note, that for simplicity, evaporation is omitted here.

power as only parameterizations that can reproduce all five calibration objectives adequately well were accepted as behavioral. In spite of rigorous model selection and calibration efforts applied here, we explicitly acknowledge the quantitative uncertainty related to virtual experiment approaches. Thus, this study is rather to be seen as a functional intercomparison with uncertainty estimates given for stream flow and tracer responses as well as for parameter estimates and modeled flux contributions.

\subsection{Definition of age distributions}

In the past few decades, many studies characterized age distributions of water with one single descriptor, i.e. the mean transit time (MTT) which resulted from the common use of models based on complete mixing and transit time distributions (TTD):

$p_{\mathrm{R}}\left(t_{j}-t_{i}, t_{j}\right)=p_{\mathrm{F}}\left(t_{j}-t_{i}, t_{j}\right)=p_{\mathrm{T}}\left(t_{i}, t_{j}-t_{i}\right)$,

where $t_{i}$ is the time of entry to the system, $t_{j}$ is the time of exit from the system, $t_{j}-t_{i}$ is the time elapsed since entry to the system or the "age of water", $p_{\mathrm{R}}\left(t_{j}-t_{i}, t_{j}\right)$ is the age distribution (i.e. probability density function) of water that entered the catchment at any time $t \leq t_{j}$ and that is stored in the entire catchment at time $t_{j}$ (Fig. 4), hereafter referred to as age distribution of resident water (Kreft and Zuber, 1978).
Similarly, $p_{\mathrm{F}}\left(t_{j}-t_{i}, t_{j}\right)$ is the age distribution of water that entered the catchment at any time $t \leq t_{j}$ and that reached one specific point in a catchment (e.g. catchment outlet) at time $t_{j}$ (Fig. 4), hereafter referred to as age distribution of water in flux (Kreft and Zuber, 1978). In other words $p_{\mathrm{R}}$ is a marginal distribution of $p_{\mathrm{F}}$ conditional on the location in the catchment. In contrast, the probability density function $p_{\mathrm{T}}\left(t_{i}, t_{j}-t_{i}\right)$ is the transfer function according to which a precipitation signal entering the catchment at $t_{i}$ is routed through the catchment over time (Fig. 4), hereafter referred to as water transit time. The equality between these three types of distributions holds only for completely mixed, timeinvariant systems (cf. Rinaldo et al., 2011). While groundwater dominated catchments with homogenous, high permeability aquifers may meet this assumption (e.g. Maloszewski and Zuber, 1996), it does not apply for the greater part of catchments. As discussed by McDonnell et al. (2010), most surface water systems are characterized by the presence of a suite of flow paths active at different timescales (e.g. preferential flow and baseflow). Although each flow path could in principle be represented individually as completely mixed, their combination is different from complete mixing of the entire system due to distinct flow velocities and dispersion/diffusion characteristics in each flow path, leading, under the time-invariance assumption, to 
$p_{\mathrm{R}}\left(t_{j}-t_{i}, t_{j}\right) \neq p_{\mathrm{F}}\left(t_{j}-t_{i}, t_{j}\right)=p_{\mathrm{T}}\left(t_{i}, t_{j}-t_{i}\right)$.

Furthermore, as demonstrated by Niemi (1977), $p_{\mathrm{F}}$ and $p_{\mathrm{T}}$ are related by the ratio of system input to output:

$p_{\mathrm{F}}\left(t_{j}-t_{i}, t_{j}\right)=\frac{I\left(t_{i}\right)}{O\left(t_{j}\right)} p_{\mathrm{T}}\left(t_{i}, t_{j}-t_{i}\right)$,

where $I\left(t_{i}\right)$ is the system input at any time $t_{i} \leq t_{j}$ and $O\left(t_{j}\right)$ is system output at $t_{j}$. Thus, $p_{\mathrm{F}}=p_{\mathrm{T}}$ only if $I\left(t_{i}\right) / O\left(t_{j}\right)$ are unity. For groundwater dominated systems with small groundwater level fluctuations $I\left(t_{i}\right) / O\left(t_{j}\right)$ can approach unity, i.e. time invariance or steady-state, as the unsaturated zone can act as a low-pass filter, dampening the temporal variability of precipitations signals in the groundwater recharge (here: $I\left(t_{i}\right)$ ). For typical surface water systems, however, this does not hold, resulting in

$$
p_{\mathrm{R}}\left(t_{j}-t_{i}, t_{j}\right) \neq p_{\mathrm{F}}\left(t_{j}-t_{i}, t_{j}\right) \neq p_{\mathrm{T}}\left(t_{i}, t_{j}-t_{i}\right) \text {. }
$$

The differences between $p_{\mathrm{R}}, p_{\mathrm{F}}$ and $p_{\mathrm{T}}$ are illustrated with a sketched, hypothetical example in Fig. 4, highlighting the relation between the 3 distributions for water entering $\left(p_{\mathrm{T}}\right)$, leaving $\left(p_{\mathrm{F}}\right)$ and being stored $\left(p_{\mathrm{R}}\right)$ at time $t=5$. In addition to the contrasting nature of $p_{\mathrm{R}}, p_{\mathrm{F}}$ and $p_{\mathrm{T}}$, it should be mentioned that water is routed along each flow path according to different transit time distributions or transfer functions $p_{\mathrm{T}}$, thereby generating distinct water age distributions $p_{\mathrm{F}}$ for each flow path (cf. Uchida et al., 2006). For example, plants frequently tap water for transpiration from much shallower and thus younger sources than those for instance groundwater flow is generated from (cf. Botter et al., 2010; Van der Velde et al., 2012). It can therefore be written as

$$
\begin{aligned}
& p_{\mathrm{T}, \mathrm{tot}}\left(t_{i}, t_{j}-t_{i}\right)=p_{\mathrm{T}, Q}\left(t_{i}, t_{j}-t_{i}\right) \frac{\sum_{t_{j}}^{\infty} Q\left(t_{i}, t_{j}\right)}{P\left(t_{i}\right)} \\
& +p_{\mathrm{T}, \mathrm{E}}\left(t_{i}, t_{j}-t_{i}\right) \frac{\sum_{t_{j}}^{\infty} E\left(t_{i}, t_{j}\right)}{P\left(t_{i}\right)} \\
& =\sum_{n=1}^{N} p_{\mathrm{T}, Q_{n}}\left(t_{i}, t_{j}-t_{i}\right) \frac{\sum_{t_{j}}^{\infty} Q_{n}\left(t_{i}, t_{j}\right)}{P\left(t_{i}\right)} \\
& +\sum_{m=1}^{M} p_{\mathrm{T}, \mathrm{E}_{m}}\left(t_{i}, t_{j}-t_{i}\right) \frac{\sum_{t_{j}}^{\infty} E_{m}\left(t_{i}, t_{j}\right)}{P\left(t_{i}\right)}
\end{aligned}
$$$$
p_{\mathrm{F}, \text { tot }}\left(t_{j}-t_{i}, t_{j}\right)=p_{\mathrm{F}, Q}\left(t_{j}-t_{i}, t_{j}\right)
$$$$
\frac{Q\left(t_{j}\right)}{Q\left(t_{j}\right)+E\left(t_{j}\right)}+p_{\mathrm{F}, \mathrm{E}}\left(t_{j}-t_{i}, t_{j}\right) \frac{E\left(t_{j}\right)}{Q\left(t_{j}\right)+E\left(t_{j}\right)}
$$$$
=\sum_{n=1}^{N} p_{\mathrm{F}, Q_{n}}\left(t_{j}-t_{i}, t_{j}\right) \frac{Q_{n}\left(t_{j}\right)}{Q\left(t_{j}\right)+E\left(t_{j}\right)}
$$$$
+\sum_{m=1}^{M} p_{\mathrm{F}, \mathrm{E}_{m}}\left(t_{j}-t_{i}, t_{j}\right) \frac{E_{n}\left(t_{j}\right)}{Q\left(t_{j}\right)+E\left(t_{j}\right)},
$$

where the transit time distribution $p_{\mathrm{T}, \text { tot }}\left(t_{i}, t_{j}-t_{i}\right)$ is the transit time distribution or transfer function of the precipitation signal $P$ entering at $t_{i}$ and routed through the system considering all possible flow paths (or exit routes) in the catchment, $p_{\mathrm{T}, Q}\left(t_{i}, t_{j}-t_{i}\right)$ and $p_{\mathrm{T}, \mathrm{E}}\left(t_{i}, t_{j}-t_{i}\right)$ are the individual transit time distributions of the exit routes runoff $Q$ and evapotranspiration $E$, which can be further split into flow paths $Q_{n}$ and $E_{m}$, where $n=1, \ldots N$ represents flow generating processes such as groundwater and preferential flow and $m=1, \ldots M$ represents evaporative processes such as interception evaporation and plant transpiration. Note that $\sum_{t j}^{\infty} Q_{n}\left(t_{i}, t_{j}\right)$ and $\sum_{t j}^{\infty} E_{m}\left(t_{i}, t_{j}\right)$ denote the amounts of water that entered the catchment at $t_{i}$ and that has already left or will eventually leave in the future over the flow paths $Q_{n}$ and $E_{m}$ (see also Fig. 4). Similarly, $p_{\mathrm{F} \text {,tot }}\left(t_{j}-t_{i}, t_{j}\right)$ is the total age distribution of all fluxes leaving the catchment at $t_{j}, p_{\mathrm{F}, Q}\left(t_{j}-t_{i}, t_{j}\right)$ and $p_{\mathrm{F}, \mathrm{E}}\left(t_{j}-t_{i}, t_{j}\right)$ are the respective age distributions of runoff $Q$ and evapotranspiration $E$ at $t_{j}$, which can be further split into $Q_{n}$ and $E_{m}$. It is thus important to note that if one is interested in flow generating processes only, analysis needs to focus on $p_{\mathrm{F}, Q_{n}}$ as inclusion of $p_{\mathrm{F}, E_{m}}$ will be likely to introduce a skew towards faster responses.

For more detailed descriptions and derivations of the different PDFs describing water age, the reader is referred to recent comprehensive papers by Botter et al. (2011) and $\mathrm{Ri}$ naldo et al. (2011). Note that here time-invariant refers to the use of identical transit time distributions $p_{\mathrm{T}}\left(t_{i}, t_{j}-t_{i}\right)$ to route the precipitation signals through the system for each time step $t_{i}(i=1, \ldots, T)$, thus assuming steady-state conditions with system input and output being constant. Further note that to avoid confusion the abbreviation TTD is hereafter only used when referring to time-invariant applications.

\subsection{Wetness regimes}

The sensitivity of $p_{\mathrm{R}}, p_{\mathrm{F}}$ and $p_{\mathrm{T}}$ to changing sub-surface wetness conditions was assessed by identifying four catchment wetness regimes that constitute the end-members of possible wetness conditions, similar to the method applied by Heidbüchel et al. (2012): (1) dry, (2) wetting-up, (3) wet and (4) drying-up. The four wetness regimes are characterized by distinct differences in the wetness states of the two major runoff generating model components, $S_{\mathrm{F}}$ and $S_{\mathrm{S}}$. Dry regimes were defined as those periods during which the states of both, $S_{\mathrm{F}}$ and $S_{\mathrm{S}}$ were low, thus not exceeding their respective 25 th percentiles. Correspondingly, wet regimes were defined as periods with water volumes in $S_{\mathrm{F}}$ and $S_{\mathrm{S}}$ exceeding their 75 th percentiles. The wetting-up regime, on the other hand, was defined as periods with $S_{\mathrm{S}} \leq 25$ th and $S_{\mathrm{F}}>75$ th percentiles, while the drying-up regime were the periods with $S_{\mathrm{S}}>75$ th and $S_{\mathrm{F}} \leq 25$ th percentiles, respectively (Fig. 5). The rational behind this was that in a wettingup period after a dry period the ground water, i.e. $S_{\mathrm{S}}$, is not 


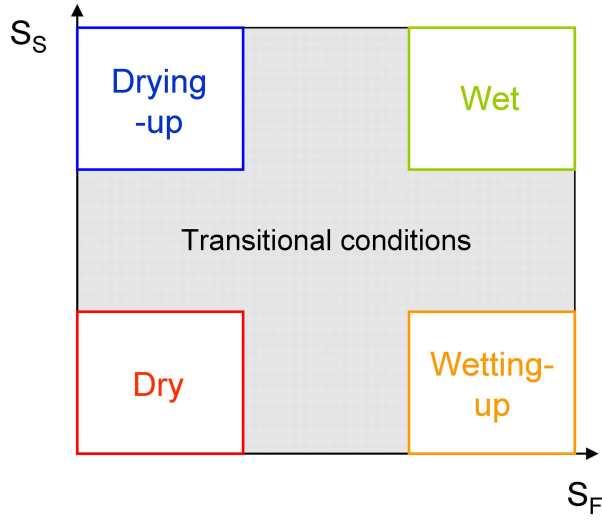

Fig. 5. Schematic of the defined hydrologic regimes used for the analysis, based on the degree of filling of $S_{\mathrm{F}}$ and $S_{\mathrm{S}}$, respectively.

yet recharged while increased high soil moisture contents can trigger preferential flows generated from $S_{\mathrm{F}}$. Conversely, while $S_{\mathrm{F}}$ can be expected to become increasingly inactive during drying-up periods, groundwater levels $\left(S_{\mathrm{S}}\right)$, recharged during the preceding wet period, are still high. Note that absolute storage differences are low in the wet and cool Scottish climate compared to drier and warmer climates with marked seasonality. Thus wetness related effects observed here can be expected to be much more pronounced in such climates.

\section{Results and discussion}

\subsection{Hydrological models}

The model structures best representing both the dynamics of the hydrographs and the tracer responses in the three study catchments not only exhibit largely adequate performance levels (Table 4), but also broadly reflect a priori conceptualizations of the study catchments. Note, that for brevity the detailed results of the model selection procedure are not shown here. Briefly, only a comparably simple core model structure, consisting of $S_{\mathrm{U}}, S_{\mathrm{F}}$ and $S_{\mathrm{S}}$ was necessary to capture the dynamics of the COIR catchment (Fig. 3a). This reflects the simple structure of the catchment which is dominated by fast responses as soils retain high moisture contents throughout the year. Humid climate, together with steep relief and thin soils, causes very pronounced and rapid switches from slow to fast processes. Slower processes only make minor contributions to modeled stream flow (3\% of water entering the catchment; Table 4) due to the elevated water holding capacities of the peat soil matrix and comparably impermeable parent material. Most of water entering the catchment thus leaves as runoff, in the model represented as overland flow $(14 \%)$ or preferential flow $(68 \%)$, while transpiration levels are rather low (15\%; Table 4). Although the lower part of the catchment is covered by forest, high precipitation and relatively low potential evaporation rates did not warrant the
Table 4. Model performance measures for the performance metrics used in model calibration. The first values represent the respective performance measures for the model with the lowest $D_{\mathrm{E}}$, i.e. the "most balanced model", the values in the brackets indicate the performance range of the 5-D pareto front. The lower part of the table gives flux contributions of individual model components from the "most balanced" parameterization and those with the members of the 5-D calibration pareto fronts (in brackets).

\begin{tabular}{|c|c|c|c|}
\hline & $\begin{array}{l}\text { Strontian - Allt } \\
\text { Coire nan Con }\end{array}$ & Loch Ard - Burn 11 & $\begin{array}{l}\text { Feshie - Allt } \\
\text { a'Mharcaidh }\end{array}$ \\
\hline \multicolumn{4}{|c|}{ Performance measure $[-]$} \\
\hline$E_{\mathrm{NS}, Q}^{*}$ & $0.85 / 0.86 / 0.84$ & $0.74 / 0.74 / 0.73$ & $0.72 / 0.72 / 0.73$ \\
\hline $\mathrm{AIC}^{*}$ & $4429 / 4478 / 4512$ & $4974 / 4989 / 5001$ & 686/694/695 \\
\hline$D_{\mathrm{E}}$ & $\begin{array}{c}0.55 \\
(0.55-0.66)\end{array}$ & $\begin{array}{c}0.69 \\
(0.69-0.75)\end{array}$ & $\begin{array}{c}1.01 \\
(1.01-1.09)\end{array}$ \\
\hline$E_{\mathrm{NS}, Q}$ & $\begin{array}{c}0.82 \\
(0.61-0.87)\end{array}$ & $\begin{array}{c}0.73 \\
(0.65-0.77)\end{array}$ & $\begin{array}{c}0.64 \\
(0.37-0.74)\end{array}$ \\
\hline$E_{\mathrm{NS}, \log \mathrm{Q}}$ & $\begin{array}{c}0.80 \\
(0.58-0.85)\end{array}$ & $\begin{array}{c}0.81 \\
(0.70-0.89)\end{array}$ & $\begin{array}{c}0.58 \\
(0.43-0.71)\end{array}$ \\
\hline$E_{\mathrm{V}, Q}$ & $\begin{array}{c}0.65 \\
(0.39-0.66)\end{array}$ & $\begin{array}{c}0.57 \\
(0.49-0.61)\end{array}$ & $\begin{array}{c}0.63 \\
(0.53-0.70)\end{array}$ \\
\hline$E_{\mathrm{NS}, \mathrm{C}}$ & $\begin{array}{c}0.79 \\
(0.71-0.83)\end{array}$ & $\begin{array}{c}0.77 \\
(0.57-0.81)\end{array}$ & $\begin{array}{c}0.47 \\
(0.39-0.52)\end{array}$ \\
\hline$E_{\mathrm{V}, \mathrm{C}}$ & $\begin{array}{c}0.80 \\
(0.67-0.83)\end{array}$ & $\begin{array}{c}0.88 \\
(0.78-0.91)\end{array}$ & $\begin{array}{c}0.87 \\
(0.86-0.93)\end{array}$ \\
\hline \multicolumn{4}{|c|}{ Flux contributions $[-]$} \\
\hline$Q_{\text {tot }}$ & $\begin{array}{c}0.85 \\
(0.83-0.86)\end{array}$ & $\begin{array}{c}0.77 \\
(0.75-0.79)\end{array}$ & $\begin{array}{c}0.66 \\
(0.63-0.70)\end{array}$ \\
\hline$Q_{\mathrm{OF}}$ & $\begin{array}{c}0.14 \\
(0.05-0.20)\end{array}$ & $\begin{array}{c}0.03 \\
(0.01-0.05)\end{array}$ & $\begin{array}{c}0.00 \\
(0.00-0.00)\end{array}$ \\
\hline$Q_{\mathrm{SF}}$ & $\begin{array}{c}0.68 \\
(0.55-0.74)\end{array}$ & $\begin{array}{c}0.60 \\
(0.47-0.64)\end{array}$ & $\begin{array}{c}0.20 \\
(0.15-0.25)\end{array}$ \\
\hline$Q_{\mathrm{SS}}$ & $\begin{array}{c}0.03 \\
(0.03-0.20)\end{array}$ & $\begin{array}{c}0.14 \\
(0.11-0.26)\end{array}$ & $\begin{array}{c}0.46 \\
(0.41-0.52)\end{array}$ \\
\hline$E_{\text {tot }}$ & $\begin{array}{c}0.15 \\
(0.14-0.17)\end{array}$ & $\begin{array}{c}0.23 \\
(0.21-0.25)\end{array}$ & $\begin{array}{c}0.34 \\
(0.30-0.38)\end{array}$ \\
\hline$E_{\mathrm{SI}}$ & $\begin{array}{c}0.00 \\
(0.00-0.00)\end{array}$ & $\begin{array}{c}0.12 \\
(0.06-0.13)\end{array}$ & $\begin{array}{c}0.00 \\
(0.00-0.00)\end{array}$ \\
\hline$E_{\mathrm{SU}}$ & $\begin{array}{c}0.15 \\
(0.14-0.17)\end{array}$ & $\begin{array}{c}0.11 \\
(0.10-0.15)\end{array}$ & $\begin{array}{c}0.34 \\
(0.30-0.38)\end{array}$ \\
\hline
\end{tabular}

* Performance measures for the three best tested model structures for each catchment based on 5-yr calibration periods (1 October 1994-30 September 1999).

inclusion of an interception component in the model. Snow was also found to be negligible as significant parts (>50\%) of the catchment did only experience negative temperatures in $2 \%$ of the time steps. BU11 at Loch Ard, while being represented by a similar core model structure as COIR and extended only by additional preferential recharge $R_{\mathrm{P}}$ to $S_{\mathrm{S}}$ (Fig. 3b), required the incorporation of an interception component in the model to ensure an adequate description of the hydrograph dynamics. It can be justified by the comparatively higher proportion of forest cover, $\sim 20 \%$ lower annual precipitation and $\sim 20 \%$ higher potential evaporation (Table 1). Although, fast runoff processes are dominant, 
base flow contributions sustained by $S_{\mathrm{S}}$ are more significant $(14 \%)$ here than at COIR, which can be linked mostly to the more subdued topography (Table 4). Further, approximately a quarter of the incoming precipitation leaves the catchment by combined interception evaporation and transpiration.

The hydrological function of the MHAR catchment is markedly different to the other two in that its higher proportion of deep and more freely draining soils entail a more damped response in the stream flow, which is thus to a large part generated by groundwater. The core model structure of the catchment accounts for the importance of groundwater using a lag function $h_{\mathrm{S}}$ for fluxes between $S_{\mathrm{U}}$ and $S_{\mathrm{S}}$ in place of lag function $h_{\mathrm{F}}$ and by the incorporation of preferential recharge to $S_{\mathrm{S}}$ (Fig. 3c). In addition, although about $20 \%$ of water entering the catchment leaves along preferential flow pathways, no second fast component such as overland flow could be identified as significant. In spite of the comparatively high proportion of precipitation leaving the catchment by evaporative fluxes ( $34 \%$ ), the absence of a significant proportion of forest cover and the dominance of relatively thin heather moorland vegetation are evidence for a lower influence of interception evaporation. As the inclusion of interception in the model structure does not improve the results it is thus effectively negligible for stream flow modeling. In contrast to the other two sites, and due the sub-arctic climate of the MHAR significant parts of the catchment (>50\%) are exposed to temperatures below freezing in $\sim 15 \%$ of the time, resulting in the need for a snow component to capture the relevant hydrograph features during winter and early spring.

\subsection{Mixing models}

The two mixing model scenarios (as discussed in Sect. 3.3), complete (CM; complete mixing in all model components) and partial mixing (PM; dynamic partial mixing in SU, static partial mixing in SS and complete mixing in the remaining model components), were tested in the three study catchments. While the PM models generally outperformed the $\mathrm{CM}$ in all catchments, the degree to which they did so strongly varied. At COIR the performance of the $\mathrm{CM}$ model $\left(E_{\mathrm{NS}, \mathrm{C}}=0.76\right)$ only slightly improved to $E_{\mathrm{NS}, \mathrm{C}}=0.79$ for the PM model. The parameters of dynamic PM $\left(\mu_{\mathrm{CM}, \mathrm{SU}}\right.$, $\left.\sigma_{\mathrm{CM}, \mathrm{SU}}\right)$ resulted in dynamic PM coefficients (Eq. 28) that differed only slightly from unity $\left(0.98 \leq C_{\mathrm{M}, \mathrm{SU}} \leq 0.99\right.$, Fig. 3d). The fact that the degree of mixing is close to CM can be explained by high turnover rates in $S_{\mathrm{U}}$, due to the extremely wet climate and low $\mathbf{S}_{\mathrm{U}_{\max }}$. Thus, the water in $S_{\mathrm{U}}$ is constantly renewed and the composition of partially mixed water is therefore close to the composition of completely mixed water, which is also reflected by the relatively wide parameter ranges of the PM parameters $\mu_{\mathrm{CM}, \mathrm{SU}}$ and $\sigma_{\mathrm{CM}, \mathrm{SU}}$ (Table 3). Although the static partial mixing coefficient for $S_{\mathrm{S}}\left(\mathbf{C}_{\mathrm{M}, \mathrm{SS}}\right)$ is also characterized by a rather high degree of equifinality, caused by the limited importance of fluxes from
$S_{\mathrm{S}}$, it remains clearly below unity, supporting the PM assumption for $S_{\mathrm{S}}$.

Consequently, lower precipitation rates and higher soil moisture capacity resulted in a clearer distinction between CM and PM models in the BU11 catchment. The PM model improves the representation of tracer dynamics compared to the CM model with an increase of $E_{\mathrm{NS}, \mathrm{C}}$ from 0.69 to 0.77 . The increased importance of PM processes in BU11 is further evidenced not only by lower mixing parameter values, which result in dynamic PM coefficients $C_{\mathrm{M}, \mathrm{SU}}$ (Eq. 28) below unity $\left(0.89 \leq C_{\mathrm{M}, \mathrm{SU}} \leq 0.95\right.$, Fig. $\left.3 \mathrm{~d}\right)$, but also by the somewhat reduced parameter ranges (Table 3 ). As at COIR, low and comparably constrained values of $\mathbf{C}_{\mathrm{M} \text {,Ss }}$ indicate the importance of PM in $S_{\mathrm{S}}$.

Clearest evidence for the suitability of the PM model was found for the MHAR catchment. $E_{\mathrm{NS}, \mathrm{C}}$ increased from 0.32 for the CM model to 0.47 for the PM model (Table 4). The well constrained dynamic mixing parameters $\left(\mu_{\mathrm{CM}, \mathrm{SU}}\right.$, $\left.\sigma_{\mathrm{CM}, \mathrm{SU}}\right)$ resulted in the $C_{\mathrm{M}, \mathrm{SU}}$ ranging between 0.28 for the wettest conditions and 0.79 for the driest conditions (Fig. 3d). Likewise, the static partial mixing coefficient also takes on a well-identifiable, low value (Table 3). The importance of dynamic partial mixing in $S_{\mathrm{U}}$ in the study catchments hence appears to be related mostly to the available soil moisture storage capacity in combination with climatic variability. In other words, the more marked the fluctuations in the soil moisture content over time, the better the dynamic PM processes can be identified and the clearer the distinction from $\mathrm{CM}$ models. Note that the reduced $E_{\mathrm{NS}, \mathrm{C}}$ at MHAR is partly an artefact of the low signal-to-noise ratio, caused by a high degree of damping, in the stream tracer signal (Hrachowitz et al., 2009b). Closely linked to this, one of the frequently discussed disadvantages of tracers like $\mathrm{Cl}^{-}$is the limited detectable variation in the observed stream tracer signal for water older than 4-5 yr (e.g. Stewart et al., 2010). As the highest contributions of such old water are generally understood to be generated by groundwater (here: $S_{\mathrm{S}}$ ), it is thus frequently difficult to identify the passive mixing storage associated with $S_{\mathrm{S}}$ within limited uncertainty (e.g. Dunn et al., 2007; Fenicia et al., 2010; Birkel et al., 2011a), which is reflected in the relatively wide parameter ranges of $\mathbf{S}_{\mathrm{P}, \mathrm{SS}}(\mathrm{Ta}-$ ble 3). Interestingly, little differences in the feasible ranges of $\mathbf{S}_{\mathrm{P}, \mathrm{SS}}$ were found between CM and PM models (not shown). Note that for consistency and brevity, the following analysis of water age distributions is focused on the results of the PM models while results of CM models are discussed for comparative reasons only.

\subsection{Flux water age distributions $p_{F}$}

The modelled age distributions of different flux components leaving the three study catchments, shown as temporally averaged, unweighted distributions for each of the pre-defined four catchment wetness conditions (see Sect. 3.7 and Fig. 5) have markedly different characteristics (Fig. 6) which largely 
(a) Strontian - Allt Coire Nan Con

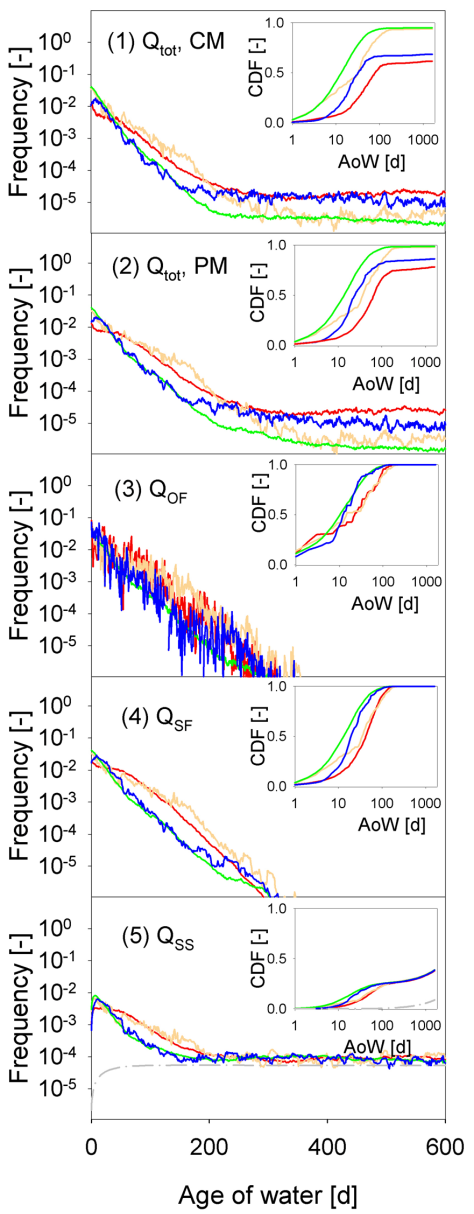

(b) Loch Ard - Burn 11

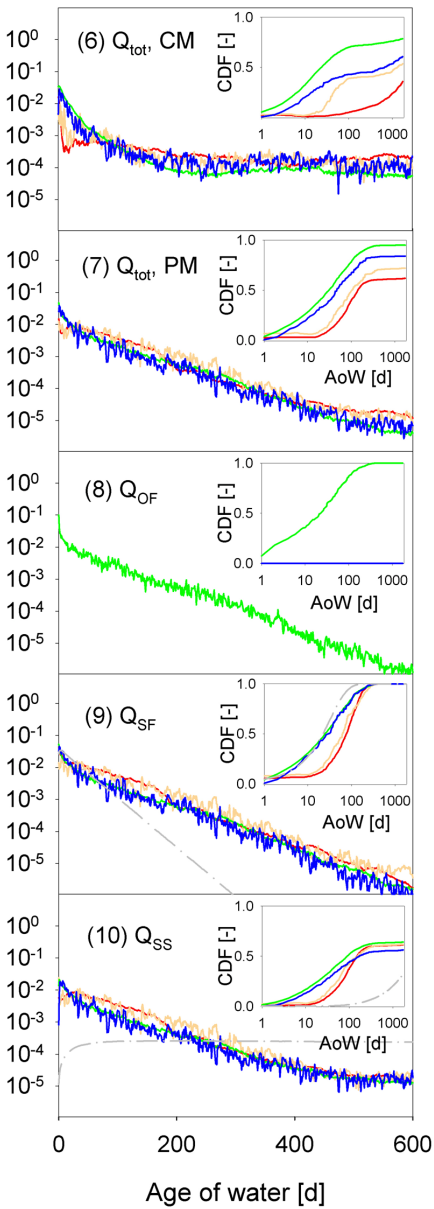

(c) Feshie - Allt a'Mharcaidh

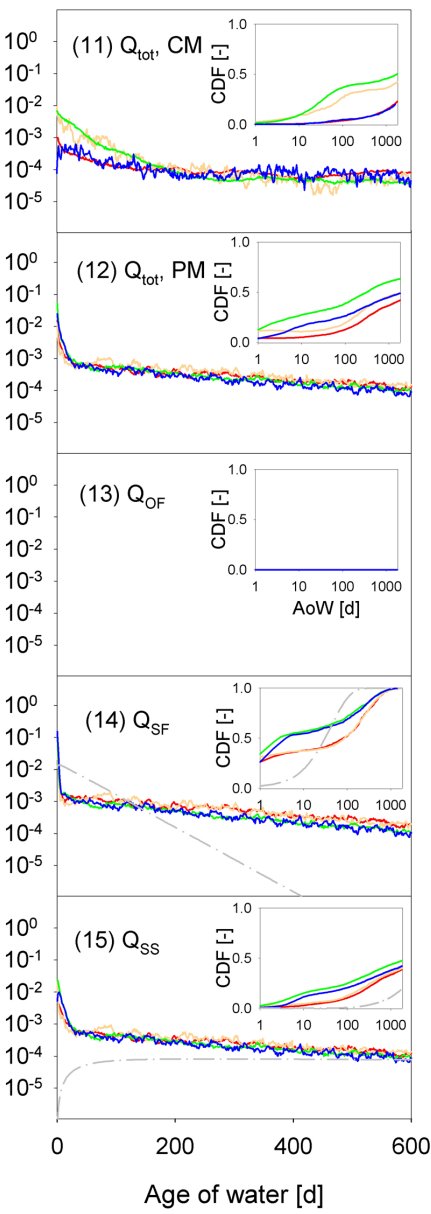

Fig. 6. Temporally averaged, unweighted flux water age distributions $p_{\mathrm{F}}$ for all runoff generating components of the three study catchments for each of the four pre-defined hydrological regimes. The averages were constructed from the median water ages for all time steps within the respective hydrological regime. CM indicates results from the complete mixing scenario and PM from the partial mixing scenario. The panels below the first row show the full results of PM scenarios and only where significant differences were found, the temporally averaged, unweighted results of the CM scenario constructed from the median of all values for the entire time series is given (grey, dash-dotted line) in addition. The color code of the lines is corresponding to the four hydrologic regimes defined in Fig. 5: red (dry), yellow (wetting-up), green (wet) and blue (drying-up).

reflect the different levels of attenuation in the tracer inputoutput relationship (Fig. 2). Note that in Fig. 6 some $p_{\mathrm{F}}$ do not add up to unity as due to computational limitations only water younger than $5 \mathrm{yr}$ could be tracked. Thus, the missing difference to unity represents the proportion of water in runoff older than $5 \mathrm{yr}$. Depending on the antecedent wetness conditions, on average between 65 and $96 \%$ of the water at the COIR catchment outlet is estimated to be younger than 100 days and up to $20 \%$ is estimated to be older than $5 \mathrm{yr}$ for both CM and PM (insets Fig. 6.1-2). In this catchment the water age distributions in the total runoff, $p_{\mathrm{F}, Q \text { tot }}$, exhibit a clear dual pattern, as previously demonstrated by others (e.g. Morgenstern et al., 2010; Roa-Garcia and Weiler, 2010). This reflects the abrupt switches between fast $\left(Q_{\mathrm{OF}}, Q_{\mathrm{SF}}\right)$ and slow $\left(Q_{\mathrm{SS}}\right)$ runoff contributions: runoff younger than $\sim 1 \mathrm{yr}$ is predominantly generated as $Q_{\mathrm{OF}}$ and $Q_{\mathrm{SF}}$, while runoff water older than that can almost exclusively be attributed to $Q_{\mathrm{Ss}}$. This is illustrated by the $p_{\mathrm{F}}$ distributions for the different flow components. While almost $100 \%$ of the water in $Q_{\mathrm{OF}}$ and $Q_{\mathrm{SF}}$ is inferred to be younger than 100 days (Fig. 6.3-4), $\sim 60 \%$ of $Q_{\mathrm{SS}}$ is estimated to be older than $5 \mathrm{yr}$ (Fig. 6.5). Due to the dynamic mixing coefficient $C_{\mathrm{M}, \mathrm{SU}}$ being close to unity, the age distributions of water generated as $Q_{\mathrm{OF}}$ and $Q_{\mathrm{SF}}\left(p_{\mathrm{F}, \mathrm{OF}}\right.$ and $\left.p_{\mathrm{F}, \mathrm{SF}}\right)$ by $\mathrm{PM}$ are effectively indistinguishable from those obtained by CM. In contrast, the break in $p_{\mathrm{F}, Q_{\mathrm{SS}}}$ at around $200 \mathrm{~d}$ (Fig. 6.5) is a consequence of the static PM process in $S_{\mathrm{S}}$ (Eqs. 25 and 26): it can be observed that PM produces higher fractions of both, relatively young and very old water compared to $\mathrm{CM}$. The close-to complete mixing in $S_{\mathrm{U}}$ in combination with the low 

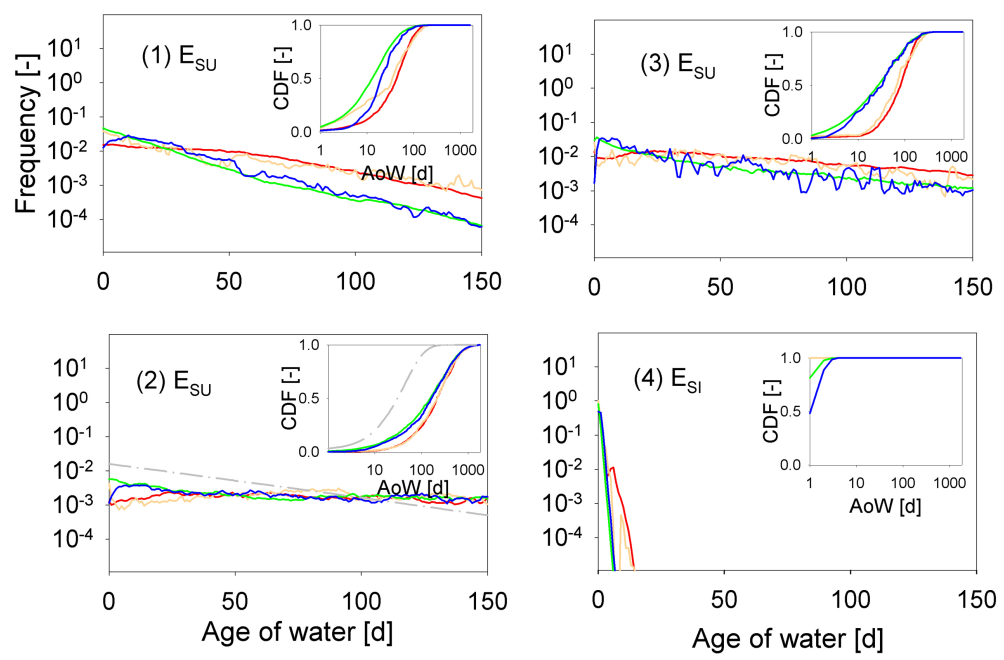

Fig. 7. Temporally averaged, unweighted flux water age distributions $p_{\mathrm{F}}$ for all evaporative processes in the three study catchments $(1-$ Allt Coir nan Con, 2 - Allt a'Mharcaidh and 3,4-Burn 11) for the four pre-defined hydrological regimes. The averages were constructed from the median water ages for all time steps within the respective hydrological regime. The figures show the full results of the PM scenarios and only where significant differences were found, the temporally averaged, unweighted results of the CM scenario constructed from the median of all values for the entire time series is given (grey, dash-dotted line) in addition. The color code of the lines is corresponding to the four hydrologic regimes defined in Fig. 5: red (dry), yellow (wetting-up), green (wet) and blue (drying-up).

contributions of $Q_{\text {ss }}$ to total runoff $Q_{\text {tot }}$, however, make this effect negligible for $p_{\mathrm{F}, Q_{\mathrm{tot}}}$. (Fig. 6.1-2). Consequently, at COIR the relatively long tails of $p_{\mathrm{F}, Q_{\mathrm{tot}}}$, i.e. the significant proportions of "old" water in $Q_{\text {tot }}$, are almost exclusively due to the switches between and the relative importance of individual processes active at different timescales, i.e. $Q_{\mathrm{OF}}$, $Q_{\mathrm{SF}}$ and $Q_{\mathrm{SS}}$, respectively. The age distribution of the runoff observed at the outlet, $p_{\mathrm{F}, Q_{\mathrm{tot}}}$, thus strongly reflects the features of $p_{\mathrm{F}, \mathrm{OF}}$ and $p_{\mathrm{F}, \mathrm{SF}}$ on the one hand as well as $p_{\mathrm{F}, \mathrm{SS}}$ on the other hand. In the light of the minor contributions of $Q_{\mathrm{SS}}$ to $Q_{\text {tot }}$ in COIR this supports evidence that even very limited groundwater contribution to runoff can have considerable effects on the tail-end of $p_{\mathrm{F}, Q}$ tot and thus on the moments of the water age distributions in runoff (e.g. MTT; Dunn et al., 2007; Stewart et al., 2012).

At the other extreme, the MHAR catchment is characterized by a damped response (Fig. 2) and the dominance of water generated from $S_{\mathrm{S}}$ (Table 4) exhibits water age distribution $\left(p_{\mathrm{F}}\right)$ characteristics markedly distinct from COIR. Depending on antecedent wetness, only 12 to $37 \%$ of the modeled stream flow is on average younger than 100 days and up to $60 \%$ is older than $5 \mathrm{yr}$ for the PM model (inset Fig. 6.12), which is significantly higher than the values obtained from the CM model (inset Fig. 6.11). Although, there is a break in $p_{\mathrm{F}, Q}$ tot at about $30 \mathrm{~d}$ in the PM model (Fig. 6.12), it has a different origin than both the breaks in $p_{\mathrm{F}, Q}$ tot in the $\mathrm{CM}$ model (Fig. 6.11) and at COIR (Fig. 6.1-2). This can be inferred by comparing $p_{\mathrm{F}, Q}$ tot of the PM and CM models. CM results in a quite subtle break in $p_{\mathrm{F}, Q \text { tot }}$ at $\sim 200 \mathrm{~d}$, created by the relatively smooth transition from $Q_{\mathrm{SF}}$ to $Q_{\mathrm{SS}}$ dominated runoff, as in the MHAR the overall proportions of fast and slow processes contributing to runoff are more balanced than at COIR (Table 4). Unlike for CM, the inflections in the age distributions of the flux components $Q_{\mathrm{SF}}$ and $Q_{\mathrm{SS}}$, $p_{\mathrm{F}, Q} \mathrm{SF}$ and $p_{\mathrm{F}, Q} \mathrm{SS}$ for PM are very similar, both exhibiting very early breaks (Fig. 6.14-15). In the PM model, the break in $p_{\mathrm{F}, Q_{\mathrm{tot}}}$ at $\sim 200 \mathrm{~d}$ is thus almost completely masked by the more pronounced break at $\sim 30 \mathrm{~d}$ (Fig. 6.12) caused mainly by partial mixing in $S_{\mathrm{U}}$ and $S_{\mathrm{S}}$ according to the coefficients $C_{\mathrm{M}, \mathrm{SU}}$ and $C_{\mathrm{M}, \mathrm{SS}} \ll 1$ (Table 3 ).

In contrast, the modeled water age distributions $p_{\mathrm{F}}$ at the BU11 catchment, which is characterized by intermediate modeled contributions of $Q_{\mathrm{OF}}, Q_{\mathrm{SF}}$ and $Q_{\mathrm{SS}}$ to $Q_{\mathrm{tot}}$ (Table 4) and a significant degree of partial mixing (Table 3), show clear evidence of the influence of both the switching between flow processes as well as partial mixing on the shape of $p_{\mathrm{F}, Q_{\text {tot }}}$ (Fig. 6.6-10). PM is responsible for a break at $\sim 20 \mathrm{~d}$, which is not present in the $p_{\mathrm{F}}$ obtained from the CM model. The switches between the runoff processes $Q_{\mathrm{OF}} / Q_{\mathrm{SF}}$ and $Q_{\text {Ss }}$, on the other hand, cause a second, smoother break at $\sim 500 \mathrm{~d}$.

Water leaving the catchment along evaporative flow paths can originate from different pools than runoff generating water, as previously discussed in detail elsewhere (e.g. Botter et al., 2010; Van der Velde et al., 2012). Transpiration, which was here conceptualized as water tapped from the soil matrix of the root zone $S_{\mathrm{U}}$ as well as from preferential flow paths (Eqs. 10 and 18), is characterized by modeled water age distributions $p_{\mathrm{F}, \mathrm{ESU}}$ that closely resemble $p_{\mathrm{F}, Q_{\mathrm{OF}}}$ and $p_{\mathrm{F}, Q_{\mathrm{SF}}}$ (cf. Figs. 6.4, 9, 14 and 7.1-3). The reason for this being that both, $Q_{\mathrm{OF}}$ and $Q_{\mathrm{SF}}$, equally draw water directly from model component $S_{\mathrm{U}}$. These fluxes are subsequently only 
subject to limited mixing in $S_{\mathrm{F}}$, where, due to the conceptualized absence of further passive mixing volumes, no significant amounts of older water are stored. However, transpiration is mainly drawn from the soil matrix which stores water of different age, while much of the water that generates preferential flow and preferential recharge can bypass the matrix without mixing according to the dynamic partial mixing coefficient $C_{\mathrm{M}, \mathrm{SU}}$. Therefore, the high modeled proportions of very young water $(<20 \mathrm{~d})$ found in $Q_{\mathrm{SF}}$ and $Q_{\mathrm{SS}}$ at MHAR (Fig. 6.14-15) do not occur in $E_{\text {SU }}$ (Fig. 7.2). Likewise, in the case of complete mixing, $p_{\mathrm{F}, \mathrm{ESU}}$ is shifted towards higher modeled proportions of younger water as, due to $C_{\mathrm{M}, \mathrm{SU}}=1$, more "new" water enters the soil matrix and mixes with the resident water. A different aspect is the incorporation of interception evaporation $E_{\mathrm{SI}}$ as individual process, e.g. BU11. As shown in Fig. 7.3-4, the inferred age signatures of $E_{\mathrm{SU}}$ and $E_{\mathrm{SI}}$ are significantly different from each other. All the water in $E_{\mathrm{SI}}$ is estimated to be younger than $\sim 10 \mathrm{~d}$ as the maximum storage capacity in model component $S_{\mathrm{I}}\left(\mathbf{I}_{\max }\right.$, Table 3$)$ roughly reflects the average evaporation rates. The small size of $S_{\mathrm{I}}$ as compared to the high precipitation rates throughout the year further ensures short turnover times in $S_{\mathrm{I}}$ as "old" water in $S_{\mathrm{I}}$ is quickly mixed and replaced by "new" precipitation. In general it can be said that, depending on the size of $S_{\mathrm{I}}$, the season and antecedent wetness, $E_{\mathrm{SI}}$ can remove significant proportions of very young water from the system and can thus emphasize wetness related changes in all model component $p_{\mathrm{F}} \mathrm{S}$ (see Sect. 4.5). In many rainfall-runoff models interception evaporation is not explicitly considered as an individual process (cf. Savenije, 2004) or it could not be identified as a dominant process in the rainfall-runoff system, like in the COIR and MHAR. However, it should be noted, that interception evaporation is always happening, albeit to varying degrees. Hence, incorporating the process will in many cases not significantly influence the modelled stream flow. However, as tested for COIR (not shown), omission of the process can introduce an important bias in our understanding of transport processes with direct implications for surface contamination with evaporative substances such as aqueous solutions of volatile compounds.

Clearly, the pattern of modeled water age distributions $p_{\mathrm{F}}$ shown here are sensitive to both, the chosen model structures and the mixing assumptions. However, the results highlight the need for a more careful characterization of the relevant flow paths in a catchment if the system as a whole wants to be understood. In spite of uncertainty in the modeling process, it can be argued that depending along which flow paths water is routed through the catchment, its age distribution $p_{\mathrm{F}}$ can exhibit distinct features, highlighting the importance of non-linearity in transport processes. Further it can be noted that the tail behavior of $p_{\mathrm{F}}$, a crucial characteristic for a better understanding of catchment scale soil and groundwater contamination dynamics (cf. Feng et al., 2004), is the result of the subtle but complex feedback between flow path connectivity and mixing processes, depending on the hydrological functioning of a given catchment.

\subsection{Resident water age distributions $p_{R}$}

The modelled resident water age distributions of different storage components are shown in Fig. 8 as temporally averaged, unweighted distributions for each of the pre-defined four catchment wetness conditions (see Sect. 3.7 and Fig. 5). Note that also here in Fig. 8 some $p_{\mathrm{R}}$ do not add up to unity as due to computational limitations only water younger than $5 \mathrm{yr}$ could be tracked. Thus, the missing difference to unity represents the proportion of stored water older than $5 \mathrm{yr}$. While in general $p_{\mathrm{R}}$ reflects the overall pattern of $p_{\mathrm{F}}$, the modeled proportion of younger water is reduced depending on the partial mixing coefficients. At COIR, the estimated age distribution $p_{\mathrm{R}, \text { Stot }}$ of all the water stored in the catchment (Fig. 8.1) is characterized by the same breakpoint at $\sim 200 \mathrm{~d}$ as $p_{\mathrm{F}}$ (Fig. 6.2), as this is a mere indication of the process variability in this catchment (see above). However, $p_{\mathrm{R}}$ is considerably shifted towards older water, with only $\sim 15 \%$ of the total water stored in the catchment being younger than $100 \mathrm{~d}$ and $\sim 70 \%$ older than $5 \mathrm{yr}$. This shift towards older water in the modeled $p_{\mathrm{R}}$ is almost entirely attributed to the substantial amounts of old water stored in and only slowly released from $S_{\mathrm{S}}$. The $p_{\mathrm{R}} \mathrm{S}$ of water stored in $S_{\mathrm{U}}$ and $S_{\mathrm{F}}$ (Fig. 8.2-3) are closely corresponding to the $p_{\mathrm{F}} \mathrm{S}$ of these storage components, since they are both subject to effectively complete mixing. In contrast, the high modeled proportions of water younger than $\sim 200 \mathrm{~d}$ present in $p_{\mathrm{F}, \mathrm{SS}}$ are not present in $p_{\mathrm{R}, \mathrm{SS}}$, where only $\sim 2 \%$ of water is younger than $100 \mathrm{~d}$ and $85 \%$ is older than $5 \mathrm{yr}$ (Fig. 8.4).

At BU11 the shift towards older water is even more significant (Fig. 8.5-8), as the amount of water stored in the passive storage $\mathbf{S}_{\mathrm{P}, \mathrm{SS}}$ outweighs the amount of modeled water stored elsewhere in the catchment. In addition, the limited estimated recharge to $S_{\mathrm{S}}\left(\mathbf{P}_{\max }, \mathbf{C}_{\mathrm{p}}\right.$; Table 3) further prevents faster turnover rates, resulting in $\sim 93 \%$ of the total water stored in the catchment being older than $5 \mathrm{yr}$ (Fig. 8.5). Similarly, $p_{\mathrm{R}, \text { Stot }}$ at MHAR (Fig. 8.9) suggests that $\sim 86 \%$ of the stored water is older than $5 \mathrm{yr}$. However, in spite of the large modeled passive storage $\mathbf{S}_{\mathrm{P}, \mathrm{SS}}$, relatively high recharge rates to $S_{\mathrm{S}}$ caused by the more freely draining soils $\left(\mathbf{P}_{\max }, \mathbf{C}_{\mathrm{p}}\right.$; Table 3), result in faster turnover of water in $S_{\mathrm{S}}$ than at BU11 (Fig. 8.12). The significant level of partial mixing in $S_{\mathrm{U}}$ at MHAR produces a particular feature in $p_{\mathrm{R}, \mathrm{SF}}$. Since partial mixing allows very young water to bypass $S_{\mathrm{U}}$ and reach $S_{\mathrm{F}}$ without further mixing and because $S_{\mathrm{F}}$ is conceptualized as completely mixed, modeled water stored in $S_{\mathrm{F}}$ preserves the high proportions of very young water leaving $S_{\mathrm{U}}$ (Fig. 8.11). Yet, due the small total volume of modeled water stored in $S_{\mathrm{F}}$ compared to the total amount of water in the system, the influence of these early peaks in $p_{\mathrm{R}, \mathrm{SF}}$ is negligible in $p_{\mathrm{R}, \mathrm{Stot}}$ (Fig. 8.9). 
(a) Strontian - Allt Coire Nan Con

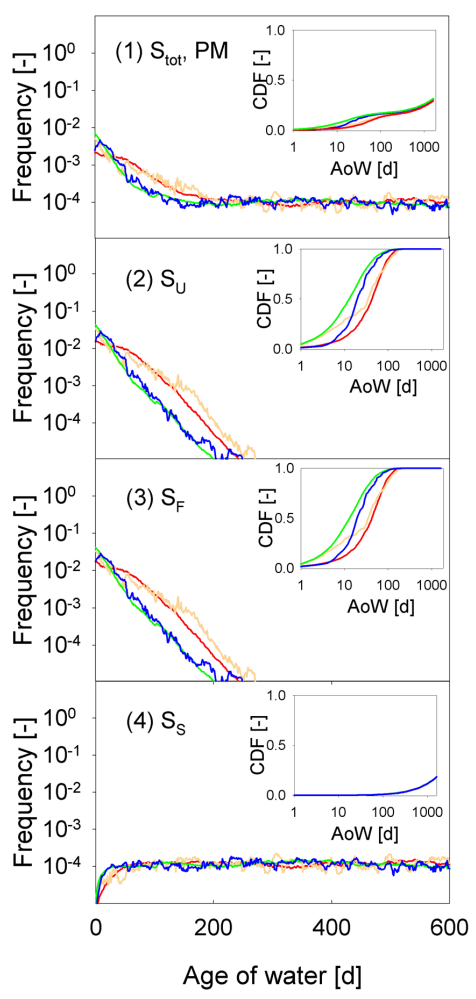

(b) Loch Ard - Burn 11

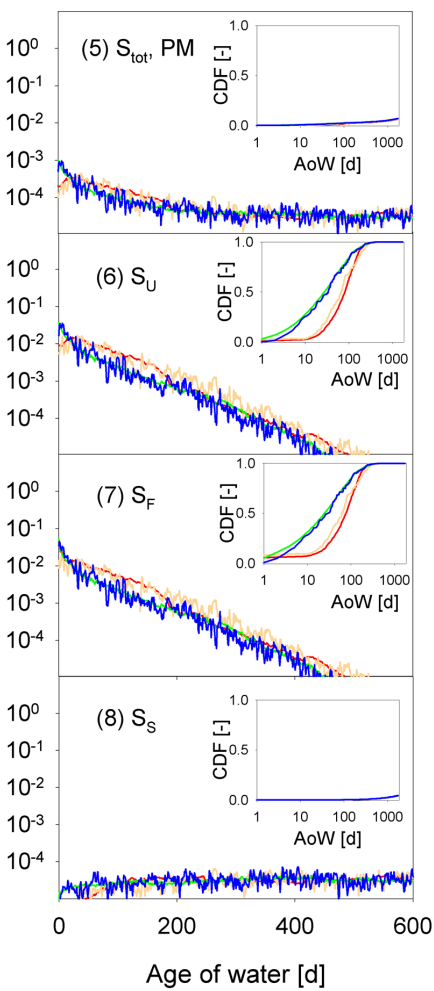

(c) Feshie - Allt a'Mharcaidh

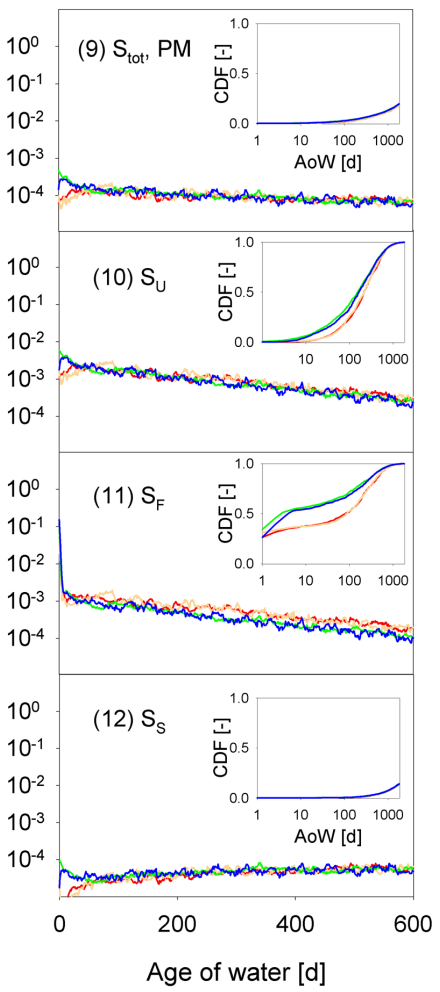

Fig. 8. Temporally averaged, unweighted resident water age distributions $p_{\mathrm{R}}$ for all the total catchment water storage $\left(S_{\text {tot }}\right)$ and the individual storage elements $S_{\mathrm{U}}, S_{\mathrm{F}}$ and $S_{\mathrm{S}}$ for the PM scenarios of the three study catchments for each of the four pre-defined hydrological regimes. The averages were constructed from the median water ages for all time steps within the respective hydrological regime. The color code of the lines is corresponding to the four hydrologic regimes defined in Fig. 5: red (dry), yellow (wetting-up), green (wet) and blue (drying-up).

Although influenced to a certain degree by the mixing assumption, the inferred resident water age distributions $p_{\mathrm{R}}$ were found to be mainly controlled by the estimated recharge to $S_{\mathrm{S}}$ and the water stored in $\mathbf{S}_{\mathrm{P}, \mathrm{SS}}$, consistent with what was reported by Dunn et al. (2007) and Heidbüchel et al. (2012). The importance of $\mathbf{S}_{\mathrm{P}, \mathrm{SS}}$ together with its frequently limited identifiability (e.g. Birkel et al., 2011a) make it the most important source of uncertainty for $p_{\mathrm{R}}$ as discussed in the Mixing models section. Notwithstanding these uncertainties, clear differences between $p_{\mathrm{F}}$ and $p_{\mathrm{R}}$ for catchments represented by multi-component models and/or partial mixing were apparent with the age of resident water being significantly higher than the age of water released from the catchment. In the potential presence of truly immobile or stagnant water (Zuber, 1986), i.e. very deep groundwater which is not affected by mixing processes, resident water is likely to be considerably older than the age modeled here using $\mathrm{Cl}^{-}$. Note, however, that the age of such deep, stagnant groundwater bodies can only be estimated by direct borehole sampling using tracers such as tritium or CFCs. The results strongly emphasize the persistence of water in catchments and their resulting long memory (cf. Kirchner et al., 2000). In other words and in contrast to the common understanding, water stored in a catchment can be considerably older than water released from a catchment, both of which are crucial aspects in attempts to better understand how catchments retain and release water (cf. Soulsby et al., 2009; McNamara et al., 2011). Furthermore, the results suggest that the longterm near-chemostatical behavior reported for a considerable range of catchments (e.g. Godsey et al., 2009; Basu et al., 2010) could at least partially be explained by the persistence of water, and thus tracer, stored especially in $\mathbf{S}_{\mathrm{P}, \mathrm{SS}}$ of a catchment. As can be seen in $p_{\mathrm{F}}$ (Fig. 6.5, 6.10 and 6.15) this water is then only released at extremely low rates over very long time periods (see also Sect. 4.7).

\subsection{Transit time distributions $p_{\mathrm{T}}$}

Precipitation entering a catchment is routed through the system along varying flow paths according to the transit time distribution $p_{\mathrm{T}}$ (Eq. 34) and it can leave the catchment over different exit routes such as runoff or evaporative fluxes. Note that in the following (Fig. 9), $p_{\mathrm{T}}$ does not refer to the actual conditional transit time distributions (i.e. they do not add up to unity) $p_{\mathrm{T}, Q}$ and $p_{\mathrm{T}, E}$ (Eq. 34 ) but to proxies, which formally are conditional finite measures (e.g. Bogachev, 2007) or, more casually, two parts of the joint distribution of $p_{\mathrm{T}, \text { tot }}$ 
(a) Strontian - Allt Coire Nan Con

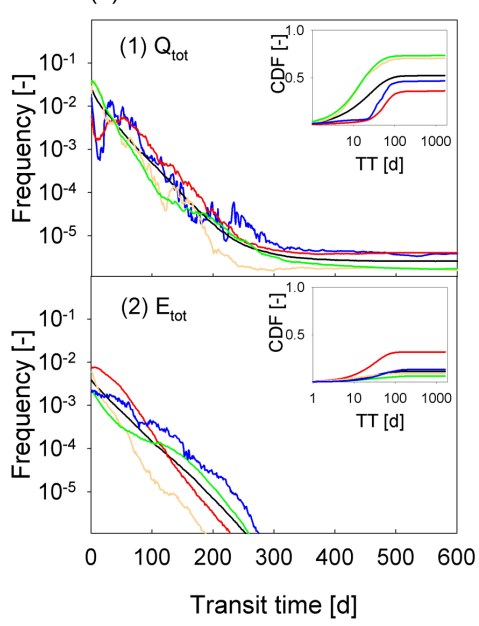

(b) Loch Ard - Burn 11

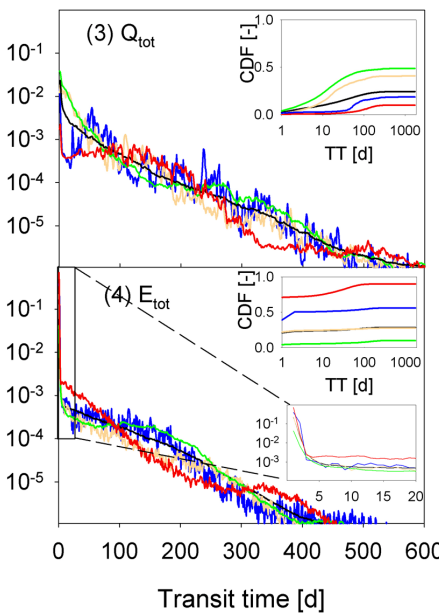

(c) Feshie - Allt a'Mharcaidh

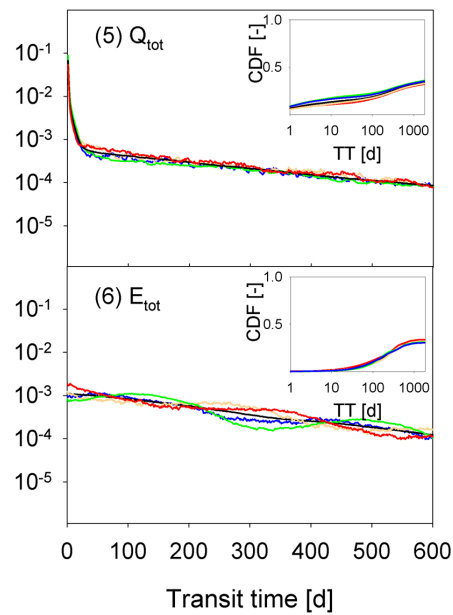

Fig. 9. Temporally averaged, unweighted proxies (i.e. conditional finite measures) for transit time distributions $p_{\mathrm{T}}$ for two exit routes (runoff and evaporative fluxes) along which incoming precipitation inputs are routed through the system for the three study catchments for each of the four pre-defined hydrological regimes according to the PM scenarios. The averages were constructed from the median water ages for all time steps within the respective hydrological regime. The color code of the lines is corresponding to the four hydrologic regimes defined in Fig. 5: red (dry), yellow (wetting-up), green (wet) and blue (drying-up).

resulting from $Q_{\text {tot }}$ and $E_{\text {tot }}$. This was necessary because no scaling factors for computing the actual conditional transit time distributions were available as, due to the computational tracking limit of $5 \mathrm{yr}$, most of the incoming precipitation signals did not completely leave the catchment after that time period. It was thus only possible to show which proportions of incoming signals left the catchment at which time and over which exit routes. These proxies are functionally the same as using actual distributions, with the only difference that they do not add up to unity. The distribution proxies shown in Fig. 9 are unweighted, temporal averages for each of the predefined four catchment wetness conditions (see Sect. 3.7 and Fig. 5).

The relative importance of runoff and evaporation can, depending on the hydrological function of a catchment, be highly sensitive to the wetness conditions before and after the moment a precipitation signal enters a catchment. At COIR, as shown in Fig. 9.1-2, on average only $\sim 65 \%$ of the precipitation entering during dry periods was estimated to have left the catchment after 5 yr. Thus, water entering the catchment at a given time during a dry period eventually exits the catchment to roughly equal proportions as runoff $(\sim 35 \%$; Fig. 9.1) and evaporative fluxes ( $\sim 30 \%$, Fig. 9.2). At early stages, i.e. $<\sim 50 \mathrm{~d}$, after entering evaporation is the dominant flux, while runoff becomes the dominant flux thereafter. Due to the low modeled water content in $S_{\mathrm{U}}$ during dry periods, considerable proportions of new precipitation are stored in $S_{\mathrm{U}}$ and mixed with the limited amounts of older resident water in the soil matrix, becoming available for $E_{\mathrm{SU}}$. Recent precipitation released from $S_{\mathrm{U}}$ to recharge $S_{\mathrm{S}}$ is only slowly discharged as $Q_{\mathrm{SS}}$ as a result of mixing with the relatively large volume of older water stored in $S_{\mathrm{S}}$. In dry periods, evaporation rates higher than runoff rates from $Q_{\mathrm{SS}}$ together with the lower amount of old water available for mixing in $S_{\mathrm{U}}$ therefore control the shapes of $p_{\mathrm{T}, Q_{\mathrm{tot}}}$ and $p_{\mathrm{T}, E_{\mathrm{tot}}}$, respectively. During wet periods, the pattern observed during dry periods is inverted. On average $\sim 76 \%$ of precipitation entering the catchment leaves the system within $5 \mathrm{yr}$. The $p_{\mathrm{T}}$ in wet periods is subject to a strong bias toward runoff which is responsible for routing $\sim 71 \%$ (Fig. 9.1) of the incoming precipitation signals through the system, as opposed to only $\sim 5 \%$ of the precipitation leaving as evaporative fluxes (Fig. 9.2). Responsible for this shift are the markedly increased relative importance of $Q_{\mathrm{SF}}$ and $Q_{\mathrm{OF}}$ over $E_{\mathrm{SU}}$ in wet periods together with increased PM induced bypass flow in $S_{U}$. While the general patterns of wetness induced dynamics in $p_{\mathrm{T}}$ are consistent across all three study catchments, the extent to which $p_{\mathrm{T}}$ changes with changing wetness depends on the hydrological functioning of the individual catchments. For example, at BU11 on average 95\% of precipitation entering the catchment during dry periods has left after $5 \mathrm{yr}$. Due to the conceptualized presence of interception evaporation, the model suggests that only minor proportions of precipitation actually reach $S_{\mathrm{U}}$ by overflow from $S_{\mathrm{I}}$. Most of the incoming precipitation $(\sim 75 \%)$ thus rapidly exits the system as $E_{\text {SI }}$ (Fig. 9.4). Significant amounts of new water actually reaching $S_{\mathrm{U}}$ are subsequently leaving as $E_{\mathrm{SU}}$, resulting in a modeled average total of $\sim 90 \%$ of incoming precipitation leaving as evaporative fluxes during dry conditions while only minor fractions of new precipitation are released as runoff $(\sim 5 \%)$ as discussed above (Fig. 9.3). In contrast, the little variations of $p \mathrm{~T}$ at MHAR are attributed to the less pronounced switches between the processes involved and the 
increased importance of $Q_{\text {SS }}$ as runoff generating flux across changing wetness conditions.

Changes in catchment wetness not only influence the relative importance of different exit routes but can also lead to changes in the shape of $p_{\mathrm{T}}$. The question which shapes $p_{\mathrm{T}}$ can take on is a matter of ongoing discussion (e.g. Kirchner et al., 2000; McGuire and McDonnell, 2006; Dunn et al., 2010). While some argue that $p_{\mathrm{T}}$ is generally characterized by sharp initial peaks (e.g. Kirchner et al., 2000; Godsey et al., 2010), Dunn et al. (2010), using a conceptual model could only reproduce delayed peaks in $p_{\mathrm{T}}$. Here it was found that $p_{\mathrm{T}}$ can potentially be characterized by both shape types (e.g. Fig. 9.1), which corresponds well with the findings of Hrachowitz et al. (2010b) who suggested that the changes of shape of $p_{\mathrm{T}}$ is partly controlled by changes in the wetness condition.

Analysis of the three study catchments also showed that there is a further important aspect of shape which is rarely reported. Water or other water-like, volatile substances affected by evaporation are routed to the stream differently than dissolved solids (e.g. $\mathrm{Cl}^{-}$) which are unaffected by evaporation. Only when no evaporation is occurring the following holds:

$p_{\mathrm{T}, \mathrm{W} \mid Q}=p_{\mathrm{T}, \mathrm{W}}=p_{\mathrm{T}, \mathrm{S}}$,

where $p_{\mathrm{T}, \mathrm{W} \mid Q}$ is the water transit time to runoff (i.e. the water transit time distribution conditional on runoff), $p_{\mathrm{T}, \mathrm{W}}$ is the transit time distribution of water and $p_{\mathrm{T}, \mathrm{S}}$ is the transit time distribution of a dissolved solid. In the presence of evaporative fluxes the three distributions cease to be equal. With increased evaporation the distribution of water routed to the stream, $p_{\mathrm{T}, \mathrm{W} \mid Q}$, is increasingly different from $p_{\mathrm{T}, \mathrm{S}}$, the distribution of solids routed to the stream. As a thought experiment consider the very simple example of an isolated precipitation input signal with a given solute concentration to a linear, initially empty, well-mixed reservoir. If no evaporation is present, the water in the reservoir is characterized by a constant solute concentration as the reservoir is draining, thus equally removing water and solute. However, if evaporation is present the solute concentration in the reservoir increases with each time step. In the most extreme case the solute concentration in the water becomes too high so as that no further dissolution is possible. If then all the water of the precipitation signal has left the reservoir either by runoff or by evaporation, a residue of formerly dissolved solids remains locked in the reservoir and can only be removed by being dissolved with future input water. This extreme hypothetical example clearly illustrates that the $p_{\mathrm{T}, \mathrm{S}}$ is different to $p_{\mathrm{T}, \mathrm{W} \mid Q}$ in the presence of evaporation. The effect is further illustrated by an example from BU11 in Fig. 10. It can be seen that the transit times of water to the stream are shorter than those of solutes, corresponding to the given hypothetical example. Clearly, the degree of difference between $p_{\mathrm{T}, \mathrm{S}}$ and $p_{\mathrm{T}, \mathrm{W} \mid Q}$ is related to the proportion of evaporation to runoff. For a low evaporation, high runoff period (e.g. persistent winter rain) the difference between the two distributions is comparatively

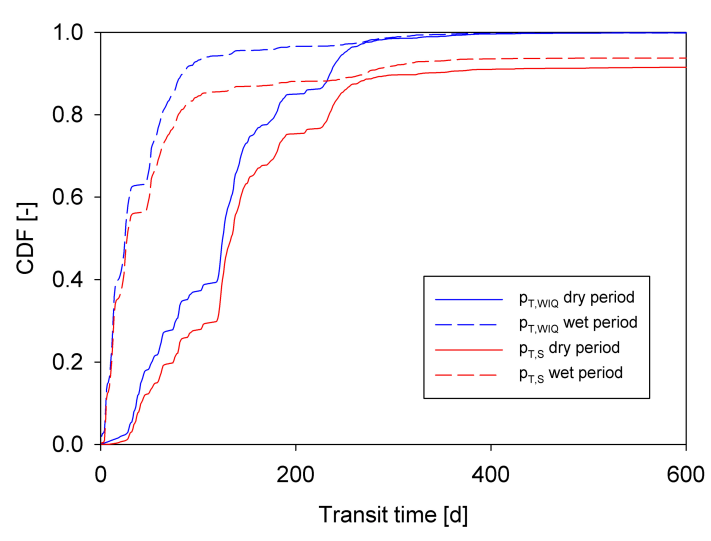

Fig. 10. Differences between the water transit time distribution to runoff $\left(p_{\mathrm{T}, \mathrm{W} \mid Q}\right)$ and the transit time distribution of a dissolved solid $\left(p_{\mathrm{T}, \mathrm{S}}\right)$ for signals entering during a dry period and a wet period, respectively.

small, whereas for a high evaporation, low discharge period (e.g. low yield summer precipitation) it is becoming more important. It can be argued that since these differences could already be distinguished in the cool and humid Scottish climate, the decoupling of $p_{\mathrm{T}, \mathrm{S}}$ and $p_{\mathrm{T}, \mathrm{W} \mid Q}$ is likely to be even more pronounced in warm, semi-arid regions. For meaningfully assessing contamination effects it is therefore crucial to consider which type of contaminant (volatile or solid) needs to be interpreted. Note that accounting for $\mathrm{Cl}^{-}$turnover by plants could potentially change the results to a certain extent, which however cannot be reliably quantified with the available data.

\subsection{Temporal dynamics and effects of wetness conditions on $p_{F}$}

To explore the effects of changing wetness conditions on modeled $p_{\mathrm{F}}$, the unweighted median $p_{\mathrm{F}}$ (i.e. temporally averaged) for the four contrasting analyzed hydrologic regimes (dry - wetting-up - wet - drying-up; cf. Fig. 5) over the entire modeling period are also shown in Fig. 6. For COIR the dry periods are characterized by an elevated proportion of modeled water older than $1000 \mathrm{~d}$ (Fig. 6.2), reflecting the importance of $Q_{\text {ss }}$ during these periods. As soon as the system is wetting up, runoff is almost exclusively composed of water younger than $100 \mathrm{~d}$, indicating a rapid switch towards $Q_{\mathrm{SF}}$ and $Q_{\mathrm{OF}}$ and rendering the $Q_{\mathrm{SS}}$ contributions negligible. Under drying-up conditions, when the contributions of $Q_{\mathrm{SF}}$ and $Q_{\mathrm{OF}}$ are reduced, the importance of old water gradually increases again. While $p_{\mathrm{F}, Q_{\mathrm{SS}}}$ is relatively insensitive to changes in the hydrologic regime (Fig. 6.5), the modeled age distributions in $Q_{\mathrm{SF}}$ (Fig. 6.4) and $E_{\mathrm{SU}}$ (Fig. 7.1) show some variation due to the lower precipitation rates and consequently the reduced availability of very young water in the system during dry periods. Very similar patterns were observed for the remaining two catchments (Fig. 6.6-15), with 


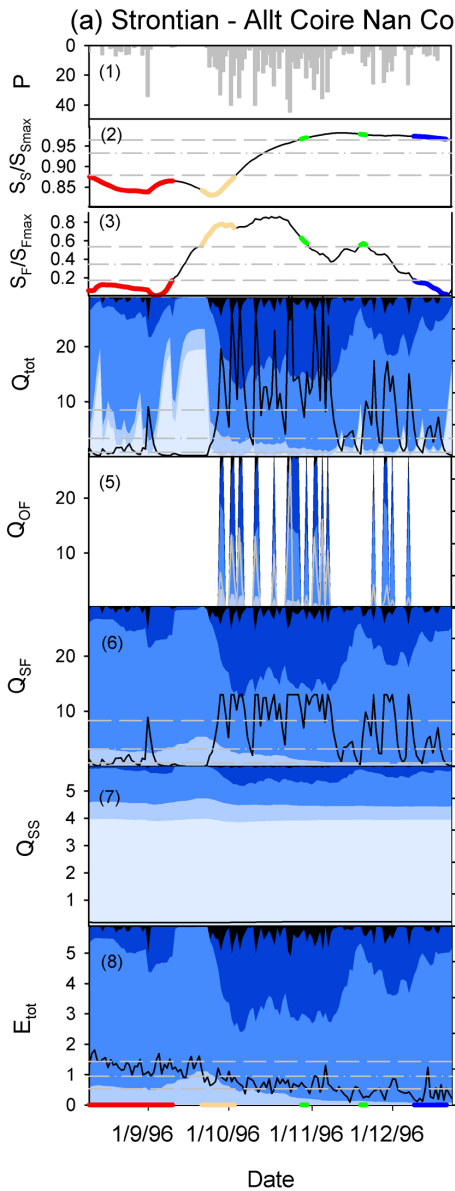

(b) Loch Ard - Burn 11

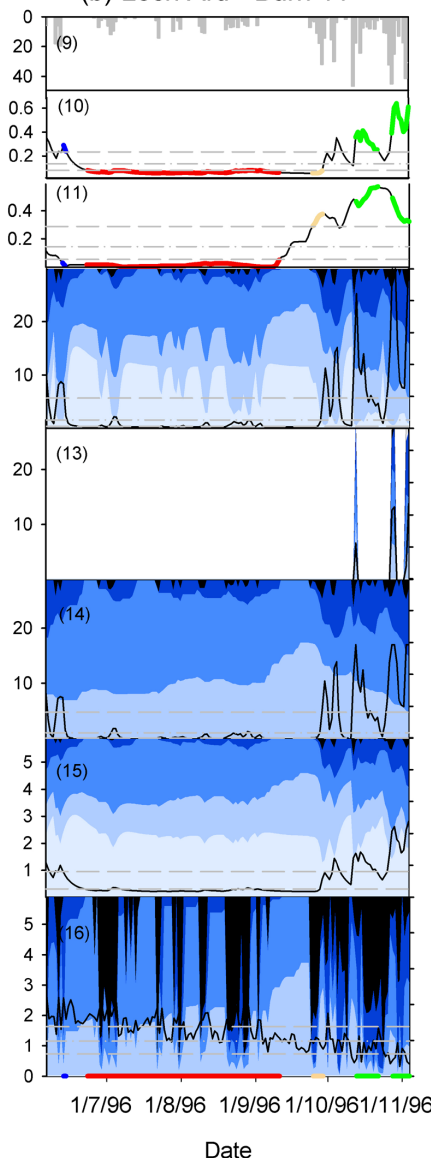

(c) Feshie - Allt a'Mharcaidh

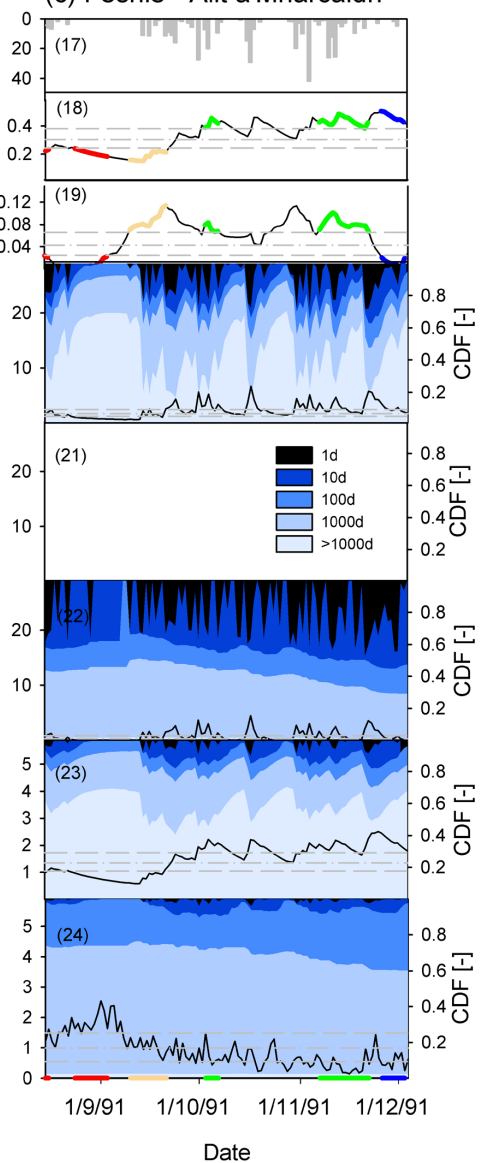

Fig. 11. Flux water age distributions $p_{\mathrm{F}}$ from the PM scenarios and following a full sequence of hydrologic regimes: dry (red) - wetting-up (yellow) - wet (green) - drying-up (blue) for the three study catchments. The first row shows the daily precipitation, the second and the third rows show the normalized states of $S_{\mathrm{S}}$ and $S_{\mathrm{F}}$ used to define the hydrologic regimes (see Fig. 5). Rows 4 to 8 show the absolute flux of the respective component (black line), the long-term means and respective standard deviations of the individual fluxes and the color shades from dark to light indicate the cumulative proportions of water younger than $1 \mathrm{~d}, 10,100,1000 \mathrm{~d}$ and older than $1000 \mathrm{~d}$ contributing to the individual fluxes at each time step.

the only major difference being that the influence of partial mixing is more evident in $Q_{\mathrm{SF}}$. While during dry periods a high degree of mixing locks a relatively high proportion of young water in $S_{\mathrm{U}}$, young water increasingly bypasses $S_{\mathrm{U}}$ to generate $Q_{\mathrm{SF}}$ under wet conditions in the models (Fig. 6.9 and 6.14). Note, that the general shapes and the wetness induced dynamics of the modeled $p_{\mathrm{F}, Q_{\mathrm{tot}}}$ at BU11 (Fig. 6.7) are corresponding well to what was reported by McMillan et al. (2012) for an adjacent catchment with similar characteristics using a suite of conceptual models from the FUSE modeling framework (Clark et al., 2008). In addition, the general pattern of inferred shifts towards younger water ages with increased wetness due to increased flow path connectivity is consistent with previous findings from both empirical and theoretical studies (e.g. McGuire et al., 2007; Botter et al., 2010; Hrachowitz et al., 2010b; Roa-Garcia and Weiler, 2010; Rinaldo et al., 2011; Birkel et al., 2012a; Segura et al., 2012).
To further illustrate the temporal dynamics of this relatively complex interplay between dry and wet periods an example period with a full sequence of hydrological regimes following the complete dry - wetting up - wet - drying up cycle with a total length of $\sim 4$ months each is shown in Fig. 11 for each of the three study catchments. For all three catchments substantial and rapid changes in the age composition of stream water can be observed. In general, old water ( $>100 \mathrm{~d}$ ) dominates stream flow particularly towards the end of dry periods, while significant contributions of very young water $(<10 \mathrm{~d})$ characterize wet periods, albeit to different extent in the individual catchments. Corresponding with the median $p_{\mathrm{F}}$ in Fig. 6.2, at COIR around $60 \%$ of the runoff is older than $1000 \mathrm{~d}$ as soon as contributions from $S_{\mathrm{F}}$ become negligible and runoff generated in $S_{\mathrm{S}}$ is the primary source of stream flow towards the end of the dry period around 15 September 1996 (Fig. 11.4). As soon as the catchment is starting to wet up after that date, a very fast switch towards 
high contributions of water younger than $10 \mathrm{~d}$ occurred in the model. As a consequence of the low contribution of $Q_{\mathrm{SS}}$ (Fig. 11.7) to $Q_{\text {tot }}$ under wet conditions the fraction of water older than $1000 \mathrm{~d}$ is rapidly reduced to below $1 \%$ which is also reflected in Fig. 6.2. With the wetting up of the system the proportion of water inferred to be older than $100 \mathrm{~d}$ gradually decreases until the drying-up period with the simultaneous increase of water younger than $100 \mathrm{~d}$. In addition, as soon as preferential flow paths in the model $\left(Q_{\mathrm{SF}}\right.$; Fig. 11.6) are connected to the stream under wetting-up conditions some water not older than $1 \mathrm{~d}$ can enter the stream, enhanced by intermittent overland flow $\left(Q_{\mathrm{OF}}\right)$ connected to the stream during high-intensity events. In contrast, the $p_{\mathrm{F}}$ of runoff peaks occurring during dry (e.g. 1 September) and dryingup (e.g. 18 December) periods show different characteristics. While the contribution of old water is reduced to a similar degree as during the wet period, the proportion of water younger than $10 \mathrm{~d}$ is approximately only half of that during the wet period which is mainly related to the limited amount of recent antecedent precipitation as well as to $Q_{\mathrm{OF}}$ being inactive at that time. Water in $Q_{\mathrm{SS}}$, on the other hand, exhibits only little variation throughout the sequence of changing hydrologic regimes (Fig. 11.7). Drawing water from the same pool as $Q_{\mathrm{SF}}$ and due to $C_{\mathrm{M}, \mathrm{SU}} \sim 1$, the dynamics in the modeled age distribution of $E_{\mathrm{SU}}$ (Fig. 11.8) closely reflect those in $Q_{\mathrm{SF}}$. Although the general pattern observed in the modeled response at COIR apply also for BU11 and MHAR (Fig. 11.9-24), the latter two catchments are also characterized by distinctly different details. For example, the inclusion of an interception component in the model of BU11 allows considerable fractions of water not older than $1 \mathrm{~d}$ to leave the catchment by interception evaporation (Fig. 11.16), reducing the modeled contributions of such young water to runoff by $Q_{\text {SF. This effect is especially pronounced during dry summer }}$ periods when potential evaporation is highest. On the other hand and somewhat counter-intuitively the MHAR with its damped stream flow and tracer response patterns is characterized by high proportions of very young water in all modeled flow components, while maintaining equally important proportions of very old water (Fig. 11.20). This results from partial mixing in $S_{\mathrm{U}}$, where even under dry conditions $\sim 20 \%$ of incoming water bypass $S_{\mathrm{U}}$ and reach $S_{\mathrm{F}}$ and $S_{\mathrm{S}}$ via preferential flow paths. Another feature in this catchment is that during dry periods the proportion of water older than $1000 \mathrm{~d}$ is similar to the one at COIR but although under wettingup conditions the switches towards higher proportions of younger water occur as fast, they are far less pronounced at MHAR. This is caused by the generally lower estimated contributions of $Q_{\mathrm{SF}}$ to $Q_{\mathrm{tot}}$ as well as by the higher proportion of old water in $S_{\mathrm{U}}$ due to lower precipitation rates which together with a high estimated storage capacity $\mathbf{S}_{\mathrm{U}_{\max }}$ result in reduced turnover rates.

To better understand the wetness induced dynamics $p_{\mathrm{F}}$, represented by the median of the 25 th percentiles of all $p_{\mathrm{F}, Q_{\text {tot }}}$ (i.e. $\left.\mathrm{TT}_{25}\right)$ during the distinct hydrological regimes, was plotted against the normalized $S_{\mathrm{F}}$ and $S_{\mathrm{S}}$ to investigate how $\mathrm{TT}_{25}$ evolves along sequences of dry - wetting-up - wet - drying up periods (Fig. 12). Note that $\mathrm{TT}_{25}$ was used as for computational reasons water was only tracked for $5 \mathrm{yr}$, making a meaningful characterization of $\mathrm{TT}_{50}$ or MTT impossible for dry periods at MHAR. $\mathrm{TT}_{25}$ in all three catchments was found to be characterized by considerable hysteresis effects. During dry periods $\mathrm{TT}_{25 \text {,dry }}$ shows the highest value, followed by a relatively rapid decline to $\mathrm{TT}_{25 \text {,wet-up }}$. This is caused by a relatively rapid modeled replacement of old water in $S_{\mathrm{U}}$ (Fig. 8) and increasing proportions of flows bypassing $S_{\mathrm{U}}$ due to $C_{\mathrm{M}, \mathrm{SU}}$. As a consequence $S_{\mathrm{F}}$ fills up with young water which results not only in increased flow contributions from $Q_{\mathrm{SF}}$ and $Q_{\mathrm{OF}}$ to $Q_{\text {tot }}$ but also higher proportions of young water in these contributions. Once significant and persistent recharge of $S_{\mathrm{S}}$ with young water is established, the lowest value, $\mathrm{TT}_{25 \text {, wet }}$, is eventually reached in the wet season, when both, fast and slow runoff processes are active. As soon as precipitation decreases in the drying-up period, the contributions from $Q_{\mathrm{SF}}$ and $Q_{\mathrm{OF}}$ also decrease. $Q_{\mathrm{SS}}$, and thus older water, becomes more important, resulting in moderately increased $\mathrm{TT}_{25}$,drying-up. However, the still high soil moisture content in $S_{\mathrm{U}}$ and the comparatively young age of this water can quickly trigger relatively high contributions of young water in the case of moderate to high precipitation, either by mixing and release or direct bypass flow to $S_{\mathrm{F}}$. Only after prolonged dry periods, when only little water is routed to $S_{\mathrm{F}}$ and most either remains locked in $S_{\mathrm{U}}$ or percolates to $S_{\mathrm{S}}, \mathrm{TT}_{25}$ recovers to $\mathrm{TT}_{25 \text {,dry }}$. On the rising limb, i.e. under wetting-up conditions, $\mathrm{TT}_{25}$ is thus dominated by fast processes (e.g. preferential flow) while on the falling limb it is controlled by slow processes (e.g. groundwater flow). This hysteresis underpins the importance of the interplay between dominant flow processes, mixing processes and age distributions of water. It further supports the hypotheses that short-term changes in stream water chemistry are partly the result of changing contributions from different components of the system according to the wetness state of the system (Kirchner, 2003). To adequately assess the system response it is therefore not only necessary to know how much water is stored in the system, i.e. antecedent wetness, but also where in the system the water is retained (e.g. unsaturated zone vs. groundwater) as this defines which flow process will be active as recently also stressed by Aubert et al. (2013) and McGlynn et al. (2012). While many studies report similar hysteresis effects, e.g. in concentration-discharge (Weiler and McDonnell, 2006; Gascuel-Odoux et al., 2010; Murphy et al., 2012) or concentration-location relationships (e.g. Rouxel et al., 2011), the mechanisms behind them are still poorly understood. The same is true for the dynamic interaction between flow generating processes. The pattern of flow process connectivity is largely dependent on the topological structure of a catchment (cf. Zehe and Sivapalan, 2009). However, very fast switches are reported for a wide range of catchments 
(a) Strontian - Allt Coire nan Con

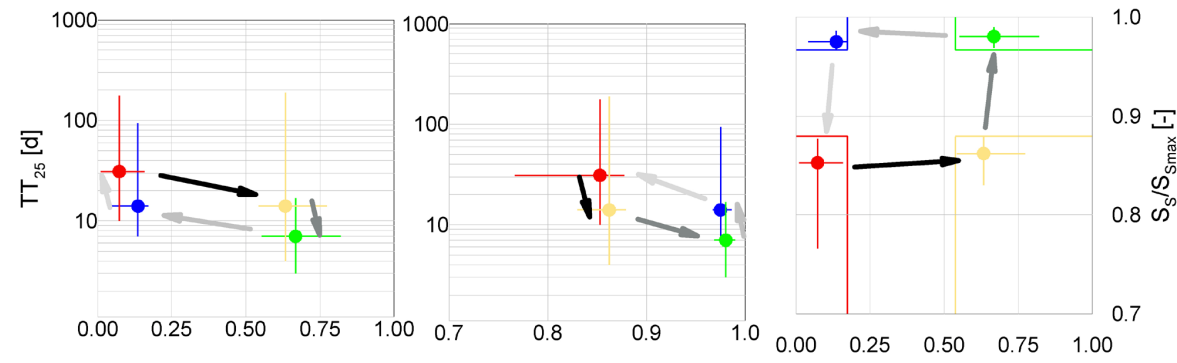

(b) Loch Ard - Burn 11
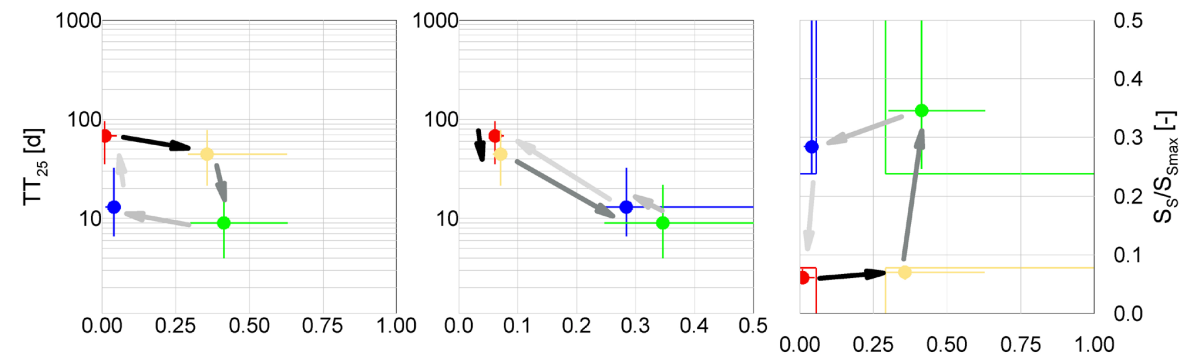

(c) Feshie - Allt a'Mharcaidh
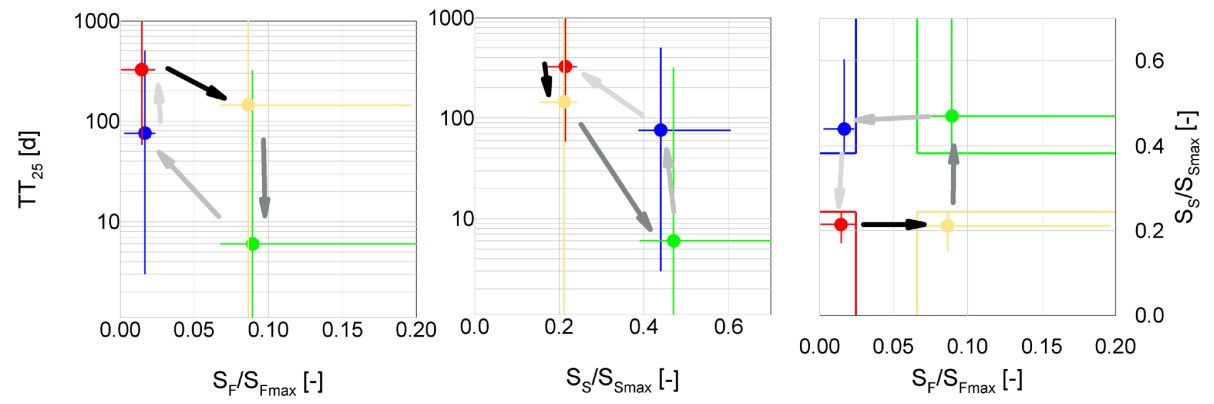

Fig. 12. Evolution of water age, here represented by the median of the 25 th percentiles $\left(\mathrm{TT}_{25}\right.$, colored dots) of all $p_{\mathrm{F}, \mathrm{Q} t o t}$ during the four distinct hydrological regimes as represented by normalized $S_{\mathrm{S}}$ and $S_{\mathrm{F}}$ (see Fig. 5). The whiskers represent the 5th and 95th percentiles of all time steps within a given hydrologic regime. The arrows indicate the direction of the hysteresis. Note, that the rather noisy actual evolution paths between the median $\mathrm{TT}_{25}$ were omitted for clarity.

and interpreted either as thresholds of intermittent processes (e.g. Detty and McGuire, 2010; Penna et al., 2011) or results of continuous processes (e.g. Weiler and McDonnell, 2007; Hrachowitz et al., 2011b). From the modeled results it can be suggested that these rapid switches do not only entail fast changes in runoff sources but also fast switches in the age composition of runoff under wetting-up, wet and drying-up conditions since they tap water from different pools, characterized by distinct age distributions.

\subsection{Long tails of $p_{\mathrm{F}}$ and $p_{\mathrm{T}}$}

Previous work suggested that the gamma distribution, characterized by tails longer than those from exponential distributions for shape parameter $\alpha<1$, may be a suitable TTD for surface water systems. However, attempts to parameterize $p_{\mathrm{T} \mid Q}$ as well as $p_{\mathrm{F}}$ for the three study catchments using gamma distributions were not successful.
Based on Monte-Carlo sampling ( $10^{6}$ realizations) with samples drawn from uniformly distributed prior parameter distributions $(0<\alpha \leq 2,0<\beta \leq 100000)$, two-sample Kolmogorov-Smirnov tests suggested that all tested gamma distribution parameterizations had to be rejected at the $95 \%$ confidence level. Although gamma distributions could fit the early parts $(<100 \mathrm{~d})$ of $p_{\mathrm{T} \mid Q}$ and $p_{\mathrm{F}}$ well, the modeled tails of all $p_{\mathrm{T} \mid Q}$ and $p_{\mathrm{F}}$ were too long and could thus not be represented by gamma distributions (not shown). There was rather evidence that $p_{\mathrm{T} \mid Q}$ and $p_{\mathrm{F}}$ could potentially be more adequately represented by a power law distribution, the generalized Pareto distribution, as parameterizations could not be rejected at the $95 \%$ confidence level, implying long tails in the formal sense (Asmussen, 2003). The question arising is thus what is the origin of these longer-than-exponential or possibly long tails in the sense of power law tails. While some argued (Kirchner et al., 2000, 2001; Godsey et al., 2010) that the tails of TTDs are manifestations of fractal $1 / f$ scaling 
which can be explained by catchment-scale advection and dispersion processes, others pointed out the possibility that the shapes of TTDs in general and their tails in particular can be a reflection of the process heterogeneity and flow path connectivity and thus casting some doubt on the generality of strict 1/f scaling (Shaw et al., 2008; Hrachowitz et al., 2010b). Similarly, Birkel et al. (2012b) reasoned that the behavior of tails, in the tracer response is an expression of the process complexity of a given catchment. Here, analyzing the long tails in $p_{\mathrm{F}}$ (Fig. 6) and $p_{\mathrm{T}}$ (Fig. 9) with respect to the modeled processes it is suggested that long tails are the result of the combined influences of the relative importance of different flow generating processes and their connectivity, as well as of the mixing processes in the individual system components, as shown above (Sext. 4.3). The discussion if advection-dispersion (Kirchner et al., 2001) or rather process heterogeneity and flow path connectivity are at the core of long tails in water age distributions is similar to the debates over whether spatial heterogeneity or non-linearity of the flow generating processes themselves lead to long tails in the flow response (Harman et al., 2009; Szilagyi, 2009). It is thus likely that the combined effects of both mechansisms generate the observed long tails.

In any case, the occurrence of long tails, corresponding to a long memory of the system, has important implications. Depending on the reactivity of a contaminant, not only high short-term contamination loads could potentially be expected in the stream. Rather, the contaminant will also remain in the system and cause continuous low level contamination of the stream for long time periods (e.g. Molenat and GascuelOdoux, 2002; Ruiz et al., 2002a). Therefore, the long tails of $p_{\mathrm{T} \mid Q}$ and $p_{\mathrm{F}}$ suggest that the near-chemostatical behavior observed in a considerable range of catchments (e.g. Godsey et al., 2009; Basu et al., 2010) can at least to some extent be explained by water/tracer storage dynamics as discussed in Sect. 4.4.

We explicitly acknowledge potentially significant influences of different sources of uncertainty when using a model as diagnostic tool, including but not limited to the choice of model structure, the parameterization as well as the mixing assumptions. Although these uncertainties can affect a wide range of details in the analysis (cf. Hrachowitz et al., 2011a; McMillan et al., 2012), the results of the functional analysis presented, such as the general influence patterns of wetness on $p_{\mathrm{F}}$ and $p_{\mathrm{T}}$, remain largely unaffected.

\section{Conclusions}

In this study we used conceptual models to simulate the integrated stream flow and tracer responses of three contrasting, upland catchments in Scotland. Using the models as diagnostic tools in a functional comparison, the water and tracer fluxes were tracked so as to analyze the model internal response patterns. The main findings of the analysis were as follows:

1. Partial mixing models were found to perform consistently better than models based on complete mixing, albeit to a varying degree, tightly linked to the importance of the unsaturated zone in a given catchment. However, the superiority of partial mixing needs to be further tested in the future potentially with the help of more data, such as other tracers (e.g. tritium) or estimates of catchment integrated soil moisture and groundwater storage changes, to more effectively constrain mixing parameters.

2. Tracking fluxes through the system showed that the various components of a model, representing individual flow processes, can be characterized by fundamentally different water age distributions. As a consequence, the wetness dependent connectivity patterns of these distinct pools of water are responsible for potentially fast switches in both, the total flux and transit time distributions, $p_{\mathrm{F}}$ and $p_{\mathrm{T}}$.

3. For the three study catchments modeled flux water age is significantly lower than the age of resident water.

4. Modeled resident water age distributions $p_{\mathrm{R}}$ exhibited only limited sensitivity to antecedent wetness compared to $p_{\mathrm{F}}$ as the modeled passive groundwater storage $\mathbf{S}_{\mathrm{P}, \mathrm{SS}}$ was substantially larger than event water amounts, allowing for a considerable buffer capacity, potentially explaining frequently observed long-term near-chemostatic behavior of catchments.

5. Modeled flux water age distributions $p_{\mathrm{F}}$ were found to be highly sensitive to variable catchment wetness conditions and exhibited considerable hysteresis effects, depending on the catchment wetness history. While the water age during wetting-up conditions is controlled by fast processes (e.g. preferential flow), it is controlled by slow processes (e.g. groundwater flow) under dryingup conditions. This non-linearity is caused by the fact that $p_{\mathrm{F}}$ is not only influenced by the total water volume stored in a catchment but also by how the water is distributed among the various components of the system such as the unsaturated zone or the groundwater, at a given time.

6. Tracking fluxes through the system also revealed that, although potentially negligible for the runoff response, the omission of processes such as interception evaporation can result in considerably biased water age distributions. This can be problematic not only for our understanding of the system but also for water management related issues such as assessment of contamination.

7. Depending on the importance of evaporation, water molecules can exhibit considerably shorter transit times 
Appendix A

Table A1. List of symbols.

\begin{tabular}{|c|c|c|c|}
\hline$c$ & Tracer concentration $\left[\mathrm{ML}^{-1}\right]$ & $Q_{\mathrm{OF}}$ & Overland flow $\left[\mathrm{L} \mathrm{T}^{-1}\right]$ \\
\hline $\mathbf{C}_{\mathrm{M}}$ & Mixing coefficient $[-]$ & $Q_{\mathrm{SS}}$ & Runoff from slow reservoir $\left[\mathrm{L} \mathrm{T}^{-1}\right]$ \\
\hline $\mathbf{C}_{\mathrm{P}}$ & Preferential recharge coefficient $[-]$ & $R_{\mathrm{F}}$ & Recharge of fast reservoir $\left[\mathrm{LT}^{-1}\right]$ \\
\hline$C_{\mathrm{R}}$ & Runoff generation coefficient $[-]$ & $R_{\mathrm{P}}$ & Preferential recharge of slow reservoir $\left[\mathrm{L} \mathrm{T}^{-1}\right]$ \\
\hline$E_{\mathrm{SF}}$ & Transpiration from fast responding reservoir $\left[\mathrm{L} \mathrm{T}^{-1}\right]$ & $R_{\mathrm{S}}$ & Recharge of slow reservoir $\left[\mathrm{L} \mathrm{T}^{-1}\right]$ \\
\hline$E_{\mathrm{SI}}$ & Evaporation from interception reservoir $\left[\mathrm{L} \mathrm{T}^{-1}\right]$ & $R_{\mathrm{U}}$ & Infiltration into unsaturated reservoir $\left[\mathrm{L} \mathrm{T}^{-1}\right]$ \\
\hline$E_{\mathrm{SU}}$ & Transpiration from unsaturated reservoir $\left[\mathrm{L} \mathrm{T}^{-1}\right]$ & $S_{\mathrm{a}}$ & Active storage $[\mathrm{L}]$ \\
\hline $\mathbf{K}_{\mathrm{F}}$ & Storage coefficient of fast reservoir $\left[\mathrm{T}^{-1}\right]$ & $S_{\mathrm{F}}$ & Storage in fast reservoir [L] \\
\hline $\mathbf{K}_{\mathrm{S}}$ & Storage coefficient of slow reservoir $\left[\mathrm{T}^{-1}\right]$ & $\mathbf{S}_{\mathrm{F}_{\max }}$ & Storage capacity of fast reservoir [L] \\
\hline $\mathbf{L}_{\mathrm{P}}$ & Transpiration threshold $[-]$ & $S_{\mathrm{I}}$ & Storage in interception reservoir [L] \\
\hline $\mathbf{F}_{M}$ & Melt factor $\left[\mathrm{L} \Theta^{-1} \mathrm{~T}^{-1}\right]$ & $S_{\mathrm{p}}$ & Passive storage $[\mathrm{L}]$ \\
\hline $\mathbf{I}_{\max }$ & Interception capacity [L] & $\mathbf{S}_{\mathrm{P}, \mathrm{SS}}$ & Passive storage in slow reservoir [L] \\
\hline$M$ & Snow melt $\left[\mathrm{L} \mathrm{T}^{-1}\right]$ & $S_{\mathrm{S}}$ & Storage in slow reservoir $[\mathrm{L}]$ \\
\hline$P$ & Total precipitation $\left[\mathrm{L} \mathrm{T}^{-1}\right]$ & $S_{\mathrm{SN}}$ & Storage in snow reservoir [L] \\
\hline$P_{\mathrm{E}}$ & Effective precipitation $\left[\mathrm{L} \mathrm{T}^{-1}\right]$ & $S_{U}$ & Storage in unsaturated reservoir [L] \\
\hline$p_{\mathrm{F}}$ & Flux water age distribution & $\mathbf{S}_{\mathrm{U}_{\max }}$ & Storage capacity in unsaturated reservoir [L] \\
\hline $\mathbf{P}_{\max }$ & Percolation capacity $\left[\mathrm{L} \mathrm{T}^{-1}\right]$ & $\mathbf{T}_{\mathrm{F}}$ & Lag time for fast reservoir $[\mathrm{T}]$ \\
\hline$p_{\mathrm{R}}$ & Resident water age distribution & $\mathbf{T}_{\mathrm{S}}$ & Lag time for slow reservoir $[\mathrm{T}]$ \\
\hline$P_{\mathrm{R}}$ & Rainfall $\left[\mathrm{L} \mathrm{T}^{-1}\right]$ & $\mathbf{T}_{\mathrm{T}}$ & Threshold temperature $[\Theta]$ \\
\hline$P_{\mathrm{SN}}$ & Snowfall $\left[\mathrm{L} \mathrm{T}^{-1}\right]$ & $\beta$ & Shape parameter $[-]$ \\
\hline$p_{\mathrm{T}}$ & Transit time distribution & $\mu_{\mathrm{CM}}$ & Location parameter $[-]$ \\
\hline$P_{\mathrm{TF}}$ & Throughfall $\left[\mathrm{L} \mathrm{T}^{-1}\right]$ & $\sigma_{\mathrm{CM}}$ & Shape parameter $[-]$ \\
\hline$Q_{\mathrm{SF}}$ & Runoff from fast reservoir $\left[\mathrm{L} \mathrm{T}^{-1}\right]$ & & \\
\hline
\end{tabular}

to the stream than dissolved solids, e.g. tracers such as $\mathrm{Cl}^{-}$.

8. It was not possible to reject the hypothesis that the water age distributions $p_{\mathrm{F}}$ and $p_{\mathrm{T}}$ in the three study catchments have power-law tails which are generated by interplay of flow path connectivity, the relative importance of different flow paths as well as by the mixing mechanisms.

9. The high age of resident water together with the long tails in $p_{\mathrm{F}}$ and $p_{\mathrm{T}}$ suggest that the frequently observed near-chemostatic conditions in catchments could in part result from persistence of water in the passive groundwater storage $\left(S_{\mathrm{P}, \mathrm{SS}}\right)$.

In spite of the need for more detailed experimental analysis of catchment internal processes which will allow more rigorous hypothesis testing, this study highlights the potential of customized integrated conceptual models and suitable mixing assumptions, to increase our functional understanding of system internal transport dynamics and their sensitivity to catchment wetness states.
Acknowledgements. The effort of many workers at the Marine Science Scotland-Freshwater Laboratory who collected and analysed the samples in the data collected here is gratefully acknowledged. In particular, Iain Malcolm is thanked for assistance in accessing these data.

Edited by: S. Attinger

\section{References}

Akaike, H.: Statistical predictor identification, Ann. Inst. Stat. Math., 22, 203-217, 1970.

Ali, G., Tetzlaff, D., Soulsby, C., McDonnell, J. J., and Capell, R.: A comparison of similarity indices for catchment classification using a cross-regional dataset, Adv. Water Resour., 40, 11-22, 2012.

Anderson, A. E., Weiler, M., Alila, Y., and Hudson, R. O.: Dye staining and excavation of a lateral preferential flow network, Hydrol. Earth Syst. Sci., 13, 935-944, doi:10.5194/hess-13-9352009, 2009a.

Anderson, A. E., Weiler, M., Alila, Y., and Hudson, R. O.: Subsurface flow velocities in a hillslope with lateral preferential flow, Water Resour. Res., 45, W11407, doi:10.1029/2008WR007121, $2009 b$.

Arheimer, B., Dahne, J., Donnelly, C., Lindström, G., and Strömqvist, J.: Water and nutrient simulations using the HYPE model for Sweden vs. the Baltic Sea basin - influence of input data quality and scale, Hydrol. Res., 43, 315-329, 2012. 
Asano, Y. and Uchida, T.: Flow path depth is the main controller of mean base flow transit times in a mountainous catchment, Water Resour. Res., 48, W03512, doi:10.1029/2011WR010906, 2012.

Asmussen, S.: Applied probability and queues, 2nd Edn., Springer, New York, 2003.

Aubert, A. H., Gascuel-Odoux, C., and Merot, P.: Annual hysteresis of water quality: a method to analyse the effect of intraand interannual climatic conditions, J. Hydrol., 478, 29-39, doi:10.1016/j.jhydrol.2012.11.027, 2013.

Barnes, C. J. and Bonell, M.: Application of unit hydrograph techniques to solute transport in catchments, Hydrol. Process., 10, 793-802, 1996.

Bastviken, D., Thomsen, F., Svensson, T., Karlsson, S., Sanden, P., Shaw, G., Matucha, M., and Öberg, G.: Chloride retention in forest soil by microbial uptake and by natural chlorination of organic matter, Geochim. Cosmochim. Acta, 71, 3182-3192, 2007.

Basu, N. B., Destouni, G., Jawitz, J. W., Thompson, S. E., Loukinova, N. V., Darracq, A., Zanardo, S., Yaeger, M., Sivapalan, M., Rinaldo, A., and Rao, P. S. C.: Nutrient loads exported from managed catchments reveal emergent biogeochemical stationarity, Geophys. Res. Lett., 37, L23404, doi:10.1029/2010GL045168, 2010.

Berne, A., Uijlenhoet, R., and Troch, P. A.: Similarity analysis of subsurface flow response of hillslopes with complex geometry, Water Resour. Res., 41, W09410, doi:10.1029/2004WR003629, 2005.

Bertuzzo, E., Thomet, M., Botter, G., and Rinaldo, A.: Catchmentscale herbicides transport: theory and application, Adv. Water Res., 52, 232-242, doi:10.1016/j.advwatres.2012.11.007, 2013.

Beven, K. J.: Kinematic subsurface stormflow, Water Resour. Res., 17, 1419-1424, 1981.

Beven, K. J.: Preferential flows and travel time distributions: defining adequate hypothesis tests for hydrological process models, Hydrol. Process., 24, 1537-1547, 2010.

Beven, K. J. and Germann, P. Macropores and water flow in soils, Water Resour. Res., 18, 1311-1325, 1982.

Beven, K. J. and Westerberg, I.: On red herrings and real herrings: disinformation and information in hydrological inference, Hydrol. Process., 25, 1676-1680, 2011.

Beven, K. J., Hornberger, G. M., and Germann, P. F., Hillslope hydrology, a multiple interacting pathways model, in: Proceedings of the British Hydrological Society Second National Hydrology Symposium, Wallingford, UK, 1-8, 1989.

Birkel, C., Tetzlaff, D., Dunn, S. M., and Soulsby, C.: Using lumped conceptual rainfall-runoff models to simulate daily isotope variability with fractionation in a nested mesoscale catchment, Adv. Water Resour., 34, 383-394, 2011a.

Birkel, C., Tetzlaff, D., Dunn, S. M., and Soulsby, C.: Using time domain and geographic source tracers to conceptualize streamflow generation processes in lumped rainfall-runoff models, Water Resour. Res., 47, W02515, doi:10.1029/2010WR009547, 2011b.

Birkel, C., Soulsby, C., and Tetzlaff, D.: Modelling catchmentscale water storage dynamics: reconciling dynamic storage with tracer-inferred passive storage, Hydrol. Process., 25, 3924-3936, 2011c.

Birkel, C., Soulsby, C., Tetzlaff, D., Dunn, S., and Spezia, L.: Highfrequency storm event isotope sampling reveals time-variant transit time distributions and influence of diurnal cycles, Hydrol.
Process., 26, 308-316, 2012a.

Birkel, C., Paroli, R., Spezia, L., Dunn, S. M., Tetzlaff, D., and Soulsby, C.: A new approach to simulating stream isotope dynamics using Markov switching autoregressive models, Adv. Water Resour., 46, 20-30, 2012b.

Bogachev, V. I.: Measure Theory, Vol. I, II, Springer Verlag, 2007.

Botter, G., Milan, E., Bertuzzo, E., Zanardo, S., Marani, M., and Rinaldo, A.: Inferences from catchment-scale tracer circulation experiments, J. Hyrol., 369, 368-380, 2009.

Botter, G., Bertuzzo, E., and Rinaldo, A.: Transport in the hydrologic response: travel time distributions, soil moisture dynamics, and the old water paradox, Water Resour. Res., 46, W03514, doi:10.1029/2009WR008371, 2010.

Botter, G., Bertuzzo, E., and Rinaldo, A.: Catchment residence and travel time distributions: the master equation, Geophys. Res. Lett., 38, L11403, doi:10.1029/2011GL047666, 2011.

Brooks, J. R., Barnard, H. R., Coulombe, R., and McDonnell, J. J.: Ecohydrologic separation of water between trees and streams in a Mediterranean climate, Nat. Geosci., 3, 100-104, 2009.

Broxton, P. D., Troch, P. A., and Lyon, S. W.: On the role of aspect to quantify water transit times in small mountainous catchments, Water Resour. Res., 45, W08427, doi:10.1029/2008WR007438, 2009.

Brutsaert, W.: Hydrology: An Introduction, Cambridge University Press, 2005.

Calder, I. R.: Evaporation in the uplands, John Wiley \& Sons Ltd., Chichester, 1990.

Capell, R., Tetzlaff, D., Hartley, A., and Soulsby, C.: Linking metrics of hydrological function and transit times to landscape controls in a heterogeneous mesoscale catcment, Hydrol. Process., 26, 405-420, 2012a.

Capell, R., Tetzlaff, D., and Soulsby, C.: Can time domain and source area tracers reduce uncertainty in rainfall-runoff models in larger heterogeneous catchments?, Water Resour. Res., 48, W09544, doi:10.1029/2011WR011543, 2012b.

Clark, M. P., Slater, A. G., Rupp, D. E., Woods, R. A., Vrugt, J. A., Gupta, H. V., Wagener, T., and Hay, L. E.: Framework for understanding structural errors (FUSE): a modular framework to diagnose differences between hydrological models, Water Resour. Res., 44, W00B02, doi:10.1029/2007WR006735, 2008.

Criss, R. E. and Winston, W. E.: Do Nash values have a value? Discussion and alternate proposals, Hydrol. Process., 22, $2723-$ 2725, 2008.

Cvetkovic, V. and Haggerty, R.: Transport with multiple-rate exchange in disordered media, Phys. Rev. E, 65, 051308-051309, 2002.

Cvetkovic, V., Carstens, C., Selroos, J. O., and Destouni, G.: Water and solute transport along hydrological pathways, Water Resour. Res., 48, W06537, doi:10.1029/2011WR011367, 2012.

Davies, J., Beven, K., Nyberg, L., and Rodhe, A., A discrete particle representation of hillslope hydrology: hypothesis testing reproducing a tracer experiment at Gårdsjön, Sweden, Hydrol. Process., 25, 3602-3612, 2011.

Destouni, G., Simic, E., and Graham, W.: On the applicability of analytical methods for estimating solute travel time statistics in nonuniform groundwater flow, Water Resour. Res., 37, 23032308, 2001. 
Detty, J. M. and McGuire, K. J.: Threshold changes in storm runoff generation at a till-mantled headwater catchment, Water Resour. Res., 46, W07525, doi:10.1029/2009WR008102, 2010.

Dunn, S. M. and Bacon, J. R.: Assessing the value of $\mathrm{Cl}^{-}$and $\delta^{18} \mathrm{O}$ data in modeling the hydrological behaviour of a small upland catchment in north-east Scotland, Hydrol. Res., 39, 337-358, 2008.

Dunn, S. M., McDonnell, J. J., and Vaché, K. B.: Factors influencing the residence time of catchment waters: a virtual experiment approach, Water Resour. Res., 43, W06408, doi:10.1029/2006WR005393, 2007.

Dunn, S. M., Bacon, J. R., Soulsby, C., Tetzlaff, D., Stutter, M. I., Waldron, S., and Malcolm, I. A.: Interpretation of homogeneity in $\delta^{18} \mathrm{O}$ signatures of stream water in a nested sub-catchment system in north-east Scotland, Hydrol. Process., 22, 4767-4782, 2008a.

Dunn, S. M., Freer, J., Weiler, M., Kirkby, M. J., Seibert, J., Quinn, P. F., Lischeid, G., Tetzlaff, D., and Soulsby, C.: Conceptualization in catchment modelling: simply learning?, Hydrol. Process., 22, 2389-2393, 2008b.

Dunn, S. M., Birkel, C., Tetzlaff, D., and Soulsby, C.: Transit time distributions of a conceptual model: their characteristics and sensitivities, Hydrol. Process., 24, 1719-1729, 2010.

Feng, X., Kirchner, J. W., and Neal, C.: Measuring catchment-scale chemical retardation using spectral analysis of reactive and passive chemical tracer time series, J. Hydrol., 292, 296-307, 2004.

Fenicia, F., Savenije, H. H. G., Matgen, P., and Pfister, L.: Is the groundwater reservoir linear? Learning from data in hydrological modelling, Hydrol. Earth Syst. Sci., 10, 139-150, doi:10.5194/hess-10-139-2006, 2006.

Fenicia, F., Savenije, H. H. G., Matgen, P., and Pfister, L.: A comparison of alternative multiobjective calibration strategies for hydrological modeling, Water Resour. Res., 43, W03434, doi:10.1029/2006WR005098, 2007.

Fenicia, F., McDonnell, J. J., and Savenije, H. H. G.: Learning from model improvement: on the contribution of complementary data to process understanding, Water Resour. Res., 44, W06419, doi:10.1029/2007WR006386, 2008a.

Fenicia, F., Savenije, H. H. G., Matgen, P., and Pfister, L.: Understanding catchment behaviour through stepwise model concept improvement, Water Resour. Res., 44, W01402, doi:10.1029/2006WR005563, 2008b.

Fenicia, F., Wrede, S., Kavetski, D., Pfister, L., Hoffmann, L., Savenije, H. H. G., and McDonnell, J. J.: Assessing the impact of mixing assumptions on the estimation of streamwater mean residence time, Hydrol. Process., 24, 1730-1741, 2010.

Fenicia, F., Kavetski, D., and Savenije, H. H. G.: Elements of a flexible approach for conceptual hydrological modeling: 1. Motivation and theoretical development, Water Resour. Res., 47, W11510, doi:10.1029/2010WR010174, 2011.

Ferrier, R. C. and Harriman, R.: Pristine transitional and acidified catchment studies in Scotland, in: The surface water acidification programme, edited by: Mason, B., Cambridge University Press, Cambridge, 9-18, 1990.

Fiori, A. and Russo, D.: Travel time distribution in a hillslope: insight from numerical simulations, Water Resour. Res., 44, W12426, doi:10.1029/2008WR007135, 2008.
Gascuel-Odoux, C., Aurousseau, P., Durand, P., Ruiz, L., and Molenat, J.: The role of climate on inter-annual variation in stream nitrate fluxes and concentrations, Sci. Total Environ., 408, 56575666, 2010.

Gerrits, A. M. J., Pfister, L., and Savenije, H. H. G.: Spatial and temporal variability of canopy and forest floor interception in a beech forest, Hydrol. Process., 24, 3011-3025, 2010.

Gleeson, T. and Manning, A. H.: Regional groundwater flow in mountainous terrain: three-dimensional simulations of topographic and hydrogeologic controls, Water Resour. Res., 44, W10403, doi:10.1029/2008WR006848, 2008.

Godsey, S. E., Kirchner, J. W., and Chow, D. W.: Concentrationdischarge relationships reflect chemostatic characteristics of US catchments, Hydrol. Process., 23, 1844-1864, 2009.

Godsey, S. E., Aas, W., Clair, T. A., deWit, H. A., Fernandez, I. J., Kahl, J. S., Malcolm, I. A., Neal, C., Neal, M., Nelson, S. J., Norton, S. A., Palucis, M. C., Skjelkvåle, B. L., Soulsby, C., Tetzlaff, D., and Kirchner, J. W.: Generality of fractal 1/f scaling in catchment tracer time series, and its implications for catchment travel time distributions, Hydrol. Process., 24, 1660-1671, 2010.

Guan, H., Love, A. J., Simmons, C. T., Hutson, J., and Ding, Z.: Catchment conceptualisation for examining applicability of chloride mass balance method in an area with historical forest clearance, Hydrol. Earth Syst. Sci., 14, 1233-1245, doi:10.5194/hess14-1233-2010, 2010

Gupta, H. V., Sorooshian, S., and Yapo, P. O.: Toward improved calibration of hydrologic models: multiple and noncommensurable measures of information, Water Reosur. Res., 34, 751-763, 1998

Harman, C. J., Sivapalan, M., and Kumar, P.: Power law catchment-scale recessions arising from heterogeneous linear small-scale dynamics, Water Resour. Res., 45, W09404, doi:10.1029/2008WR007392, 2009.

Heidbüchel, I., Troch, P. A., Lyon, S. W., and Weiler, M.: The master transit time distribution of variable flow systems, Water Resour. Res., 48, W06520, doi:10.1029/2011WR011293, 2012.

Helliwell, R. C., Soulsby, C., Ferrier, R. C., Jenkins, A., and Harriman, R.: Influence of snow on the hydrology and hydrochemistry of the Allt a'Mharcaidh, Cairngorm mountains, Scotland, Sci. Total Environ., 217, 59-70, 1998.

Hough, M. N. and Jones, R. J. A.: The United Kingdom Meteorological Office rainfall and evaporation calculation system: MORECS version 2.0 - an overview, Hydrol. Earth Syst. Sci., 1, 227-239, doi:10.5194/hess-1-227-1997, 1997.

Hrachowitz, M., Soulsby, C., Tetzlaff, D., Dawson, J. J. C., and Malcolm, I. A.: Regionalization of transit time estimates in montane catchments by integrating landscape controls, Water Resour. Res., 45, W05421, doi:10.1029/2008WR007496, 2009a.

Hrachowitz, M., Soulsby, C., Tetzlaff, D., Dawson, J. J. C., Dunn, S. M., and Malcolm, I. A.: Using long-term data sets to understand transit times in contrasting headwater catchments, J. Hydrol., 367, 237-248, doi:10.1016/j.jhydrol.2009.01.001, 2009b.

Hrachowitz, M., Soulsby, C., Tetzlaff, D., and Speed, M.: Catchment transit times and landscape controls - does scale matter?, Hydrol. Process., 24, 117-125, doi:10.1002/hyp.7510, 2010a.

Hrachowitz, M., Soulsby, C., Tetzlaff, D., Malcolm, I. A., and Schoups, G.: Gamma distribution models for transit time estimation in catchments: Physical interpretation of parameters and implications for time-variant transit time assessment, Water Resour. Res., 46, W10536, doi:10.1029/2010WR009148, 2010 b. 
Hrachowitz, M., Soulsby, C., Tetzlaff, D., and Malcolm, I. A.: Sensitivity of mean transit time estimates to model conditioning and data availability, Hydrol. Process., 25, 980-990, doi:10.1002/hyp.7922, 2011a.

Hrachowitz, M., Bohte, R., Mul, M. L., Bogaard, T. A., Savenije, H. H. G., and Uhlenbrook, S.: On the value of combined event runoff and tracer analysis to improve understanding of catchment functioning in a data-scarce semi-arid area, Hydrol. Earth Syst. Sci., 15, 2007-2024, doi:10.5194/hess-15-2007-2011, 2011 b.

Iorgulescu, I., Beven, K. J., and Musy, A.: Flow, mixing, and displacement in using a data-based hydrochemical model to predict conservative tracer data, Water Resour. Res., 43, W03401, doi:10.1029/2005WR004019, 2007.

Katsuyama, M., Kabeya, N., and Ohte, N., Elucidation of the relationship between geographic and time sources of stream water using a tracer approach in a headwater catchment, Water Resour. Res., 45, W06414, doi:10.1029/2008WR007458, 2009.

Katsuyama, M., Tani, M., and Nishimoto, S.: Connection between streamwater mean residence time and bedrock groundwater recharge/discharge dynamics in weathered granite catchments, Hydrol. Process., 24, 2287-2299, 2010.

Kauffman, S. J., Royer, D. S., and Berner, R. A.: Export of chloride after clear cutting in the Hubbard Brook sanbox experiment, Biogeochemistry, 63, 23-33, 2003.

Kavetski, D. and Fenicia, F.: Elements of a flexible approach for conceptual hydrological modeling: 2. Application and experimental insights, Water Resour. Res., 47, W11511, doi:10.1029/2011WR010748, 2011.

Kirchner, J. W.: A double paradox in catchment hydrology and geochemistry, Hydrol. Process., 17, 871-874, 2003.

Kirchner, J. W.: Getting the right answers for the right reasons: linking measurements, analyses, and models to advance the science of hydrology, Water Resour. Res., 42, W03S04, doi:10.1029/2005WR004362, 2006.

Kirchner, J. W., Feng, X., and Neal, C.: Fractal stream chemistry and its implications for contaminant transport in catchments, Nature, 403, 524-527, 2000.

Kirchner, J. W., Feng, X., and Neal, C.: Catchment-scale advection and dispersion as a mechanism for fractal scaling in stream tracer concentrations, J. Hydrol., 254, 82-101, 2001.

Kirchner, J. W., Tetzlaff, D., and Soulsby, C.: Comparing chloride and water isotopes as hydrological tracers in two Scottish catchments, Hydrol. Process., 24, 1631-1645, 2010.

Klaus, J., Zehe, E., Elsner, M., Külls, C., and McDonnell, J. J.: Macropore flow of old water revisited: experimental insights from a tile-drained hillslope, Hydrol. Earth Syst. Sci., 17, 103118, doi:10.5194/hess-17-103-2013, 2013.

Königer, P., Leibundgut, C., Link, T., and Marshall, J. D.: Stable isotopes applied as water tracers in column and field studies, Org. Geochem., 41, 31-40, 2010.

Kreft, A. and Zuber, A.: On the physical meaning of the dispersion equation and its solutions for different initial and boundary conditions, Chem. Eng. Sci., 33, 1471-1480, 1978.

Lamb, R. and Beven, K.: Using interactive recession curve analysis to specify a general catchment storage model, Hydrol. Earth Syst. Sci., 1, 101-113, doi:10.5194/hess-1-101-1997, 1997.

Laudon, H., Sjöblom, V., Buffam, I., Seibert, J., and Mörth, M.: The role of catchment scale and landscape characteristics for runoff generation of boreal streams, J. Hydrol., 344, 198-209, 2007.
Legout, C., Molenat, J., Aquilina, L., Gascuel-Odoux, C., Faucheux, M., Fauvel, Y., and Bariac, T.: Solute transfer in the unsaturated zone-groundwater continuum of a headwater catchment, J. Hydrol., 332, 427-441, 2007.

Legout, A., Legout, C., Nys, S., and Dambrine, E.: Preferential flow and slow convective chloride transport through the soil of a forested landscape (Fougères, France), Geoderma, 151, 179190, 2009.

Lindgren, G. A., Destouni, G., and Miller, A. V.: Solute transport thorugh the integrated groundwater-stream system of a catchment, Water Resour. Res., 40, W03511, doi:10.1029/2003WR002765, 2004.

Lindström, G., Pers, C., Rosberg, J., Strömqvist, J., and Arheimer, B.: Development and testing of the HYPE (Hydrological Predictions for the Environment) water quality model for different spatial scales, Hydrol. Res., 41, 295-319, 2010.

Liu, C., Westman, C. J., Berg, B., Kutsch, W., Wang, G. Z., Man, R., and Ilvesniemi, H.: Variation in litterfall-climate relationships between coniferous and broadleaf forests in Eurasia, Global Eco. Biogeogr., 13, 105-114, 2004.

Lovett, G. M., Likens, G. E., Buso, D. C., Driscoll, C. T., and Bailey, S. W.: The biogeochemistry of chlorine at Hubbard Brook, New Hampshire, USA, Biogeochemistry, 72, 191-232, 2005.

Lyon, S. W., Laudon, H., Seibert, J., Mörth, M., Tetzlaff, D., and Bishop, K.: Controls on snowmelt water mean transit times in northern boreal catchments, Hydrol. Process., 24, 1672-1684, 2010a.

Lyon, S. W., Mörth, M., Humborg, C., Giesler, R., and Destouni, G.: The relationship between subsurface hydrology and dissolved carbon fluxes for a sub-arctic catchment, Hydrol. Earth Syst. Sci., 14, 941-950, doi:10.5194/hess-14-941-2010, 2010 b.

Maloszewski, P. and Zuber, A.: Determining the turnover time of groundwater systems with the aid of environmental tracers, J. Hydrol., 57, 207-231, 1982.

Maloszewski, P. and Zuber, A.: Lumped parameter models for the interpretation of environmental tracer data, Manual on Mathematical Models in Isotope Hydrogeology, International Atomic Energy Agency, Vienna, 1996.

Martinec, J., Siegenthaler, U., Oeschger, H., and Tongiorgi, E.: New insights into the run-off mechanism by environmental isotopes, International Atomic Energy Agency, Vienna, 1974.

McDonnell, J. J., Sivapalan, M., Vaché, K., Dunn, S., Grant, G., Haggerty, R., Hinz, C., Hooper, R., Kirchner, J., Roderick, M. L., Selker, J., and Weiler, M.: Moving beyond heterogeneity and process complexity: a new vision for watershed hydrology, Water Resour. Res., 43, W07301, doi:10.1029/2006WR005467, 2007.

McDonnell, J. J., McGuire, K., Aggarwal, P., Beven, K. J., Biondi, D., Destouni, G., Dunn, S., James, A., Kirchner, J., Kraft, P., Lyon, S., Maloszewski, P., Newman, B., Pfister, L., Rinaldo, A., Rodhe, A., Sayama, T., Seibert, J., Solomon, K., Soulsby, C., Stewart, M., Tetzlaff, D., Tobin, C., Troch, P., Weiler, M., Western, A., Wörman, A., and Wrede, S.: How old is streamwater? Open questions in catchment transit time conceptualization, modeling and analysis, Hydrol. Process., 24, 1745-1754, 2010.

McGlynn, B., McDonnell, J. J., Stewart, M., and Seibert, J.: On the relationships between catchment scale and streamwater mean residence time, Hydrol. Process., 17, 175-181, 2003. 
McGlynn, B. L., Jencso, K. G., and Carlson, S.: Hysteresis in catchment storage-discharge relationships: Implications for interpreting catchment biochemical fluxes, Research Abstract H11L-07, American Geophysical Union Fall Meeting, 2012.

McGrane, S. J., Tetzlaff, D., and Soulsby, C.: Influence of lowland aquifers and anthropogenic impacts on the isotope hydrology of contrasting mesoscale catchments, Hydrol. Process., doi:10.1002/hyp.9610, in press, 2012.

McGuire, K. J. and McDonnell, J. J.: Hydrological connectivity of hillslopes and streams: characteristic time scales and nonlinearities, Water Resour. Res., 46, W10543, doi:10.1029/2010WR009341, 2010.

McGuire, K. J., McDonnell, J. J., Weiler, M., Kendall, C., McGlynn, B. L., Welker, J. M., and Seibert, J.: The role of topography on catchment-scale water residence time, Water Resour. Res., 41, W05002, doi:10.1029/2004WR003657, 2005.

McGuire, K. J., Weiler, M., and McDonnell, J. J.: Integrating tracer experiments with modeling to assess runoff processes and water transit times, Adv. Water Resour., 30, 824-837, 2007.

McMillan, H. K., Clark, M. P., Bowden, W. B., Duncan, M., and Woods, R. A.: Hydrological field data from a modeller's perspective: Part 1. Diagnostic tests for model structure, Hydrol. Process., 25, 511-522, 2011.

McMillan, H. K., Tetzlaff, D., Clark, M., and Soulsby, C.: Do timevariable tracers aid the evaluation of hydrological model structure? A multimodel approach, Water Resour. Res., 48, W05501, doi:10.1029/2011WR011688, 2012.

McNamara, J., Tetzlaff, D., Bishop, K., Soulsby, C., Seyfried, M., Peters, N. E., Aulenbach, B. T., nad Hooper, R.: Storage as a Metric of Catchment Comparison, Hydrol. Process., 25, 3364 3371, 2011.

Miller, J. D., Anderson, H. A., Ferrier, R. C., and Walker, T. A. B.: Comparison of the hydrological budgets and detailed hydrological responses in two forested catchments, Forestry, 63, 251-269, 1990.

Molenat, J. and Gascuel-Odoux, C.: Modelling flow and nitrate transport in groundwater for the prediction of water travel times and of consequences of land use evolution on water quality, Hydrol. Process., 16, 479-492, 2002.

Morgenstern, U., Stewart, M. K., and Stenger, R.: Dating of streamwater using tritium in a post nuclear bomb pulse world: continuous variation of mean transit time with streamflow, Hydrol. Earth Syst. Sci., 14, 2289-2301, doi:10.5194/hess-14-22892010, 2010

Munoz-Villers, L. E. and McDonnell, J. J.: Runoff generation in a steep, tropical montane cloud forest catchment on permeable volcanic substrate, Water Resour. Res., 48, W09528, doi:10.1029/2011WR011316, 2012.

Murphy, J. C., Hornberger, G. C., and Liddle, R. G.: Concentrationdischarge relationships in the coal mined region of the New River basin and Indian Fork sub-basin, Tennessee, USA, Hydrol. Process., doi:10.1002/hyp.9603, in press, 2012.

Nash, J. E. and Sutcliffe, J. V.: River flow forecasting through conceptual models, Part I - A discussion of principles, J. Hydrol., 10, 282-290, 1970.

Neal, C., Christophersen, N., Neale, R., Smith, C. J., Whitehead, P. G., and Reynolds, B.: Chloride in precipitation and streamwater for the upland catchment of river Severn, Mid-Wales; some consequences for hydrological models, Hydrol. Process., 2,
155-165, 1988.

Neal, C., Reynolds, B., Neal, M., Wickham, H., Hill, L., and Williams, B.: The water quality of streams draining a plantation forest on gley soils: the Nant Tanllwyth, Plynlimon mid-Wales, Hydrol. Earth Syst. Sci., 8, 485-502, doi:10.5194/hess-8-4852004, 2004.

Niemi, A.: Residence time distributions of variable flow processes, Int. J. Appl. Radiat. Is., 28, 855-860, 1977.

Nippgen, F., McGlynn, B. L., Marshall, L. A., and Emanuel, R. E.: Landscape structure and climate influences on hydrologic response, Water Resour. Res., 47, W12528, doi:10.1029/2011WR011161, 2011.

Oda, T., Asano, Y., and Suzuki, M.: Transit time evaluation using a chloride concentration input step shift after forest cutting in a Japanese headwater catchment, Hydrol. Process., 23, 27052713, 2009.

Page, T., Beven, K. J., Freer, J., and Neal, C.: Modelling the chloride signal at Plynlimon, Wales, using a modified dynamic TOPMODEL incorporating conservative chemical mixing (with uncertainty), Hydrol. Process., 21, 292-307, 2007.

Penna, D., Tromp-van Meerveld, H. J., Gobbi, A., Borga, M., and Dalla Fontana, G.: The influence of soil moisture on threshold runoff generation processes in an alpine headwater catchment, Hydrol. Earth Syst. Sci., 15, 689-702, doi:10.5194/hess-15-6892011, 2011.

Rinaldo, A., Beven, K. J., Bertuzzo, E., Nicotina, L., Davies, J., Fiori, A., Russo, D., and Botter, G.: Catchment travel time distributions and water flow in soils, Water Resour. Res., 47, W07537, doi:10.1029/2011WR010478, 2011.

Roa-García, M. C. and Weiler, M.: Integrated response and transit time distributions of watersheds by combining hydrograph separation and long-term transit time modeling, Hydrol. Earth Syst. Sci., 14, 1537-1549, doi:10.5194/hess-14-1537-2010, 2010.

Rouxel, M., Molenat, J., Ruiz, L., Legout, C., Faucheux, M., and Gascuel-Odoux, C.: Seasonal and spatial variation in groundwater quality along the hillslope of an agricultural research catchment (Western France), Hydrol. Process., 25, 831-841, 2011.

Ruiz, L., Abiven, S., Durand, P., Martin, C., Vertès, F., and Beaujouan, V.: Effect on nitrate concentration in stream water of agricultural practices in small catchments in Brittany: I. Annual nitrogen budgets, Hydrol. Earth Syst. Sci., 6, 497-506, doi:10.5194/hess-6-497-2002, 2002a.

Ruiz, L., Abiven, S., Martin, C., Durand, P., Beaujouan, V., and Molénat, J.: Effect on nitrate concentration in stream water of agricultural practices in small catchments in Brittany: II. Temporal variations and mixing processes, Hydrol. Earth Syst. Sci., 6, 507-514, doi:10.5194/hess-6-507-2002, 2002b.

Savenije, H. H. G.: The importance of interception and why we should delete the term evapotranspiration from our vocabulary, Hydrol. Process., 18, 1507-1511, 2004.

Savenije, H. H. G.: HESS Opinions "The art of hydrology", Hydrol. Earth Syst. Sci., 13, 157-161, doi:10.5194/hess-13-1572009, 2009.

Sayama, T., and McDonnell, J. J.: A new time-space accounting scheme to predict stream water residence time and hydrograph source components at the watershed scale, Water Resour. Res., 45, W07401, doi:10.1029/2008WR007549, 2009. 
Schoups, G., Hopmans, J. W., Young, C. A., Vrugt, J. A., and Wallender, W. W.: Multi-criteria optimization of a regional spatiallydistributed subsurface water flow model, J. Hydrol., 311, 20-48, 2005.

Schoups, G., van de Giesen, N. C., and Savenije, H. H. G.: Model complexity control for hydrologic prediction, Water Resour. Res., 44, W00B03, doi:10.1029/2008WR006836, 2008.

Segura, C., James, A. L., Lazzati, D., and Roulet, N. T.: Scaling relationships for event water contributions and transit times in small-forested catchments in Eastern Quebec, Water Resour. Res., 48, W07502, doi:10.1029/2012WR011890, 2012.

Seibert, J. and Beven, K. J.: Gauging the ungauged basin: how many discharge measurements are needed?, Hydrol. Earth Syst. Sci., 13, 883-892, doi:10.5194/hess-13-883-2009, 2009.

Shaw, S., Harpold, A. A., Taylor, J. C., and Walter, M. T.: Investigating a high resolution, stream chloride time series from the Biscuit Brook catchment, Catskills, NY, J. Hydrol., 348, 245-256, 2008.

Soulsby, C. and Reynolds, B.: Influence of soil hydrological pathways on stream aluminium chemistry at Llyn Brianne, MidWales, Environ. Pollut., 81, 51-60, 1993.

Soulsby, C., Chen, M., Ferrier, R. C., Helliwell, R. C., Jenkins, A., and Harriman, R.: Hydrogeochemistry of shallow groundwater in an upland Sottish catchment, Hydrol. Process., 12, 1111-1127, 1998.

Soulsby, C., Malcolm, R., Helliwell, R., Ferrier, R. C., and Jenkins, A.: Isotope hydrology of the Allt a'Mharcaidh catchment, Cairngorms, Scotland: implications for hydrological pathways and residence times, Hydrol. Process., 14, 747-762, 2000.

Soulsby, C., Tetzlaff, D., Rodgers, P., Dunn, S., and Waldron, S.: Runoff processes, stream water residence times and controlling landscape characteristics in a mesocale catchment: an initial evaluation, J. Hydrol., 325, 197-221, 2006.

Soulsby, C., Tetzlaff, D., van den Bedem, N., Malcolm, I. A., Bacon, P. J., and Youngson, A. F.: Inferring groundwater influences on surface water in montane catchments from hydrochemical surveys of springs and streamwaters, J. Hydrol., 333, 199-213, 2007.

Soulsby, C., Tetzlaff, D., and Hrachowitz, M.: Tracers and transit times: windows for viewing catchment scale storage?, Hydrol. Process., 23, 3503-3507, 2009.

Soulsby, C., Tetzlaff, D., and Hrachowitz, M.: Are transit times useful process-based tools for flow prediction and classification in ungauged basins in montane regions?, Hydrol. Process., 24, 1685-1696, 2010.

Speed, M., Tetzlaff, D., Soulsby, C., Hrachowitz, M., and Waldron, S.: Isotopic and geochemical tracers reveal similarities in transit times in contrasting mesoscale catchments, Hydrol. Process., 24, 1211-1224, 2010.

Stewart, M. K., Morgenstern, U., and McDonnell, J. J.: Truncation of stream residence time: how the use of stable isotopes has skewed our concept of streamwater age and origin, Hydrol. Process., 24, 1646-1659, 2010.

Stewart, M. K., Morgenstern, U., McDonnell, J. J., and Pfister, L.: The hidden streamflow challenge in catchment hydrology: a call to action for stream water transit time analysis, Hydrol. Process., 26, 2061-2066, 2012.

Stumpp, C., and Maloszewski, P.: Quantification of preferential flow and flow heterogeneities in an unsaturated soil planted with different crops using the environmental isotope $\delta^{18} \mathrm{O}$, J. Hydrol.,
394, 407-415, 2010.

Sutanto, S. J., Wenninger, J., Coenders-Gerrits, A. M. J., and Uhlenbrook, S.: Partitioning of evaporation into transpiration, soil evaporation and interception: a comparison between isotope measurements and a HYDRUS-1D model, Hydrol. Earth Syst. Sci., 16, 2605-2616, doi:10.5194/hess-16-2605-2012, 2012.

Szilagyi, J.: Comment on "Power law catchment-scale recessions arising from heterogeneous linear small-scale dynamics" by C. J. Harman, M. Sivapalan, and P. Kumar, Water Resour. Res., 45, W12601, doi:10.1029/2009WR008321, 2009.

Tetzlaff, D., Malcolm, I. A., and Soulsby, C.: Influence of forestry, environmental change and climatic variability on the hydrology, hydrochemistry and residence times of upland catchments, J. Hydrol., 346, 93-111, 2007.

Tetzlaff, D., Seibert, J., and Soulsby, C.: Inter-catchment comparison to assess the influence of topography and soils on catchment transit times in a geomorphic province; the Cairngorm mountains, Scotland, Hydrol. Process., 23, 1874-1886, 2009a.

Tetzlaff, D., Seibert, J., McGuire, K. J., Laudon, H., Burns, D. A., Dunn, S. M., and Soulsby, C.: How does landscape structure influence catchment transit time across different geomorphic provinces?, Hydrol. Process., 23, 945-953, 2009b.

Tetzlaff, D., Soulsby, C., Hrachowitz, M., and Speed, M.: Relative influence of upland and lowland headwaters on the isotope hydrology and transit times of larger catchments, J. Hydrol., 400, 438-447, 2011.

Turner, J. V., Macpherson, D. K., and Stokes, R. A.: The mechanisms of catchment flow processes using natural variations in deuterium and oxygen-18, J. Hydrol., 94, 143-162, 1987.

Uchida, T., McDonnell, J. J., and Asano, Y.: Functional intercomparison of hillslopes and small catchments by examining water source, flowpath and mean residence time, J. Hydrol., 327, 627642, 2006.

Uhlenbrook, S. and Sieber, A.: On the value of experimental data to reduce the prediction uncertainty of a process-oriented catchment model, Environ. Model. Softw., 20, 19-32, 2005.

Vaché, K. B. and McDonnell, J. J.: A process-based rejectionist framework for evaluating catchment runoff model structure, Water Resour. Res., 42, W02409, doi:10.1029/2005WR004247, 2006.

Van der Velde, Y., de Rooij, G. H., Rozemeijer, J. C., van Geer, F. C., and Broers, H. P.: Nitrate response of a lowland catchment: on the relation between stream concentration and travel time distribution dynamics, Water Resour. Res., 46, W11534, doi:10.1029/2010WR009105, 2010.

Van der Velde, Y., Torfs, P. J. J. F., van der Zee, S. E. A. T. M., and Uijlenhoet, R.: Quantifying catchment-scale mixing and its effects on time-varying travel time distributions, Water Resour. Res., 48, W06536, doi:10.1029/2011WR011310, 2012.

Van Schaik, N. L. M. B., Schnabel, S., and Jetten, V. G.: The influence of preferential flow on hillslope hydrology in a semi-arid watershed (in the Spanish Dehesas), Hydrol. Process., 22, 38443855, 2008.

Vogel, T., Sanda, M., Dusek, J., Dohnal, M., and Votrubova, J.: Using oxygen-18 to study the role of preferential flow in the formation of hillslope runoff, Vadose Zone J., 9, 252-259, 2008.

Weiler, M. and Naef, F.: An experimental tracer study of the role of macropores in infiltration in grassland soils, Hydrol. Process., 17, 477-493, 2003. 
Weiler, M. and McDonnell, J. J.: Virtual experiments: a new approach for improving process conceptualization in hillslope hydrology, J. Hydrol., 285, 3-18, 2004.

Weiler, M. and McDonnell, J. J.: Testing nutrient flushing hypotheses at the hillslope scale: A virtual experiment approach, J. Hydrol., 319, 339-356, 2006.

Weiler, M. and McDonnell, J. J.: Conceptualizing lateral preferential flow and flow networks and simulating the effects on gauged and ungauged hillslopes, Water Resour. Res., 43, W03403, doi:10.1029/2006WR004867, 2007.

Weiler, M., McGlynn, B. L., McGuire, K. J., and McDonnell, J. J.: How does rainfall become runoff? A combined tracer and runoff transfer function approach, Water Resour. Res., 39, 1315, doi:10.1029/2003WR002331, 2003.
Wenninger, J., Uhlenbrook, S., Lorentz, S., and Leibundgut, C.: Identification of runoff generation processes using combined hydrometric, tracer and gepphysical methods in a headwater catchment in South Africa, Hydrolog. Sci. J., 53, 65-80, 2008.

Ye, S., Yaeger, M., Coopersmith, E., Cheng, L., and Sivapalan, M. Exploring the physical controls of regional patterns of flow duration curves - Part 2: Role of seasonality, the regime curve, and associated process controls, Hydrol. Earth Syst. Sci., 16, 44474465, doi:10.5194/hess-16-4447-2012, 2012.

Zehe, E. and Sivapalan, M.: Threshold behaviour in hydrological systems as (human) geo-ecosystems: manifestations, controls, implications, Hydrol. Earth Syst. Sci., 13, 1273-1297, doi:10.5194/hess-13-1273-2009, 2009.

Zuber, A.: On the interpretation of tracer data in variable flow systems, J. Hydrol., 86, 45-57, 1986. 